\title{
Hydro-Connected Floating PV Renewable Energy System and Onshore Wind Potential in Zambia
}

\author{
Kumbuso Joshua Nyoni ${ }^{1, *(D)}$, Anesu Maronga ${ }^{1}$ (D), Paul Gerard Tuohy ${ }^{2}$ and Agabu Shane ${ }^{3, *(D)}$ \\ 1 Department of Mechanical and Aerospace Engineering, University of Strathclyde, Glasgow G1 1XJ, UK; \\ anesu@centragrid.com \\ 2 Energy Systems Research Unit (ESRU), University of Strathclyde, Glasgow G1 1XJ, UK; \\ paul.tuohy@strath.ac.uk \\ 3 School of Mines and Mineral Sciences, Copperbelt University, P.O. Box 21692, Kitwe 10101, Zambia \\ * Correspondence: joshua.kumbuso.nyoni@ieee.org or jnyoni@zesco.co.zm (K.J.N.); \\ agabu.shane@cbu.ac.zm (A.S.); Tel.: +260-977883212 (K.J.N.); +260-977457561 (A.S.)
}

Citation: Nyoni, K.J.; Maronga, A.;

Tuohy, P.G.; Shane, A.

Hydro-Connected Floating PV

Renewable Energy System and Onshore Wind Potential in Zambia.

Energies 2021, 14, 5330. https://

doi.org/10.3390/en14175330

Academic Editor:

Zbigniew Leonowicz

Received: 4 July 2021

Accepted: 17 August 2021

Published: 27 August 2021

Publisher's Note: MDPI stays neutral with regard to jurisdictional claims in published maps and institutional affiliations.

Copyright: (c) 2021 by the authors. Licensee MDPI, Basel, Switzerland. This article is an open access article distributed under the terms and conditions of the Creative Commons Attribution (CC BY) license (https:/ / creativecommons.org/licenses/by/ $4.0 /)$.

\begin{abstract}
The adoption of a diversification strategy of the energy mix to include low-water consumption technologies, such as floating photovoltaics (FPV) and onshore wind turbines, would improve the resilience of the Zambian hydro-dependent power system, thereby addressing the consequences of climate change and variability. Four major droughts that were experienced in the past fifteen years in the country exacerbated the problems in load management strategies in the recent past. Against this background, a site appraisal methodology was devised for the potential of linking future and existing hydropower sites with wind and FPV. This appraisal was then applied in Zambia to all the thirteen existing hydropower sites, of which three were screened off, and the remaining ten were scored and ranked according to attribute suitability. A design-scoping methodology was then created that aimed to assess the technical parameters of the national electricity grid, hourly generation profiles of existing scenarios, and the potential of variable renewable energy generation. The results at the case study site revealed that the wind and FPV integration reduced the network's real power losses by $5 \%$ and improved the magnitude profile of the voltage at nearby network buses. The onshore wind, along with FPV, also added $341 \mathrm{GWh} /$ year to the national energy generation capacity to meet the 4.93 TWh annual energy demand, in the presence of $4.59 \mathrm{TWh}$ of hydro with a virtual battery storage potential of approximately $7.4 \%$ of annual hydropower generation. This was achieved at a competitive levelized cost of electricity of GBP $0.055 / \mathrm{kWh}$. Moreover, floating PV is not being presented as a competitor to ground-mounted systems, but rather as a complementary technology in specific applications (i.e., retrofitting on hydro reservoirs). This study should be extended to all viable water bodies, and grid technical studies should be conducted to provide guidelines for large-scale variable renewable energy source (VRES) integration, ultimately contributing to shaping a resilient and sustainable energy transition.
\end{abstract}

Keywords: energy transition; site appraisal and ranking; time complementarity; onshore wind; levelized cost of electricity; hydro generation; grid integration; floating photovoltaics; energy mix; electrical load; dispatch

\section{Introduction \\ 1.1. Overview}

Man-made reservoirs currently have a global footprint of not less than $400,000 \mathrm{~km}^{2}$, theoretically translating into a floating photovoltaic (FPV) potential in the terawatt scale, excluding anchoring and mooring considerations. Mooring involves securing a system of devices on water that are connected with fasteners or wires and anchored to the floor of the water body. The 2017 installed global cumulative PV capacity of 400 GWp is presently exceeded by the FPV global conservative estimate on man-made reservoirs [1]. Floating photovoltaics, otherwise known as "floatovoltaics", originally gained acceptance in Japan 
owing to limitations in land acquisition and utilization for new power generation projects and thus took advantage of unused water surfaces [2]. Moreover, the new market of FPV swiftly came into fruition as the price of solar photovoltaic modules dropped by 75 percent, between 2010 and 2017, and PV panel efficiency increased from 14 to 21 percent. [3-5]. From the global viewpoint, between 2015 and 2018, more than 100 FPV plants had been installed and commissioned, with a total cumulative equivalent capacity of $1.3 \mathrm{GWp}[1,6,7]$. With approximately 73 percent of the total global installed capacity in 2018 translating to an equivalent of $950 \mathrm{MW}$, China had become the FPV systems market leader. The remainder of the installed capacity was distributed among South Korea (6\%), the United Kingdom $(1 \%)$, Japan $(16 \%)$, and Taiwan $(2 \%)$, while the rest of the world was represented by $2 \%$ at the beginning of 2019. However, no fewer than thirty countries had FPV projects under development [1]. Albeit on a large scale, FPV technology deployment having been initially pioneered by Asian countries (i.e., Thailand, China, Japan, and South Korea), interest had also spread to South America, North America and Europe [8,9]. Consequently, this technology could be embraced by Sub-Saharan African (SSA) countries to complement ground-mounted-based photovoltaics.

According to a recent World Bank and Joint Research Centre (JRC) under the European Commission study, installing floating photovoltaics on $1 \%$ of the area of the African hydropower reservoirs corresponds to $101 \mathrm{GWp}$ of FPV potential. This could double the current installed hydropower capacity and increase the electricity output by $58 \%$. Moreover, a $5 \%$ and $10 \%$ retrofitting of FPV on the reservoirs could translate into $506 \mathrm{GWp}$ and $1011 \mathrm{GWp}$, respectively, in the African context [1]. Combining solar PV with hydropower installations and hybridizing their output is of keen interest in many countries, in particular for smaller and weaker grids in Sub-Saharan Africa and in places with significant differences in water availability between the dry and wet seasons. The hybrid "hydro + solar PV" plant could behave as a PV + battery plant but can be more affordable and safer while retaining the benefits of hydropower [1,2]. Additionally, FPV presents the added benefit of saving water by decreasing the evaporation in reservoirs. Adding solar capacity (land-based or floating) to existing hydropower plants utilizes the existing transmission infrastructure. Hydropower can smooth the variable output by serving as a storage asset. The FPV brings out resilience by helping manage periods of low water availability [3-5].

\subsection{Objectives and Research Contributions}

The specific aims of this study are: (1) to document and categorize the potential of FPV and wind near hydropower sites; (2) to develop a selection process based on the documented capabilities of the sites; (3) to develop a systematic scoping design process that can be applied anywhere in the country, region or globe. This will be achieved through:

i An initial filtering and screening process identifying potential sites for floating PV and onshore wind installations near existing and future hydropower plants.

ii Development of a ranking and scoring methodology of filtered sites using multicriteria decision-making and the application of the same.

iii Development of a methodology for scoping the case study design.

iv Application of the design methodology on an actual site.

v Discussion of the findings.

The advent of FPV has been driven mostly by land scarcity for projects, energy security and decarbonization targets, and a loss in PV system efficiency at high operating temperatures. FPV has demonstrated great global market potential in the recent past, with enhanced technological development in photovoltaic modules and a reduction in the levelized cost of energy (LCOE) of PV energy systems [10,11]. Appraising FPV systems and projects has been a challenge, owing to the scarcity of suitable energy simulation tools for approximating the percentage increase in yield due to the cooling effect of the water surface and the different technologies employed for floaters housing the PV modules. However, 
research [12] correlated different heat loss factors in $\mathrm{W} / \mathrm{m}^{2} \mathrm{~K}$ to the configuration of the floating photovoltaic structure (i.e., free-standing and small/large footprint).

This study aimed to harness the quantitative benefits of coupling FPV and onshore wind facilities with hydropower plants by relating the proximity to the existing infrastructure and grid connection, technical characteristics of the electrical network, the water-saving potential of the hydro reservoir through optimal dispatch strategies, and consequently, reducing the seasonal variations of VRES. Moreover, this study utilized the time complementarity among hydropower, floating photovoltaics and onshore wind power to alleviate the current national estimated power deficit of $810 \mathrm{MW}$. This has been attributed to reduced hydropower generation, owing to low water levels in hydro reservoirs emanating from climate change-induced droughts in the past six years [13,14]. Furthermore, this study related the integration of VRES to the hydro reservoir water-saving potential by throttling down on hydropower generation in the presence of FPV and wind power. Even though there is growing interest in floating photovoltaics, there has been no systematic appraisal of the techno-economical potential in the Zambian context and Sub-Saharan Africa (SSA). This study provides the first national-level techno-economical site assessment of onshore wind and FPV potential using a combination of validated datasets, geospatial analytical tools, site-specific wind/PV energy production models and VRES grid assessment models near existing and future hydropower plants. Furthermore, this research will help in the implementation of renewable energy technologies, such as floating photovoltaics and onshore wind power, to help increase electricity generation and supply. The study will contribute to closing the data gaps that have existed in this field of study in Zambia. To put this into perspective, the existing national grid code does not address the technical requirements (i.e., rate of frequency change, low/high voltage fault ride-through, the extent of reactive power support, etc.) of integrating VRES into the network. Therefore, this paper also addresses the nature and depth of technical studies that will have to be completed in the future to bridge this gap and thus enhance participation from independent power producers. Moreover, the research will help decision-makers to make timely and informed decisions in this area. The paper will also form a basis for further studies in the academic realm.

Therefore, the authors are highly motivated to contribute to improving the lives of all Zambians and that of neighboring citizens, by enhancing electricity access and increasing the total power generation through the adoption of renewable energy technologies such as onshore wind farms and floating photovoltaics, thus alleviating the energy poverty being faced in the region. Additionally, Zambia has the potential to enhance FOREX (foreign exchange) earnings through power exports with the interconnected SAPP countries, mitigating the chronic trade deficit with which the country has been grappling.

Against this background, the remainder of the paper is structured as follows. The subsequent section looks at the literature review; thereafter, the development of a site assessment, and the screening and ranking methodology employed in this study, are described. This ranged from site identification to the filtering and ranking of sites based on the assigned relative weight and attribute suitability scores as adopted from the literature, industry practice and stakeholder engagement. The developed methodology was then applied to a case study in Zambia. Additionally, the limitations in the site appraisal methods and tools used were highlighted. Having appraised and ranked the sites accordingly, a scoping design methodology was developed to be applied to the site with the most promising potential (i.e., highly ranked site). Furthermore, the results of the detailed case study design and formulated models were examined and discussed. Lastly, the conclusion and recommendations from the research were drawn by referencing the research outcomes, key results, study limitations and further work to be done.

\section{Literature Review}

\subsection{Overview on FPV and Onshore Wind Potential}

The evolution of FPV has, in the recent past, included the hydropower industry, owing to the opportunity for retrofitting or installing FPV panels on the abundant water 
surface area of hydro dams $[6,15]$. To put this into perspective, hydropower represents a vital aspect of the renewable energy system and covered approximately 16.4 percent of the global electricity generation at the end of 2017, which is equivalent to $1.27 \mathrm{TW}$ and 4.185 TWh of total installed capacity and generated energy, respectively, owing to the increased technological investment in the equatorial regions and China. However, the negative impact of climate change (i.e., noticeable droughts) over the past decade in some regions of the world has necessitated the rapid penetration of solar photovoltaics and wind technologies [11]. The global FPV potential for waterbodies was mapped by research with hydropower capabilities, which included electricity generation and installation capacity in terawatt-hours and gigawatts, respectively. Figure 1 below outlines the total world energy distribution in "GW" at the top and "TWh" at the bottom [16].

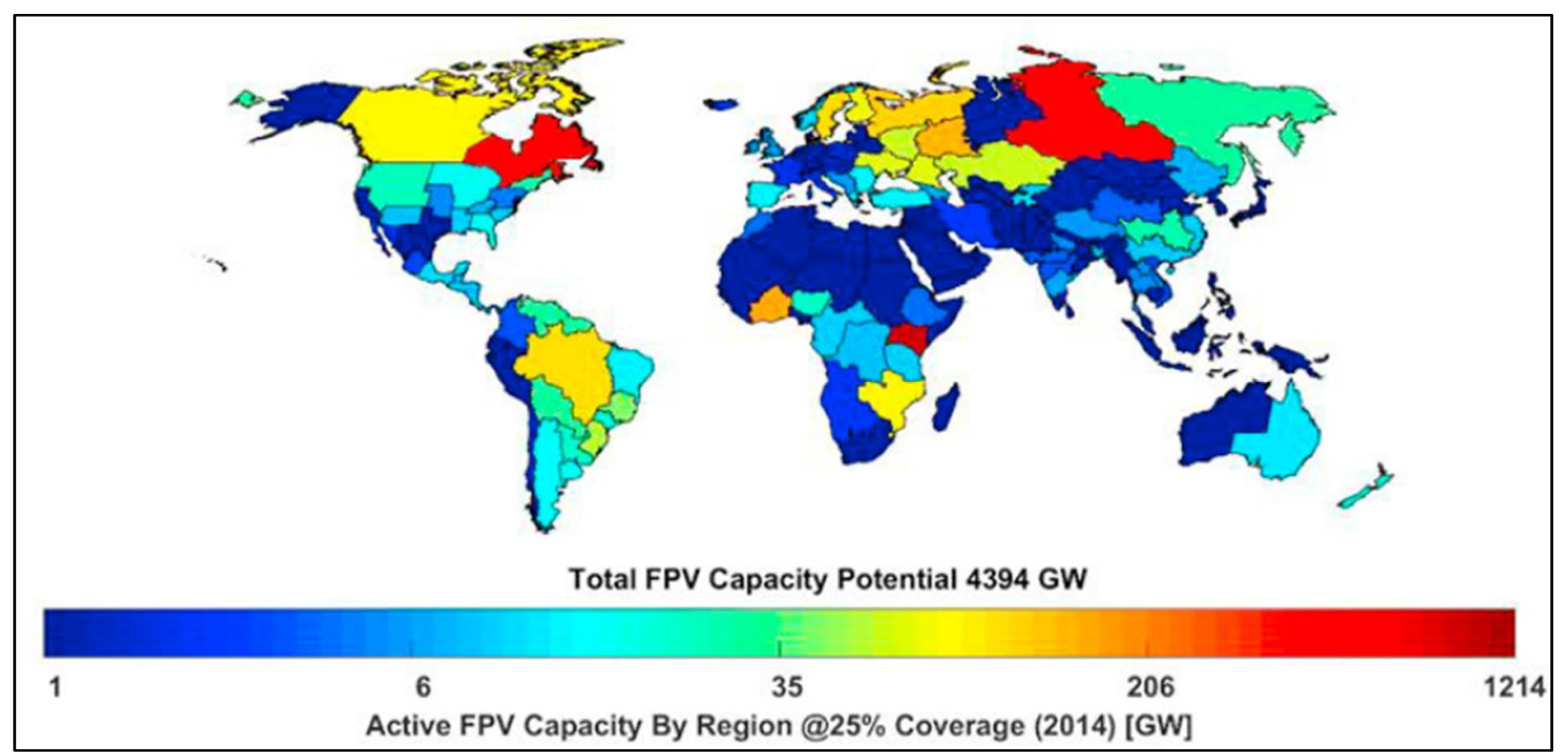

(a)

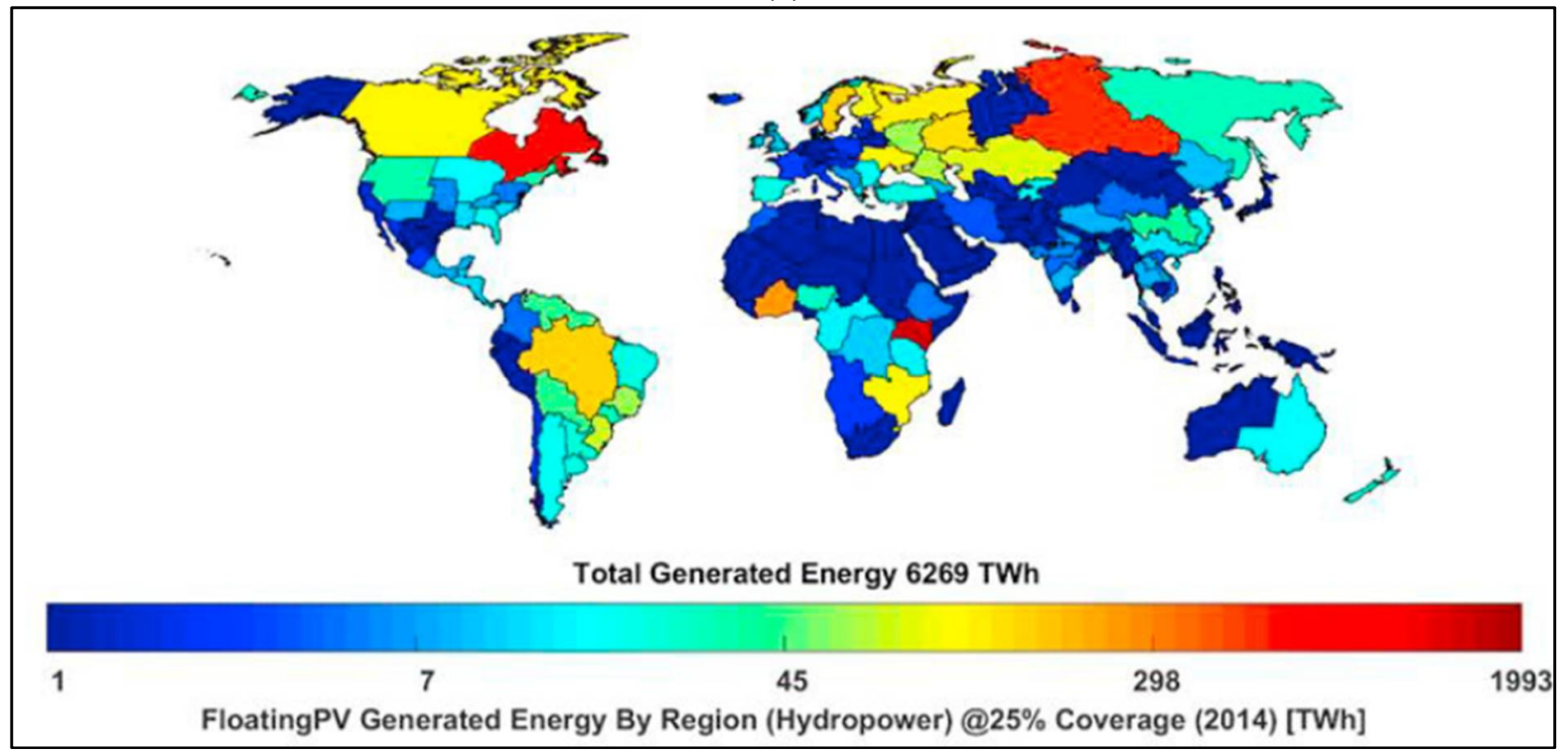

(b)

Figure 1. (a) Illustrating FPV capacity distribution potential in GW. (b) Showing electricity generation in TWh.

The percentage requirement of water-body surface area that matches the capacity of some hydropower plants in Ghana, Brazil, Malaysia, India, Turkey, Egypt, Venezuela, and Zambia is given in Table 1, which compares the various powerplants under consideration. 
Table 1. Showing estimated reservoir size and power generation to match hydropower capacity ([1] and authors' compilation). Reproduced from [1], the name of the publisher: ESMAP 2019.

\begin{tabular}{|c|c|c|c|c|}
\hline Reservoir/Dam & Country & Dam Size $\left(\mathrm{km}^{2}\right)$ & Hydropower (GW) & $\begin{array}{l}\text { \% Dam Area for FPV } \\
\text { to Match Hydropower }\end{array}$ \\
\hline Aswan Dam & Egypt & 5000 & 2.0 & $<1 * /<1(0.68)$ \\
\hline Attaturk Dam & Turkey & 820 & 2.4 & $3 * / 5$ \\
\hline Bakun Dam & Malaysia & 690 & 2.4 & $3 * / 6$ \\
\hline Guri Dam & Venezuela & 4250 & 10.2 & $2 * / 4$ \\
\hline Itezhi-tezhi Dam & Zambia & 113 & 0.12 & $1 * / 2$ \\
\hline Kafue Gorge Upper & Zambia & 70 & 0.99 & $14 * / 24$ \\
\hline Kariba North Bank & Zambia & 4354 & 1.08 & $<1 * /<1(0.42)$ \\
\hline Lake Volta & Ghana & 8500 & 1.0 & $<1 * /<1(0.2)$ \\
\hline Narmada Dam & India & 375 & 1.5 & $4 * / 7$ \\
\hline Sobradinho Lake & Brazil & 4220 & 1.0 & $<1 * /<1(0.4)$ \\
\hline
\end{tabular}

Note: * means percentage excluding mooring ( $1 \mathrm{MW}$ covers $\sim 0.01 \mathrm{~km}^{2}$ ), including mooring $\left(1 \mathrm{MW}\right.$ covers $\left.\sim 0.017 \mathrm{~km}{ }^{2}\right)$.

To put things into perspective, and by taking Kafue Gorge Upper as an example, Table 1 shows that approximately $14 \%$ of the dam area is required to match the existing hydropower capacity of $990 \mathrm{MW}$, excluding mooring considerations, while the value increases to about $24 \%$ by including mooring.

According to research published by Rosa-Clot and Tina, Farfan and Breyer, Cazzaniga, and Nordmann et al., $[11,16,17]$, the potential of large-scale hydro-connected photovoltaics is vastly promising, owing to photovoltaics' technological advancement, including enhanced mooring and anchoring techniques. The Longyangxia power plant in China is an example of a large-scale hydro-PV hybrid energy generation system, with a distribution of $850 \mathrm{MW}$ and $1250 \mathrm{MW}$ of solar PV ground-mounted and hydropower plants, respectively. This energy mix offers a time complementarity in the output by utilizing dispatchable hydropower to reduce the power variations and voltage sags of the system, due to intermittent solar power. The network energy dispatch curve is thus met by the downward or upward throttling of hydropower, depending on whether the photovoltaics output is high or low, respectively, thereby improving the reliability and enhancing the total energy generation of the system $[11,18]$. Scholarly analyses had brought to light the mutual benefits of FPV systems by not only reducing algae growth and evaporation but also making a reduction in the generation cost of solar PV energy, owing to the lower operating temperatures of PV panels [16,19].

With regard to wind energy reviews, the research by Local-Arantegui and SerranoGonzalez [20] has shown a technological evolution toward larger machines (i.e., taller towers, longer blades and high-capacity power generators). To put this into a global perspective, the size of the wind turbines in terms of hub height, rated power and rotor diameter had increased from $30 \mathrm{~m}$ hub height, $30 \mathrm{~m}$ rotor diameters and $300 \mathrm{~kW}$ rated power in the late 1980s, to $87.7 \mathrm{~m}$ hub height, $92.7 \mathrm{~m}$ rotor diameter and 2.1 MW rated power at the beginning of 2015. This technological evolution has been driven mainly by the process of attaining carbon neutrality, grid code integration adherence, scaling up the process to minimize reliability issues, and further cost reductions owing to the increase in capacity factor of most projects. Moreover, higher wind speeds, and consequently high energy yields, prevail at high altitudes; as such, wind turbine technology has advanced to accommodate longer heights of wind turbines (i.e., an increase in hub height and rotor diameter) [21,22]. According to the global wind energy council and Jin et al., [23], at the beginning of 2015, wind resources had become the largest and most successful renewable technology deployment, with $370 \mathrm{GW}$ of global cumulative capacity. This feat was achieved in approximately 20 years. Many wind turbine configuration types have been addressed in 
the literature; nonetheless, the doubly fed induction generator (DFIG) configuration stood out in terms of mainstream technological development, owing to its high energy efficiency, low power consumption and low mechanical stress [24]. The evaluation and analysis of the impact of the DFIG on system stability and reliability have become pertinent with the increase in penetration of variable renewable energy source-VRES (i.e., wind) [25-28]. Swarna et al. [29] revealed the reactive power support capability of DFIGs at the wind turbine machine terminals during instances of active power generation curtailment.

\subsection{Local Context Perspective}

Zambia has great solar thermal and photovoltaic application potential (i.e., $5.5 \mathrm{kWh} / \mathrm{m}^{2} /$ day of average solar insolation, with approximately 3000 sunshine hours per annum) [30], coupled with 13 hydropower plants, accounting for 85 percent of the total installed generation capacity $(2800 \mathrm{MW})$, making the nation better suited to a mix in generation sources. A recent wind resource study conducted by the World Bank revealed great wind-speed potential (i.e., from 6 to $12 \mathrm{~m} / \mathrm{s}$ ) in some parts of Zambia (i.e., Luangwa, Serenje, Muchinga, etc.) for utility-scale wind power generation at heights above sea level between 80 and $200 \mathrm{~m}$. These heights confirm that reasonable wind speeds with the potential for wind energy occur at great altitudes. This resulted in the validation and commissioning of a wind atlas with a mesoscale resolution, based on a 2-year period of accurate wind speed measurement data taken from the 8 meteorological masts [31,32].

Moreover, Zambia aims to become a middle-income nation by the year 2030 (Vision 2030), even though the country is faced with significant challenges in the quest to achieve this feat. Some of the issues faced include a limited infrastructure for electricity evacuation, low electrification rates, and low access to clean energy technologies. With urban and rural access to electricity at $67 \%$ and $4 \%$, respectively, translating into a national average of access to electricity of $31 \%$, this leaves approximately 12 million people without access [33,34]. Thus, these unelectrified households depend on other fuel types for energy consumption and utilization (conventional biomass for their cooking and heating, lighting using kerosene and candles). The high dependence on biomass has resulted in huge deforestation of about $250,000-300,000$ hectares per annum $[35,36]$. With a power consumption of approximately $706 \mathrm{kWh}$ per capita, this is below expectations relative to Zambia's economic and social potential, when compared to other resource-rich countries like Namibia, Peru, South Africa and Chile, whose per capita consumption is about 2 to 3 times higher than that of Zambia. At the end of 2016, Zambia had a gross domestic product (GDP) of USD 20.5 billion for a population of about 16 million people and scooped the eighteenth rank in terms of growth economic prospects in Africa. Currently, approximately 69\% of the Zambian population has a lack of access to electricity, although the $31 \%$ with access usually experience power outages, especially during the drought seasons [34]. The country's estimated $2800 \mathrm{MW}$ of total installed capacity limits economic growth, mostly in drought-ridden years when the expected generation output is lower than normal. This is because eighty-five percent of the total installed capacity is hydropower, which depends on good water resource availability. The country's 3 major hydropower plants (Kafue Gorge, Kariba North Extension and Kariba North) account for $81 \%$ of electricity production. This dependency on hydropower can be ascribed to the vast water resource availability, resulting in an estimated hydropower potential of $6000 \mathrm{MW}$. However, climate change has in the recent past shrunk the dynamics of this potential by making the electrical power system susceptible to droughts. To put this into perspective, four major droughts have been experienced in Zambia in the last fifteen years, with the most recent occurring in the 2015/2016, 2016/2017 and 2019/2020 rainfall seasons. Consequently, the difficulties in load management strategies by the country's power utility companies were exacerbated in the quest to conserve water resources. This led in turn to turmoil in the national GDP, owing to reduced economic activity from the commercial, manufacturing and mining sectors [33,34,37].

This study encourages all stakeholders involved in electricity generation by promoting the use of alternative renewable energy technologies, such as onshore wind and floating 
photovoltaics, to enhance the capacity of electricity in the country, which is in tune with the perceived outcomes of the Zambia energy policy of 2019. Although there is a need to develop a firm and clear policy framework for effective regulation of these renewable energy technologies, this could help abate risks in project financing and enhance investor confidence. This could be key in transforming Zambia into a prosperous middle-income country by 2030, owing to the technologies' contribution in promoting sustainable and safe electricity generation for economic development and growth. The capacity and provisions to build resilient and better climate models (i.e., global circulation models) and the increase in understanding natural variability would help in enacting sound and well-informed environmental policies that tackle the existing energy challenges faced in the country and prepare for the future at the same time [34].

\subsection{Role of Renewable-Energy Hybrid Systems in Energy Transition (Climate Mitigation and Dispatch)}

The fight against climate change, through the attainment of carbon neutrality, has been the major motivator toward the adoption of renewable energy systems globally [18,38]. Nevertheless, concerns about system security and stability are amplified by the huge penetration of variable renewable energy sources (VRES), such as wind and solar photovoltaics, into the electrical network grids [39]. The inherent fluctuations in VRES technologies add to the uncertainty and variability in the electric power network and could negatively impact system operations if they are not addressed [40]. Li et al. [41] define uncertainty as an unanticipated change in demand and generation balance from what was forecasted, while variability is an anticipated change in the demand-generation balance. The increase in the penetration of VRES has necessitated the need to understand grid code constraints and electrical network parameters to maintain the integrity, efficiency, and reliability of the power system [42,43]. Large-scale penetration of VRES is one of the main challenges faced in modern electric power systems, owing to the complexities in the interactions between active and reactive power flows in the network, based on system design and connection characteristics, thus impacting dispatch operating costs, network losses and the voltage profile [43].

Certain scholarly analyses $[18,44]$ found an economical operational balance between non-dispatchable (i.e., solar) and dispatchable (i.e., hydro) power sources, hence promoting the penetration of more renewable sources. Due to the benefit of increased system efficiency and enhanced energy supply balance, many countries have adopted hybrid energy systems providing a dynamic mix of two or more energy sources [45,46]. Typical hybrid energy systems include hydro-PV [47,48], hydro-wind-thermal [49], hydro-wind [50,51] and hydro-wind-PV systems [52,53]. A recent study by Maronga et al. [54] evaluated the optimal mix of PV, concentrated solar power (CSP) and storage, for a mining context in Zimbabwe. Previous research [55] found a mix of hydro and photovoltaics to be broadly used in many countries, owing to the vast spread of solar PV as a principal renewable energy source globally, and the swift regulation response of hydropower. Consequently, regions such as SSA (i.e., Zambia) that are rich in both hydropower and solar PV renewable resources are better suited in the development and deployment of hydro-PV energy systems. Regarding the dynamic and optimal mix of renewable energy sources involving solar PV, hydro and wind, research mostly focuses on resource temporal complementarity [56-58], plant operations management $[18,53,58]$, and the optimization of system configuration [48,58-60]. A study by Beluco et al. [56] revealed a reduction in customer power outages because of the time complementarity benefits attributed to the solar PV and hydro hybrid system. Research conducted in Italy by Francois et al. [57] revealed a decrease in energy balance fluctuations, owing to the mix of solar PV and hydro (run-of-river type) power. Kougias et al. [58] were able to relate an improvement in the output of the PV-small hydro energy system by the optimization of the tilt angle and system azimuth.

Studies on hybrid energy systems involving wind, PV, and hydro aim at enhancing reliability and system flexibility by optimally dispatching the available resources. Such scholarly analyses, however, introduce errors in the modeling process by omitting to 
include the stochastic tendencies of solar PV and wind power [61-63]. Furthermore, by using deterministic and stochastic programming, Wei and Liu [64] tackled the uncertainties of solar PV and wind systems. The enhanced system security, coupled with limitations on the system economy and flexibility resulting from the deterministic inclusion of spinning reserve to the dispatch model, were revealed by Wei and Liu [64] and Liu et al. [53]. Dong et al. [65] and Zou [66] revealed that by adopting a structured multi-scenario perspective, a stochastic optimization problem in nature was able to be converted to a deterministic one, with the inaccuracy in the optimization output being the main trade-off.

In the recent past, the economic coordination of energy systems had employed robust and resilient optimization techniques, owing to its efficiency in excluding large-scale sampling variable datasets and probability models that have a precise distribution [67]. The random nature of VRES necessitates the adaptions between the forecasted and the actual generation of a hybrid system, so as to meet the load curve at any instant in time $[52,68]$. Researchers [69] had developed a method to track real-time deviations between two consecutive energy-scheduling intervals, while attaching the variability and uncertainty cost of energy. Another research study [64] incorporated the energy curtailment of solar $\mathrm{PV}$ and wind as a penalty cost in the scheduling.

\section{Methodology}

3.1. Site Appraisal and Ranking Methodology

\subsubsection{Overview}

The decision-making process regarding the suitability and location of sites for variable renewable energy sources (solar PV and wind) utilizes geospatial parameters, mainly involving GIS models in dynamic analysis (i.e., to capture, analyze, store, manage, and manipulate spatial or geographical data) [70-73]. To aid in formulating a ranking and geospatial data interpretation methodology, such GIS modeling is usually paired with multi-criteria decision-making (MCDM) [73]. Moreover, in the late 1990s, literature in the development of VRES models started gaining traction [74,75]. Global interest in the optimal siting of solar PV and wind in the recent past has arisen, due to the quest of attaining carbon neutrality, leading to the development of generic models based on the process shown in Figure 2. Firstly, the input parameter selection, ranging from socialeconomical, technical, and environmental factors, is completed [76]. For example, ideal wind site considerations typically include the proximity to the existing electrical network (i.e., for easy grid connection), proximity to a good road network, positioning further away from protected zones (i.e., national parks or heritage land), or further away from settlements to prevent noise and flicker, good resource potential (i.e., average wind speeds and capacity factor above sea level), and being further away from the flight path to prevent interference with radar equipment near airports. Unsuitable sites are then excluded from further analysis by scoring against the model input parameters (i.e., sites with low resource potential).

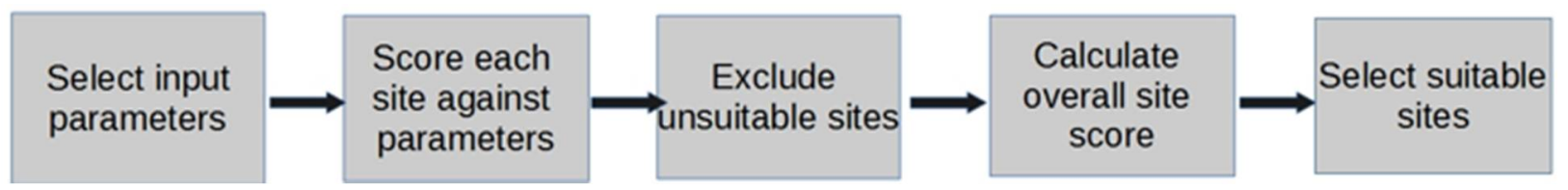

Figure 2. Diagram showing the typical structure of the multicriteria decision method (source: [71]). Reproduced from [71], the name of the publisher: ePrints Soton 2017.

The sites that have the potential for further development and pass the filtering stage are then scored and ranking using the weighted sum method (WSM) to assess their suitability (WSM is given in the equation below) [71,73]:

$$
A_{i}^{W S M}=\sum_{j=1}^{n} w_{j} a_{i j} \text { for } i=1,2,3, \ldots N
$$


where $\mathrm{w}$ is the relative parameter weighting, $\mathrm{a}$ is the parameter score value, and $\mathrm{i}$ is the attribute layer.

\subsubsection{Proposed Study Methodology}

The proposed study methodology for assessing site suitability was confirmed after stakeholder engagements (i.e., local experts, power utility) and extensive reviews from the literature [77-80]. The sites of interest included 5 reservoir-type, 2 pondage-type and 7 run-of-river (RoR)-type hydro plants, as shown in Table 2.

Table 2. Showing the identification of the hydro sites under study.

\begin{tabular}{|c|c|c|c|c|c|c|c|c|}
\hline No & $\begin{array}{l}\text { Hydro Power } \\
\text { Station }\end{array}$ & Coordinates & Rating (MW) & Owner & River & Country & Type & Note \\
\hline 1 & $\begin{array}{l}\text { Kafue Gorge } \\
\text { Upper }\end{array}$ & $\begin{array}{l}15^{\circ} 48^{\prime} 25.0^{\prime \prime} \mathrm{S} \\
28^{\circ} 25^{\prime} 16.0^{\prime \prime} \mathrm{E}\end{array}$ & 990 & Zesco & Kafue & Zambia & Reservoir & Grid \\
\hline 2 & Kariba North Bank & $\begin{array}{l}16^{\circ} 31^{\prime} 20.0^{\prime \prime} \mathrm{S} \\
28^{\circ} 45^{\prime} 42.0^{\prime \prime} \mathrm{E}\end{array}$ & 1080 & Zesco & Zambezi & Zambia & Reservoir & Grid \\
\hline 3 & $\begin{array}{c}\text { Kafue Gorge } \\
\text { Lower }\end{array}$ & $\begin{array}{l}15^{\circ} 53^{\prime} 46.0^{\prime \prime} \mathrm{S} \\
28^{\circ} 33^{\prime} 33.0^{\prime \prime} \mathrm{E}\end{array}$ & 750 & Zesco & Kafue & Zambia & RoR & Grid \\
\hline 4 & Itezhi-Tezhi & $\begin{array}{l}15^{\circ} 45^{\prime} 55.0^{\prime \prime} \mathrm{S} \\
26^{\circ} 01^{\prime} 05.0^{\prime \prime} \mathrm{E}\end{array}$ & 120 & Zesco/ITPC & Kafue & Zambia & Reservoir & Grid \\
\hline 5 & Lusiwasi Upper & $\begin{array}{l}12^{\circ} 59^{\prime} 18.2^{\prime \prime} \mathrm{S} \\
30^{\circ} 51^{\prime} 53.6^{\prime \prime} \mathrm{E}\end{array}$ & 15 & Zesco & Lusiwasi & Zambia & Pondage & Grid \\
\hline 6 & Lusiwasi Lower & $\begin{array}{l}12^{\circ} 59^{\prime} 18.2^{\prime \prime} \mathrm{S} \\
30^{\circ} 51^{\prime} 53.6^{\prime \prime} \mathrm{E}\end{array}$ & 12 & Zesco & Lusiwasi & Zambia & Pondage & Grid \\
\hline 7 & Lunzua & $\begin{array}{c}8^{\circ} 48^{\prime} 06.4^{\prime \prime} \mathrm{S} \\
31^{\circ} 20^{\prime} 18.3^{\prime \prime} \mathrm{E}\end{array}$ & 14.8 & Zesco & Lunzua & Zambia & RoR & Grid \\
\hline 8 & Musonda & $\begin{array}{l}10^{\circ} 42^{\prime} 39.5^{\prime \prime} \mathrm{S} \\
28^{\circ} 48^{\prime} 23.1^{\prime \prime} \mathrm{E}\end{array}$ & 10 & Zesco & Luongo & Zambia & RoR & Grid \\
\hline 9 & Chishimba & $\begin{array}{l}10^{\circ} 06^{\prime} 29.8^{\prime \prime} \mathrm{S} \\
30^{\circ} 55^{\prime} 02.7^{\prime \prime} \mathrm{E}\end{array}$ & 6 & Zesco & Luombe & Zambia & RoR & Grid \\
\hline 10 & Shiwangandu & $\begin{array}{l}11^{\circ} 13^{\prime} 10.25^{\prime \prime} \mathrm{S} \\
31^{\circ} 45^{\prime} 0.61^{\prime \prime} \mathrm{E}\end{array}$ & 1 & Zesco & Munshya & Zambia & RoR & Grid \\
\hline 11 & Lunsemfwa Hydro & $\begin{array}{l}14^{\circ} 29^{\prime} 33.7^{\prime \prime} \mathrm{S} \\
29^{\circ} 06^{\prime} 54.6^{\prime \prime} \mathrm{E}\end{array}$ & 24 & LHPC & Lunsemfwa & Zambia & Reservoir & Grid \\
\hline 12 & $\begin{array}{l}\text { Mulungushi } \\
\text { Hydro }\end{array}$ & $\begin{array}{l}14^{\circ} 43^{\prime} 47.48^{\prime \prime} \mathrm{S} \\
28^{\circ} 50^{\prime} 39.22^{\prime \prime} \mathrm{E}\end{array}$ & 32 & LHPC & Lunsemfwa & Zambia & Reservoir & Grid \\
\hline 13 & Victoria Falls & $\begin{array}{l}17^{\circ} 55^{\prime} 52.5^{\prime \prime} \mathrm{S} \\
25^{\circ} 51^{\prime} 37.9^{\prime \prime} \mathrm{E}\end{array}$ & 108 & Zesco & Zambezi & Zambia & RoR & Grid \\
\hline 14 & Zengamina & $\begin{array}{l}11^{\circ} 07^{\prime} 26.0^{\prime \prime} \mathrm{S} \\
24^{\circ} 11^{\prime} 32.0^{\prime \prime} \mathrm{E}\end{array}$ & 0.7 & NWZDT & & Zambia & RoR & Off-Grid \\
\hline
\end{tabular}

The developed methodology for the placement of wind turbines and FPV near hydropower sites is illustrated in the flowchart given in Figure 3, below. 


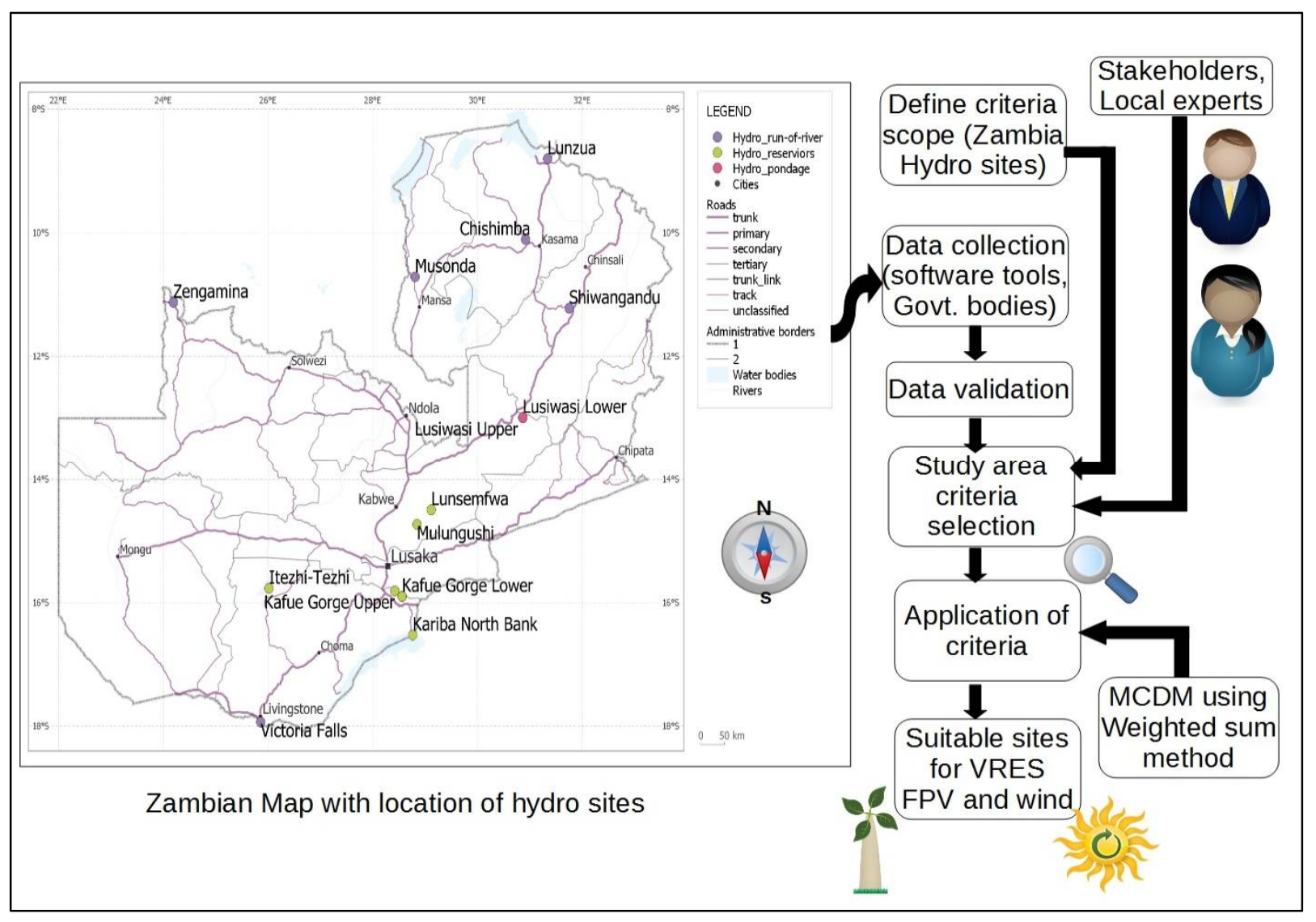

Figure 3. Diagram showing a proposed methodology flowchart of the study area shown.

\subsubsection{Criteria Hierarchy Structure Optimal FPV Site}

A two-stage approach was utilized in the selection of FPV sites, namely, screening and filtering (stage 1), and ranking and scoring (stage 2), as shown in Figure 4. The filtering stage looked at the capacity factor, distance to the grid, water surface area and distance to protected zones as the model input parameters [81-83]. The scoring and ranking stage included the relative weight (r.w.) distribution of the energy export $(20 \%$ r.w.), ease of access (15\% total r.w.), demand (5\% total r.w.) and floating PV potential (60\% total r.w.) [84-87].

\section{Optimal Wind Site}

The selection of onshore wind sites utilized a two-stage approach, namely, filtering and screening (stage 1) and scoring and ranking (stage 2), which is similar to the process employed under FPV (please refer to Figure A1 in Appendix A). The filtering stage looked at the distance to the grid, distance to the protected zone, wind speed, capacity factor, the security risk of installation, and noise and flicker considerations due to proximity to buildings and settlements, as the model input parameters [88-95]. The second stage (ranking and scoring) included the distribution of the energy export (20\% of r.w.), ease of access ( $15 \%$ of total r.w.), demand ( $5 \%$ of total r.w.) and wind potential ( $60 \%$ of total r.w.).

\subsubsection{Site Attribute Suitability Score}

Adopted from previous research, three site-attribute suitability tables were developed (shown in Appendix A); these included onshore wind, floating photovoltaics and hybrid suitability, looking at the balanced parameters of FPV and wind [72,77-80,96-105]. Since the wind potential is less pronounced than PV in Zambia, the relative weight for the wind was set lower than that of FPV in the balanced suitability ranking. 


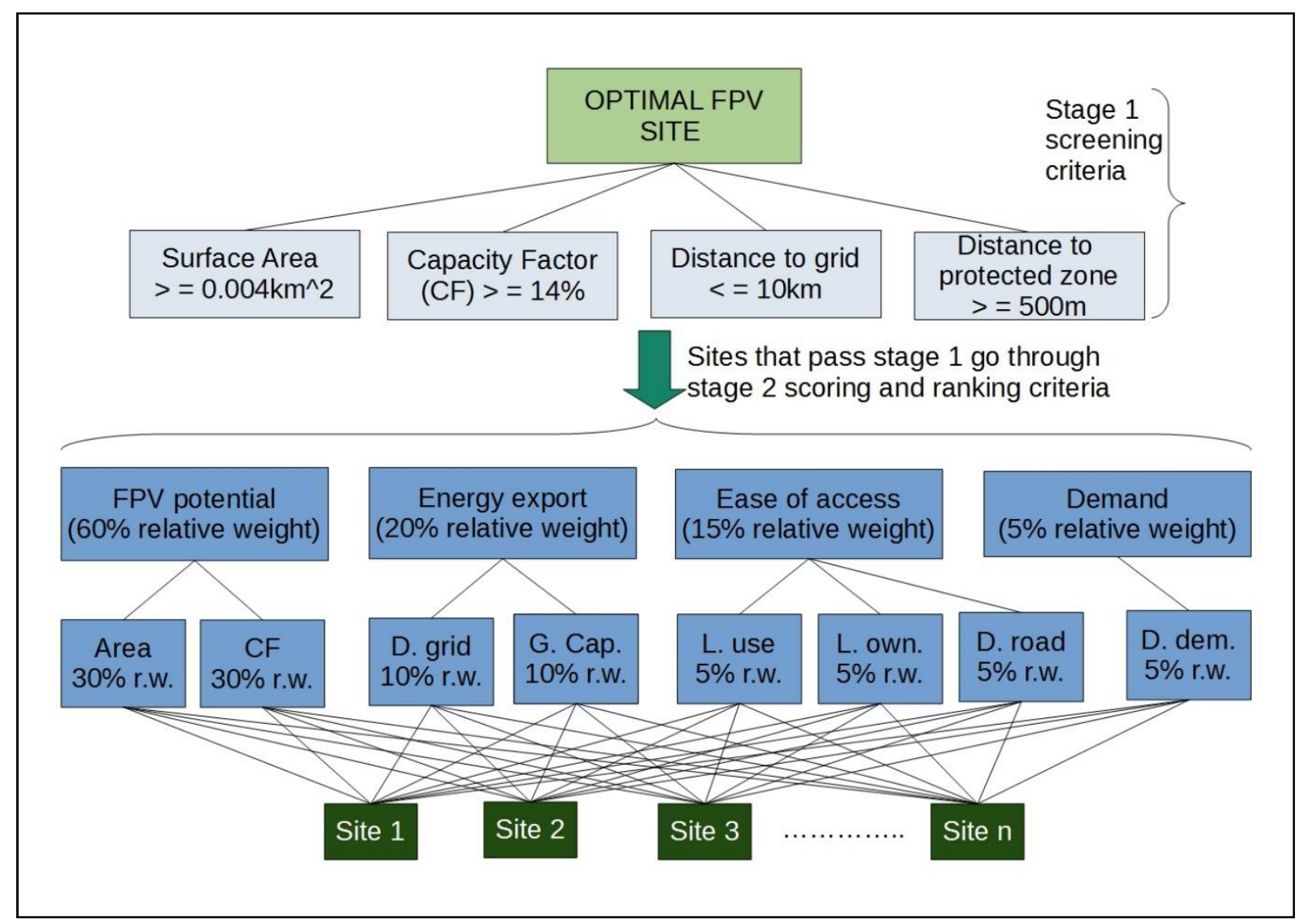

Figure 4. Diagram showing the proposed methodology flowchart of a 2-stage hierarchy structure for optimal floating photovoltaics site selection. Abbreviations: CF-capacity factor, D. grid-distance to grid, G. Cap.-capacity of grid, L. use-land use, L. own-land ownership, D. road—distance to road, D. dem.- distance to demand center, r.w.—relative weight.

\subsubsection{Methodology Limitations}

The weighted sum method (WSM) was applied without having insight about the assigned relative weight to the attribute layers and the layer combination procedures [73]. On the other hand, the analytic hierarchy procedure (AHP) was able to mitigate raised concerns regarding the WSM [77], although the models remain sensitive to the adopted relative weighting, as evidenced by planning permission refusal for some high-level projects within the United Kingdom. Van Rensburg et al. [106] were able to address the weighting concerns of input parameters by establishing the relationship between significant parameters influencing the quantitative assessment-based decision and the project receiving planning permission. This was then coupled with GIS modeling to assess the geospatial parameters of influence in the UK [71].

To mitigate concerns raised about the weighted sum method, the proposed study looked at a wide range of input parameters that include environmental, social, climate, economic and topographical factors to attain a more pragmatic and acceptable site appraisal (screening and ranking) process. Additionally, this was done with the help of stakeholder engagement, the solicitation of local expert opinions and an extensive literature review in the decision-making process; consequently, this contributed to the reduction in uncertainties when categorizing the attribute suitability scoring scale owing to certain assumptions that were made.

Since there is no commercial floating PV and wind project currently in Zambia, there is an element of bias in the contribution to the study from stakeholders and experts on the renewable energy generation forecast plan and agenda in line with existing policies (i.e., 
Vision 2030, National Energy Policy 2019, and the Seventh National Development Plan). Moreover, the authors acknowledge that the proposed appraisal method is an ongoing process, and hence is prone to some fine-tuning, as stakeholders (i.e., project developers, investors) with specific interests and viewpoints come on board.

\subsection{Design Scoping Methodology}

\subsubsection{Design Methodology Formulation}

The proposed energy system at Kafue Gorge Upper will comprise hydro, onshore wind, floating photovoltaics and grid load, as given in the schematic in Figure 5. The schematic shows the existing automatic generation control (AGC), excluding VRES, and the proposed Hydro-FPV-Wind daily dispatch (HFWDD) strategy. The model assumes that all the three sources of generation under consideration are coupled to the same generation bus. Moreover, the model receives inputs from the reservoir height variation " $\mathrm{H}_{\mathrm{r}}(\mathrm{t})$ ", reservoir inflow " $\mathrm{Q}_{\text {in }}(\mathrm{t})$ ", hydro generation schedule " $\mathrm{P}_{\mathrm{HYg}}(\mathrm{t})$ ", water usage/consumption " $\mathrm{Q}_{\mathrm{T}}(\mathrm{t})$ ", the hydro virtual battery from saved water " $\mathrm{Q}_{\mathrm{s}}(\mathrm{t})$ ", grid load " $\mathrm{P}_{\mathrm{LD}}(\mathrm{t})$ ", penstock flowrate " $\mathrm{Q}_{\mathrm{p}}(\mathrm{t})$ ", onshore wind output " $\mathrm{P}_{\mathrm{WDg}}(\mathrm{t})$ " and floating photovoltaic output " $\mathrm{P}_{\mathrm{PVg}}(\mathrm{t})$ ".

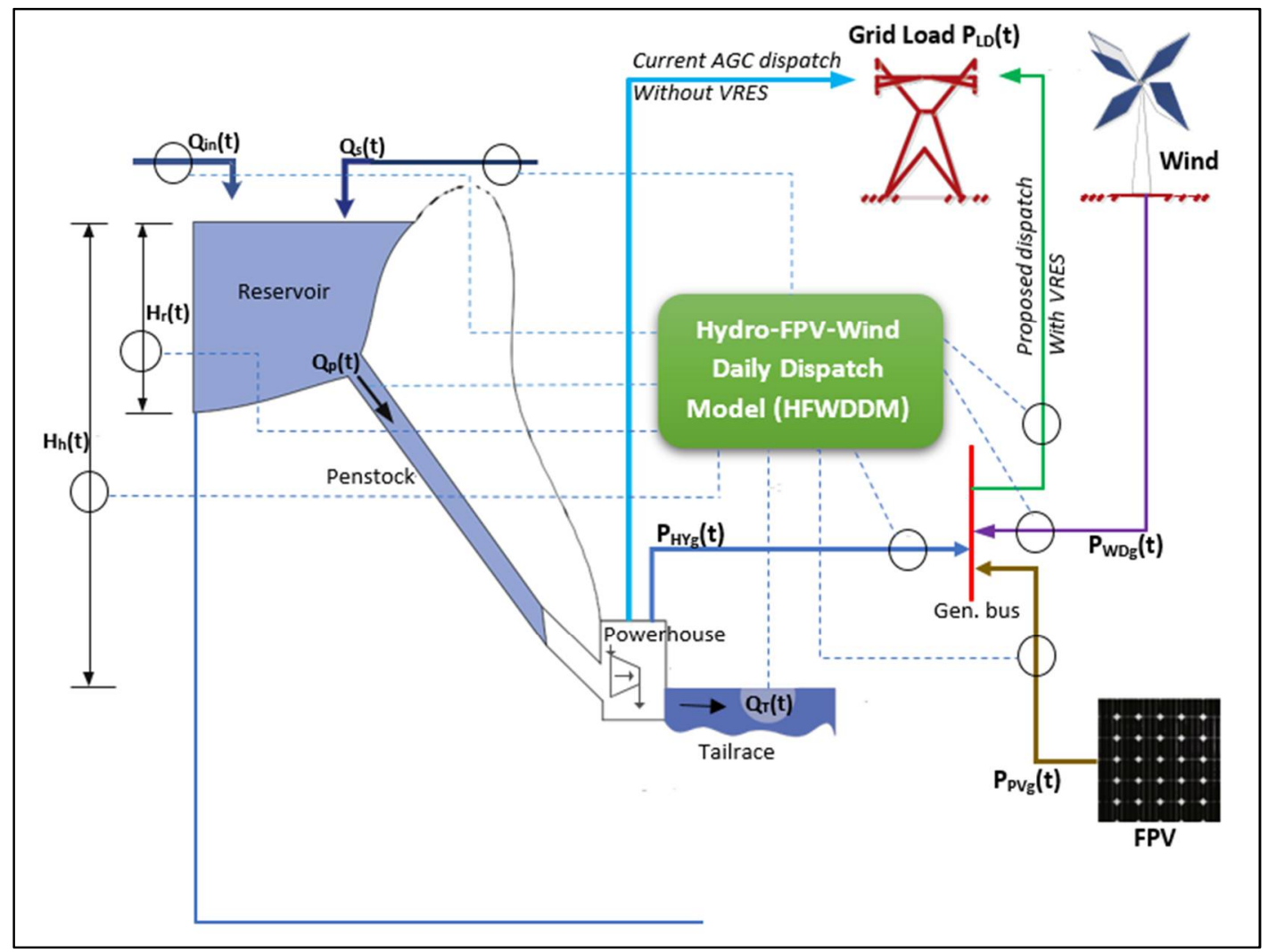

Figure 5. Diagram showing the schematic for the hydro-FPV-wind grid-tied system (adopted from [107]). Reproduced from [107], the name of the publisher: Elsevier 2019.

\subsubsection{Hydro-FPV-Wind Daily Dispatch (HFWDD) Model}

The objective of the HFWDD model is to balance the seasonal load characteristic curve on the grid by optimally dispatching the three generation sources (i.e., hydro, FPV and wind). This entails developing a two-stage model that addresses the technical parameters of the electrical network for any additional generation and, thereafter, optimizes the energy system using a customized dispatch algorithm (Figure 6). Firstly, the extent of wind and FPV integration on the grid that would negatively impact the network parameters (i.e., power losses, voltage magnitude and stability) is assessed in the two-stage model. 
This is in line with previous research $[33,42,108-114]$. Secondly, seasonal hourly reservoir inflows, water consumption targets, grid demand characteristics and the total generation scenarios (wind, FPV and hydro) are incorporated into the model. Subsequently, the grid load is served by prioritizing the integration of VRES [115] as readily available, followed by a downward regulation of hydro-generation at any moment. This throttling down of hydropower is equivalent to the water-saving potential (virtual hydro battery). Nevertheless, limited reservoir capacity, coupled with a reduction in the grid demand, could present storage challenges in a wet year (which is "rarely experienced"), hence necessitating the opening of the floodgates to get rid of excess water. Similar optimization and dispatch studies of RES were conducted by [111,116-126].

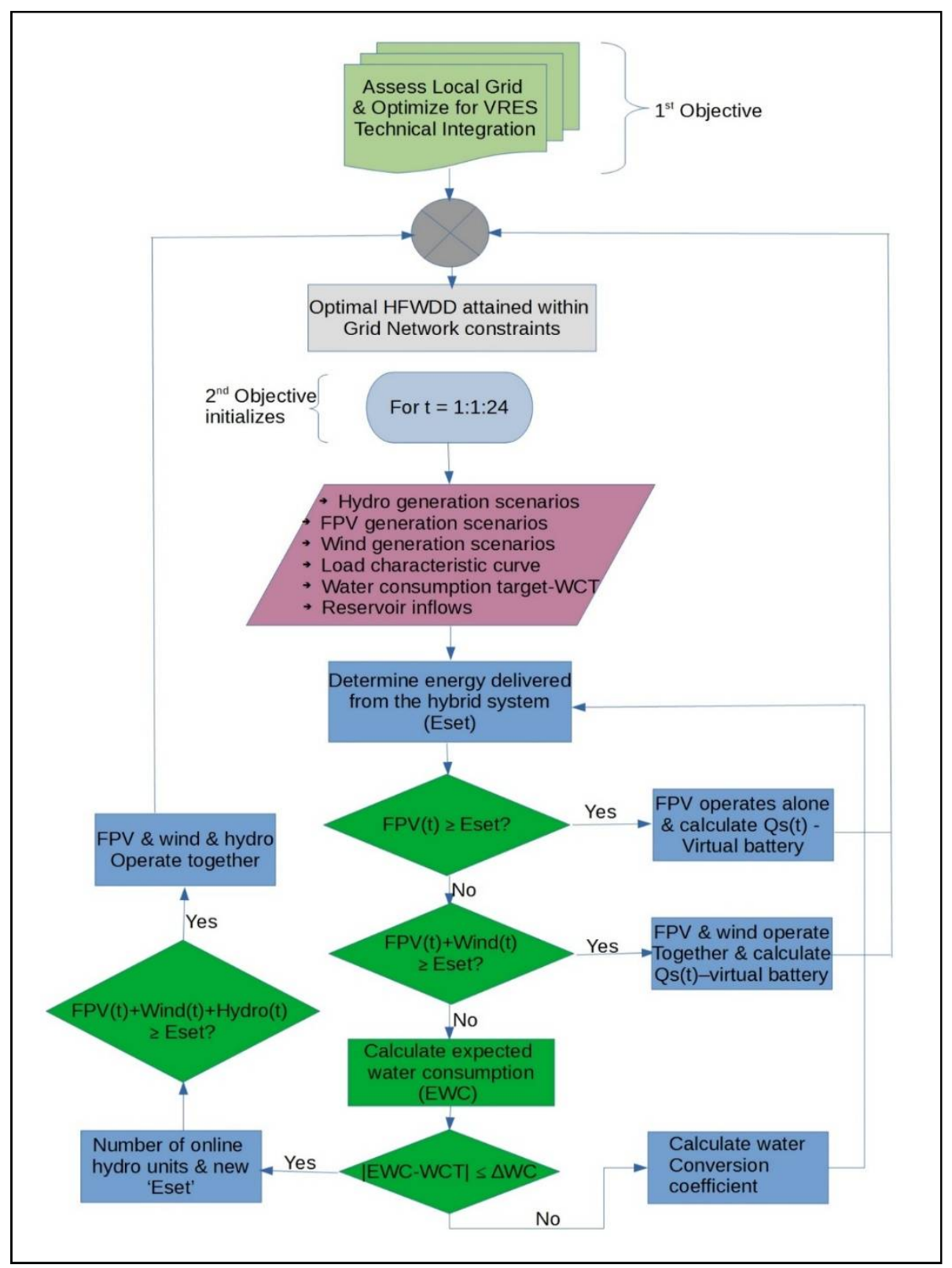

Figure 6. Diagram showing the systematic flow of the decision level to attain optimal hydro-FPVwind daily dispatch (HFWDD).

Without putting the stochastic nature of wind and FPV power under consideration, the optimization problem is the seasonal daily dispatch on a typical day, based on the minimization of the operating cost of the existing automatic generation controller at the 
hydropower plant. Additionally, owing to the perceived low operational cost of wind and FPV, the optimization problem also prioritizes the dispatch of VRES over other conventional generation sources:

$$
\operatorname{Min}_{\mathrm{k}} \rightarrow \operatorname{Conv}_{\text {operate }}(\mathrm{k})
$$

where " $\mathrm{k}$ " is the dispatch scenario for the day, including hydropower plant status, and Convoperate(.) is the daily operating cost of the power plant.

Virtual storage, as indicated in Figures 5 and 6, was modeled in HomerPro in Section 4.2.4. This looks at the availability of variable renewable energy sources (FPV and wind). Based on this factor, the model calculates how much hydro would have to be ramped down. The ramping down of hydro means that less water is utilized that is then available later (i.e., at night when the sun is not shining, and also at times when the wind is calm) - the dark/calm periods will require the saved water to be utilized.

Based on the relationship between hydrogeneration and the level of the reservoir, the $\mathrm{Qs}(\mathrm{t})$ is determined. This also looks at the reservoir rule curves that must not be violated to ensure optimal operation.

However, for a very wet year, which is "rarely experienced", the storage can have limitations in terms of reservoir capacity, and thus excess water is just wasted by opening the flood gates.

Parameter Uncertainty of VRES

Adopted from [59,127], the wind and FPV outputs can be represented as shown below:

$$
\begin{aligned}
& \text { For wind } \rightarrow \mathrm{P}_{\mathrm{WDg}, \mathrm{t}} \in\left[\mathrm{P}_{\mathrm{WDg}, \mathrm{t}(\mathrm{pre})}-\mathrm{P}_{\mathrm{WDg}, t(\mathrm{flu})}, \mathrm{P}_{\mathrm{WDg}, t(\mathrm{pre})}+\mathrm{P}_{\mathrm{WDg}, \mathrm{t}(\mathrm{flu})}\right] \\
& \text { For FPV } \rightarrow \mathrm{P}_{\mathrm{PVg}, \mathrm{t}} \in\left[\mathrm{P}_{\mathrm{PVg}, \mathrm{t}(\text { pre })}-\mathrm{P}_{\mathrm{PVg}, t(\mathrm{flu})}, \mathrm{P}_{\mathrm{PVg}, \mathrm{t}(\text { pre })}+\mathrm{P}_{\mathrm{PVg}, t(\mathrm{flu})}\right]
\end{aligned}
$$

where $\mathrm{P}_{\mathrm{WDg} / \mathrm{PVg}, \mathrm{t}(\mathrm{pre})}$ is the predicted VRES output, $\mathrm{P}_{\mathrm{WDg} / \mathrm{PVg}, \mathrm{t}(\mathrm{flu})}$ is the maximum output fluctuation, and $\mathrm{P}_{\mathrm{WDg} / \mathrm{PVg}, \mathrm{t}}$ is the time-dependent power output of the VRES for any given day.

\section{Model Objective Function}

Cost parameters are considered for the different generation stages to attain the economical and optimum dispatch scenario " $k$ ". The hydro unit's generation cost Conv $v_{\text {operate }}$ (" $\mathrm{C}_{\text {ope }}=$ in short form" $\left.=\mathrm{C}_{\mathrm{HYg}}\right)$ is the first stage. The second stage $\left(\mathrm{C}^{+}\right.$ope $)$mostly includes the hydro unit's adjustment costs $\mathrm{C}_{\mathrm{HYg} \Delta}$, curtailment costs of FPV and wind, given as $\mathrm{C}_{\mathrm{PVg}(\text { curt) }}$ and $\mathrm{C}_{\mathrm{WDg} \text { (curt), }}$ respectively [128]. Thus, the cost minimization objective function is given as:

$$
\mathrm{C}_{\mathrm{ope}}=\mathrm{C}_{\mathrm{HDg}}=\sum_{\mathrm{t}=1}^{\mathrm{T}}\left(\mathrm{a} \times \mathrm{P}_{\mathrm{HYg}, \mathrm{t}}^{2}+\mathrm{b} \times \mathrm{P}_{\mathrm{HYg}, \mathrm{t}}+\mathrm{c}\right)
$$

$$
\begin{aligned}
\mathrm{C}^{+} \text {ope } & =\mathrm{C}_{\mathrm{PVg}(\text { curt })}+\mathrm{C}_{\mathrm{WDg}(\text { curt })}+\mathrm{C}_{\mathrm{HYg} \Delta} \\
& =\sum_{\mathrm{t}=1}^{\mathrm{T}}\left[y_{\mathrm{PVg}(\text { curt })} \times\left(\mathrm{P}_{\mathrm{PVg}, \mathrm{t}}-\mathrm{P}_{\mathrm{PVg}, \mathrm{t} \text { (inject) }}\right)+y_{\mathrm{HYg}} \times \Delta \mathrm{P}_{\mathrm{HY}, \mathrm{t}}+y_{\mathrm{WDg}(\text { curt })} \times\left(\mathrm{P}_{\mathrm{WDg}, \mathrm{t}}-\mathrm{P}_{\mathrm{WDg}, \mathrm{t} \text { (inject) }}\right)\right]
\end{aligned}
$$

where the hydro units' power output at time " $t$ " is $\mathrm{P}_{\mathrm{HYg}, \mathrm{t}}, \mathrm{P}_{\mathrm{WDg}, \mathrm{t}(\text { inject) }}$ and $\mathrm{P}_{\mathrm{PVg}, \mathrm{t}(\text { inject })}$ are the wind and FPV injected power into the grid at time " $\mathrm{t}$ ", respectively, $\kappa \mathrm{HYg}$ is the hydro units adjustment penalty price, $\Delta \mathrm{P}_{\mathrm{HYg}, \mathrm{t}}$ the power output adjustment of hydro units, $\kappa W D g($ curt) and $\Lambda$ PVg(curt) are curtailment penalty prices for wind and FPV, respectively, and "a", "b" and "c" are hydro unit cost coefficients.

HFWDD Model Constraints

Hydro Constraints:

$$
\begin{gathered}
P_{H Y g(\max )} \geq P_{H Y g, t} \geq P_{H Y g(\min )} \\
Q_{H Y g, t}=y^{b}{ }_{H Y g}+y^{a}{ }_{H Y g} \times P_{H Y g, t}
\end{gathered}
$$




$$
\begin{gathered}
\mathrm{V}_{\text {flow (max) }} \geq \mathrm{Q}_{\mathrm{HYg}, \mathrm{t}} \geq \mathrm{V}_{\text {flow }(\min )} \\
\mathrm{Q}_{\mathrm{t}+1}=\mathrm{Q}_{\mathrm{in}, \mathrm{t}}-\mathrm{Q}_{\mathrm{HYg}, \mathrm{t}(\text { curt })}-\mathrm{Q}_{\mathrm{HYg}, \mathrm{t}}+\mathrm{Q}_{\mathrm{s}, \mathrm{t}} \\
\mathrm{Q}^{\max } \geq \mathrm{Q}_{\mathrm{s}, \mathrm{t}} \geq \mathrm{Q}^{\text {min }} \\
\mathrm{Q}_{\mathrm{s}, \mathrm{t}}=\mathrm{Q}_{\mathrm{s}, \mathrm{ini}} \\
\mathrm{Q}_{\mathrm{s}, \mathrm{T}}=\mathrm{Q}_{\mathrm{s}, \text { term }}
\end{gathered}
$$

where $y^{\mathrm{b}} \mathrm{HYg}$ and $y^{\mathrm{a}} \mathrm{HYg}$ are hydro water conversion coefficients, $\mathrm{Q}_{\mathrm{s}, \text { term }}$ and $\mathrm{Q}_{\mathrm{s}, \text { ini }}$ are final and initial storage values of the reservoir, $\mathrm{Q}^{\max }$ and $\mathrm{Q}^{\min }$ are the upper and lower reservoir storage limit at time " $\mathrm{t}$ ", $\mathrm{QHYg}_{\mathrm{H}, \mathrm{t}}$ is the water consumption at any time " $\mathrm{t}$ " of the hydro unit, $P_{H Y g, t}$ is the power output of the hydro unit at time " $t$ ", $Q_{\text {in, } t}$ is the inflow of reservoir at time " $\mathrm{t}$ "; $\mathrm{Q}_{\mathrm{s}, \mathrm{t}}$ is the hydro reservoir storage at time " $\mathrm{t}$ ", $\mathrm{Q}_{\mathrm{HY}, \mathrm{t}(\mathrm{curt})}$ is the curtailment of the reservoir water, and $V_{\text {flow(max) }}$ and $V_{\text {flow(min) }}$ are the water consumption upper and lower limits in a given period.

Power Flow Branch Constraints:

$$
\sum_{\mathrm{i}=1}^{\mathrm{Ni}}\left(\mathrm{f}_{\mathrm{bi}} \times \mathrm{P}_{\mathrm{it}}\right) \leq \mathrm{S}_{\mathrm{b}(\max )}
$$

where $\mathrm{S}_{\mathrm{b}(\max )}$ is the branch maximum capacity, " $\mathrm{i}$ " is the power system node identifier, " $\mathrm{b}$ " is the branch identifier, $\mathrm{N}_{\mathrm{i}}$ is the number of system network nodes in total, $\mathrm{P}_{\mathrm{i}, \mathrm{t}}$ is the net active power injected into the $\mathrm{i}^{\text {th }}$ node. $\mathrm{f}_{\mathrm{bi}}$ is the sensitivity factor of the $\mathrm{b}^{\text {th }}$ node.

Power Balance Constraints:

$$
\mathrm{P}_{\mathrm{WDg}, \mathrm{t}(\mathrm{pre})}+\mathrm{P}_{\mathrm{HYg}, \mathrm{t}}+\mathrm{P}_{\mathrm{PVg}, \mathrm{t}(\mathrm{pre})}=\mathrm{P}_{\mathrm{LD}, \mathrm{t}}
$$

where $\mathrm{P}_{\mathrm{LD}, \mathrm{t}}$ is the grid load of the system at any given time " $\mathrm{t}$ ".

Onshore Wind Power Constraints:

$$
\mathrm{P}_{\mathrm{WDg}, t} \geq \mathrm{P}_{\mathrm{WDg}, \mathrm{t}(\text { inject })} \geq 0
$$

where $\mathrm{P}_{\mathrm{WDg}, \mathrm{t}}$ is the variable wind generator power output at time " $\mathrm{t}$ ".

Floating PV Power Constraints:

$$
\mathrm{P}_{\mathrm{PVg}, \mathrm{t}} \geq \mathrm{P}_{\mathrm{PVg}, \mathrm{t}(\text { inject })} \geq 0
$$

where $P_{P V g, t}$ the variable FPV power output at time " $t$ ".

\section{Results and Discussions}

\subsection{Application of Appraisal and Ranking Methodology}

\subsubsection{Stage 1 -Site Screening}

The floating photovoltaics site screening process involved the definition of five criteria that include a distance to protected zones greater than or equal to $500 \mathrm{~m}$, a distance to existing electrical infrastructure less than or equal to $10 \mathrm{~km}$, a capacity factor $(\mathrm{CF})$ greater than or equal to $14 \%$, and a water body surface area greater than or equal to $4000 \mathrm{~m}^{2}$. Against this benchmark, Zengamina, Victoria, and Lunzua run-of-river sites were excluded on account of having a surface area $<4000 \mathrm{~m}^{2}$ to accommodate a commercially and economically viable FPV project. Further, wind site filtering involved the definition of six criteria that include a distance to protected zones (i.e., national parks) greater than or equal to $500 \mathrm{~m}$, the security risk (i.e., war-prone area) of installation, an average wind speed value at $150 \mathrm{~m}$ above ground level greater than or equal to $6 \mathrm{~m} / \mathrm{s}$, noise and flicker allowance at five times the rotor diameter (5D), a distance to electrical infrastructure less than or equal to $60 \mathrm{~km}$, and a capacity factor greater than or equal to $26 \%$. Due to the security risk zone bordering the Democratic Republic of Congo, the Zengamina wind site was excluded from the list of potential sites. This is in line with the World Bank findings 
on mapping security risk-prone areas for the installation of wind validation masts. Table 3 summarizes the stage 1 screening and filtering process for all the FPV and wind sites.

Table 3. Table showing the combined stage 1 screening outcome for both FPV and onshore wind sites.

\begin{tabular}{|c|c|c|c|c|c|c|c|c|}
\hline \multirow[b]{2}{*}{ ID \# } & \multirow{2}{*}{$\begin{array}{l}\text { Name of } \\
\text { Site (FPV } \\
\text { and Wind) }\end{array}$} & \multicolumn{7}{|c|}{ Screening Criteria (Yes/No) } \\
\hline & & $\begin{array}{c}\text { Capacity } \\
\text { Factor }\end{array}$ & Area & $\begin{array}{c}\text { Distance to } \\
\text { Protected } \\
\text { Zone }\end{array}$ & $\begin{array}{l}\text { Distance to } \\
\text { Grid/ } \\
\text { Substation }\end{array}$ & $\begin{array}{c}\text { Flicker and } \\
\text { Noise } \\
\text { Distance }\end{array}$ & $\begin{array}{l}\text { Wind } \\
\text { Speed } \\
(\mathrm{m} / \mathrm{s})\end{array}$ & $\begin{array}{c}\text { Security } \\
\text { Risk }\end{array}$ \\
\hline Site 1 & KGU & Yes & Yes & Yes & Yes & Yes & Yes & Yes \\
\hline Site 2 & Kariba & Yes & Yes & Yes & Yes & Yes & Yes & Yes \\
\hline Site 3 & KGL FPV & Yes & Yes & Yes & Yes & Yes & Yes & Yes \\
\hline Site 4 & $\begin{array}{l}\text { Itezhi- } \\
\text { Tezhi }\end{array}$ & Yes & Yes & Yes & Yes & Yes & Yes & Yes \\
\hline Site 5 & Lusiwasi & Yes & Yes & Yes & Yes & Yes & Yes & Yes \\
\hline Site 6 & Lunzua & Yes & No & Yes & Yes & Yes & Yes & Yes \\
\hline Site 7 & Musonda & Yes & Yes & Yes & Yes & Yes & Yes & Yes \\
\hline Site 8 & Chishimba & Yes & Yes & Yes & Yes & Yes & Yes & Yes \\
\hline Site 9 & Shiwangandu & Yes & Yes & Yes & Yes & Yes & Yes & Yes \\
\hline Site 10 & Lunsemfwa & Yes & Yes & Yes & Yes & Yes & Yes & Yes \\
\hline Site 11 & Mulungushi & Yes & Yes & Yes & Yes & Yes & Yes & Yes \\
\hline Site 12 & $\begin{array}{l}\text { Victoria } \\
\text { FPV }\end{array}$ & Yes & No & Yes & Yes & Yes & Yes & Yes \\
\hline Site 13 & Zengamina & Yes & No & Yes & Yes & Yes & Yes & No \\
\hline
\end{tabular}

\subsubsection{Stage 2-Ranking and Scoring}

Three ranking and scoring tables were developed; however, only the analysis for the balanced ranking of the hybrid system is presented for simplicity. Table 4 illustrates the site scoring results for a balanced ranking using the weighted sum method (WSM). The distribution of the relative weight for the various attributes is as follows: demand at $5 \%$, ease of access at $15 \%$, energy export at $20 \%$, wind potential at $25 \%$ and floating photovoltaics at 35\%. Taking "FPV distance to grid" as an example under the "Energy export" attribute layer, the application of the weight sum equation 1 is presented in Figure 7. The results analysis places Kafue Gorge Upper (KGU) and Itezhi-Tezhi at second and first rank, with total attribute values of $86.9 \%$ and $90 \%$, respectively, while the least-ranked site is Chishimba, with a total attribute combined value of $70.6 \%$.

Figure 7 presents an example of how to apply the weighted sum method. This looks at the "Energy Export attribute layer", with a focus on the "Distance of the floating photovoltaic plant from the grid". With reference to Table 4, part 1 of Tables A1-A3 in Appendix A, there are 5 attribute layers, namely, $(i=1)$ "Wind potential", $(i=2)$ "Floating PV potential", $(i=3)$ "Energy export", $(i=4)$ "Ease of access" and $(i=5)$ "Demand". These attribute layers have the following maximum weight distribution: attribute layer $(i=1) \rightarrow 25 \%$, $(i=2) \rightarrow 35 \%,(i=3) \rightarrow 20 \%$, $(i=4) \rightarrow 15 \%,(i=5) \rightarrow 5 \%$. Therefore, under "select input parameters" in Figure 7, $(i=3)$ represents the energy export attribute layer, with $20 \%$ as total weight. The energy export layer is further broken down in "FPV distance to grid" given a maximum weight of 5\%, "Wind distance to grid", also given $5 \%$, and "Grid capacity availability", given 10\%. Under the "weigh input parameters" FPV distance to the grid is appearing as the first layer $(j=1)$ under the energy export attribute layer. This is assigned as "w1" with reference to Equation (1). Under "score each site against parameter", if the site's FPV distance from the grid is less than or equal to $2 \mathrm{~km}$, then according to Table A1 in Appendix A, the suitability score for the site will be $100 \%$. This is assigned 
as "a31" from Equation (1). Therefore, to get the overall site score, the product between the assignment " $w 1$ " under "weigh input parameters" and the assignment " $a 31$ " under "score each site against parameter" is calculated. Multiplying " $w 1$ " by " $a 31$ " translates into $5 \% \times 100 \%$, yielding a value of $5 \%$. The process is repeated for all other attribute layers and the layers contained underneath. The total site score is the summation of the wind total, FPV total, energy export total, ease of access total and demand total.

Table 4. Table showing balanced scoring and ranking matrix. Analysis based on sources [70,75-78,94-103] (detailed table shown in Appendix A-Tables A2 and A3).

\begin{tabular}{|c|c|c|c|c|c|c|c|}
\hline & & $\begin{array}{c}\text { Wind } \\
\text { Potential }\end{array}$ & $\begin{array}{c}\text { FPV } \\
\text { Potential }\end{array}$ & $\begin{array}{l}\text { Energy } \\
\text { Export }\end{array}$ & $\begin{array}{l}\text { Ease of } \\
\text { Access }\end{array}$ & Demand & Site Total \\
\hline & & $\begin{array}{c}\text { Score * } \\
\text { (25\% Weight) }\end{array}$ & $\begin{array}{c}\text { Score * } \\
(35 \% \text { Weight })\end{array}$ & $\begin{array}{c}\text { Score }{ }^{*} \\
(20 \% \text { Weight })\end{array}$ & $\begin{array}{c}\text { Score * } \\
\text { (15\% Weight) }\end{array}$ & $\begin{array}{c}\text { Score * } \\
\text { (5\% Weight) }\end{array}$ & $\begin{array}{c}\text { (100\% } \\
\text { Weight) }\end{array}$ \\
\hline Rank \# & Name of Site & Wind $\sum$ & FPV $\sum$ & Export $\sum$ & Access $\sum$ & Demand $\sum$ & $\begin{array}{l}\text { Score * } \\
\text { Weight }\end{array}$ \\
\hline$=1$ & $\begin{array}{l}\text { Itezhi-tezhi } \\
\text { FPV/wind site }\end{array}$ & $22.5 \%$ & $35.0 \%$ & $12.5 \%$ & $15.0 \%$ & $5.0 \%$ & $90.0 \%$ \\
\hline$=2$ & KGU FPV/wind site & $21.3 \%$ & $30.6 \%$ & $18.8 \%$ & $11.3 \%$ & $5.0 \%$ & $86.9 \%$ \\
\hline$=3$ & KGL FPV/wind site & $25.0 \%$ & $26.3 \%$ & $15.0 \%$ & $13.8 \%$ & $5.0 \%$ & $85.0 \%$ \\
\hline$=3$ & Kariba FPV/wind site & $18.8 \%$ & $26.3 \%$ & $20.0 \%$ & $15.0 \%$ & $5.0 \%$ & $85.0 \%$ \\
\hline$=3$ & $\begin{array}{l}\text { Lusiwasi } \\
\text { FPV/wind site }\end{array}$ & $20.0 \%$ & $35.0 \%$ & $12.5 \%$ & $15.0 \%$ & $2.5 \%$ & $85.0 \%$ \\
\hline$=6$ & $\begin{array}{c}\text { Musonda } \\
\text { FPV/wind site }\end{array}$ & $22.5 \%$ & $30.6 \%$ & $8.8 \%$ & $15.0 \%$ & $2.5 \%$ & $79.4 \%$ \\
\hline$=6$ & $\begin{array}{l}\text { Mulungushi } \\
\text { FPV/wind site }\end{array}$ & $22.5 \%$ & $30.6 \%$ & $10.0 \%$ & $13.8 \%$ & $2.5 \%$ & $79.4 \%$ \\
\hline$=8$ & $\begin{array}{l}\text { Shiwangangu } \\
\text { FPV/wind site }\end{array}$ & $21.3 \%$ & $26.3 \%$ & $12.5 \%$ & $13.8 \%$ & $2.5 \%$ & $76.3 \%$ \\
\hline$=9$ & $\begin{array}{l}\text { Lunsemfwa } \\
\text { FPV/wind site }\end{array}$ & $25.0 \%$ & $21.9 \%$ & $8.8 \%$ & $15.0 \%$ & $2.5 \%$ & $73.1 \%$ \\
\hline$=10$ & $\begin{array}{l}\text { Chishimba } \\
\text { FPV/wind site }\end{array}$ & $20.0 \%$ & $21.9 \%$ & $11.3 \%$ & $15.0 \%$ & $2.5 \%$ & $70.6 \%$ \\
\hline
\end{tabular}

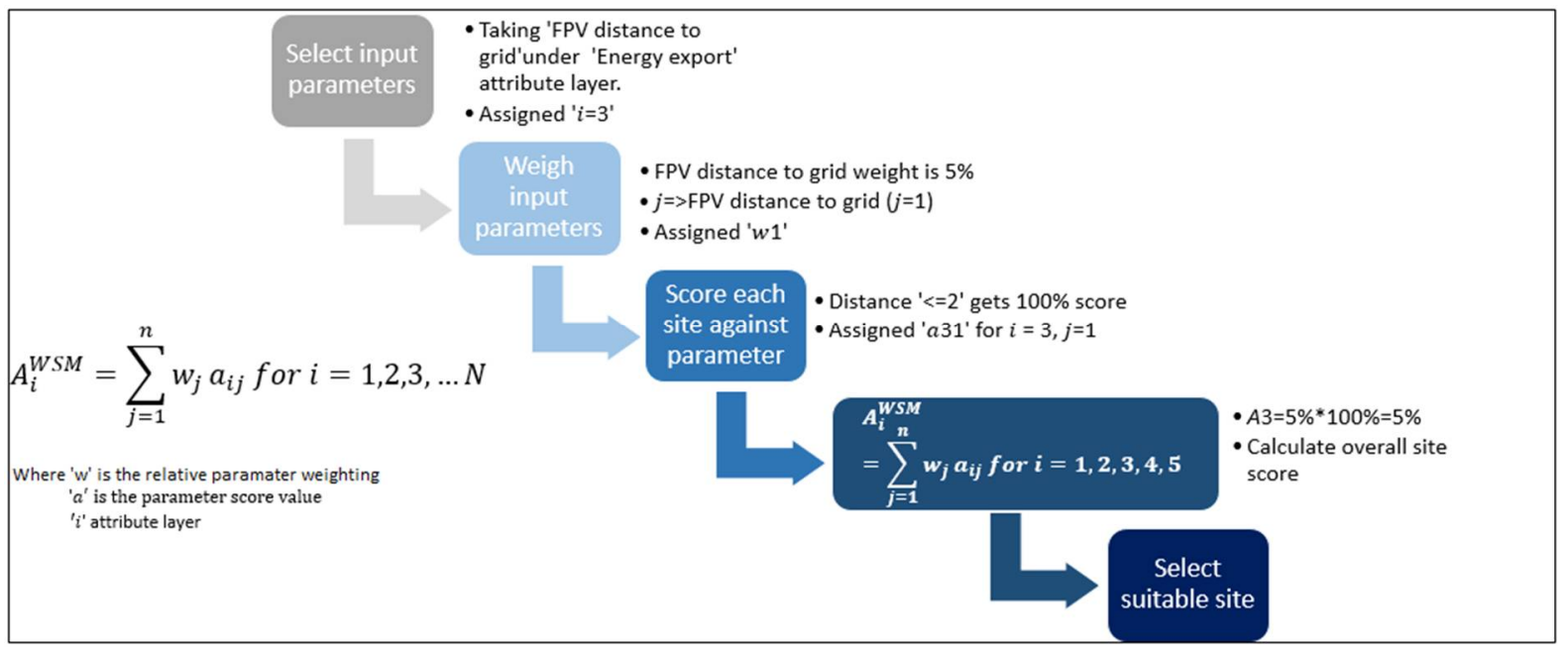

Figure 7. Diagram showing the application of the weighted sum equation under balanced scoring and ranking. 


\subsection{Application of Design Scoping Methodology—Kafue Gorge Upper Case Study}

After appraising the potential wind and FPV sites, the stakeholder (ZESCO Ltd.) was presented with the three ranking matrices (FPV, onshore wind and balanced) of the ten potential sites to choose from. The power utility opted to adopt the balanced ranking for the hybrid energy system, with Kafue Gorge Upper (KGU) as the chosen candidate site for detailed design. Even though Itezhi-Tezhi (ITT) was ranked first over KGU, which was second under the balanced scoring, the latter was chosen over the former owing to the following factors: the presence of a data validation wind mast at KGU, the presence of debris and dead trees in the ITT reservoir, the distance to the demand center (300 km from ITT, compared to $100 \mathrm{~km}$ for KGU), less reliability and stability of the grid at ITT, with one $220 \mathrm{kV}$ line emanating from ITT compared to three $330 \mathrm{kV}$ lines from KGU to the grid.

\subsubsection{VRES Grid Impact Study}

Using the power system analysis toolbox (PSAT), the Zambian electrical power grid was modeled at a $330 \mathrm{kV}$ voltage level comprising a 27-bus system. The model for the existing network had a real and reactive power load distribution of $2383 \mathrm{MW}$ and 1061.8 MWVAr, respectively. The total modeled existing generation was 2530.6 MW real power and 857.4 MVAr reactive power, comprising the following power stations: ItezhiTezhi via Nambala, Lunzua via Kasama, Victoria Falls via Mukuni, Maamba Collieries Limited (MCL), PV plant at Lusaka South Multi-Facility Economic Zone (LSMFEZ), Kariba North Bank and Kafue Gorge Upper. For additional generation, 200 MW of VRES was later integrated and modeled, comprising $100 \mathrm{MW}$ FPV and $100 \mathrm{MW}$ wind at the KGU generation bus. The actual PSAT single-line diagram model for the network is shown in Appendix B. The key summary results for the grid impact of VRES are presented below.

Analysis of Existing Network

Figure 8 shows the voltage violations at 11 out of the $27,330 \mathrm{kV}$ buses for the existing network before the addition of compensating equipment and additional generation (VRES, in this case). According to the Zambian grid code limits, the permissible and acceptable voltage should fall in the range between 313.5 and $346.5 \mathrm{kV}$, which is a tolerance of $+/-5 \%$. The total power losses of the existing network were 1475 MW real and -204.3 MVAr reactive power, as shown in the global power summary in Figure 9.

\section{Analysis after VRES Integration}

The addition of network compensating equipment corrected all 11 voltage violations with the integration of VRES at the KGU bus, comprising $100 \mathrm{MW}$ wind and $100 \mathrm{MW}$ floating photovoltaics, improving the voltage magnitude profile even further at buses near the KGU generation bus (Figure 10). The integration of $200 \mathrm{MW}$ of VRES contributed to the reduction in the voltage support requirement by the network, owing to the drop in the generated reactive power by the Kafue Gorge hydro plant from 239 to $201 \mathrm{MVAr}$. The results also showed all the line flows to be within range (less than the 700 MVA maximum line capacity). Moreover, VRES integration also reduced the network's real power losses by 5 percent (from 147 MW to 140 MW), as can be seen in Figure 11. 


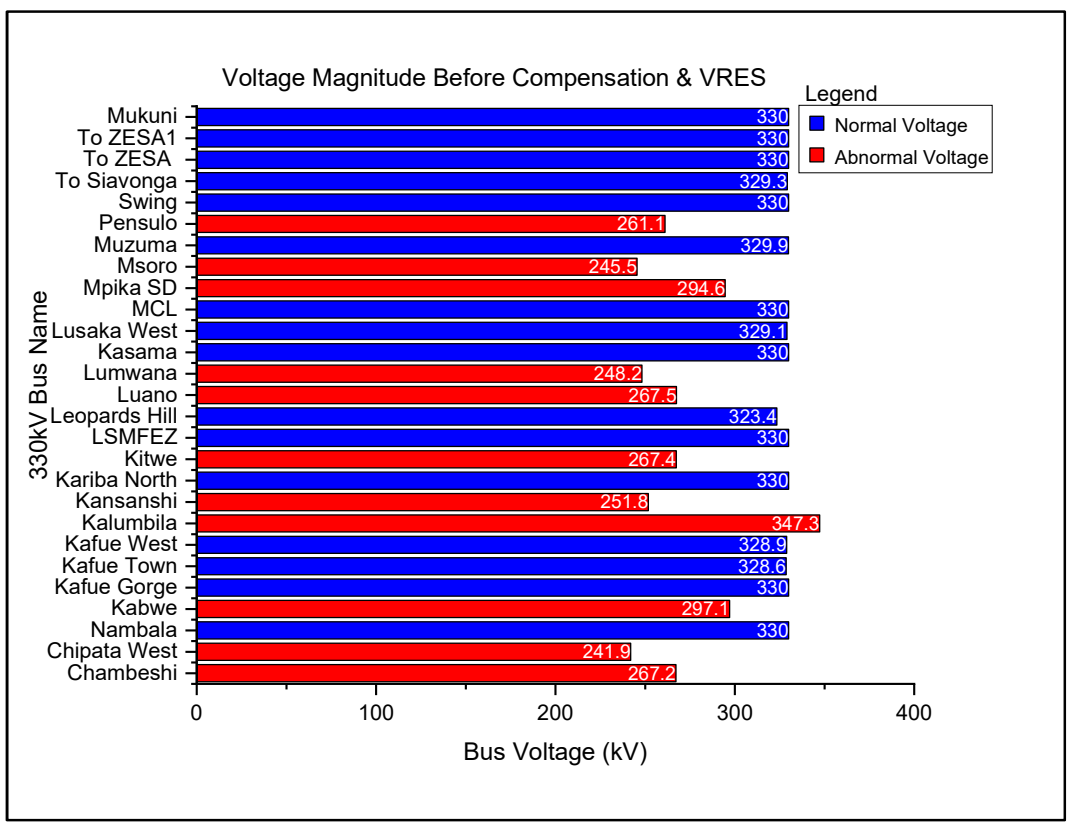

Figure 8. Figure showing the existing $330 \mathrm{kV}$ bus voltage profile without VRES integration and reactive compensation at Luano, Kansanshi, Lumwana, Kitwe, Kalumbila, and Chipata West network buses.

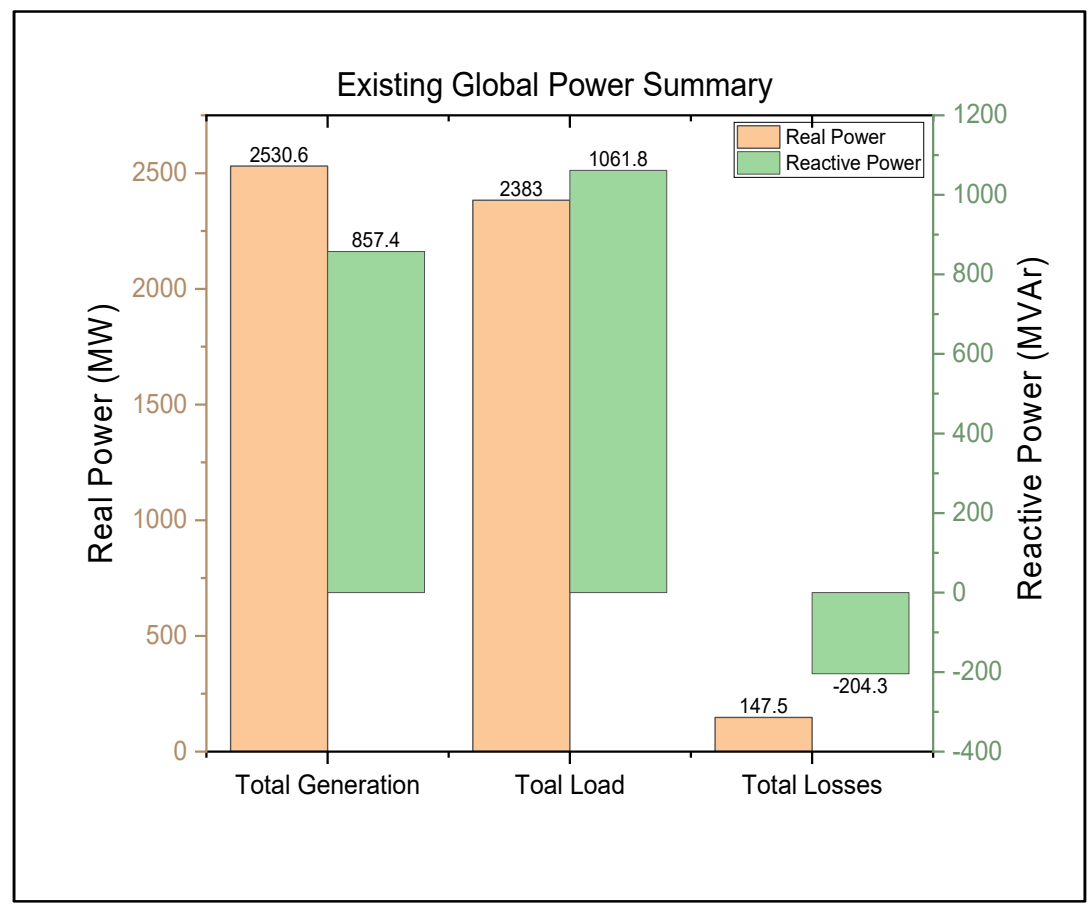

Figure 9. Figure showing the global power summary for the existing network. 


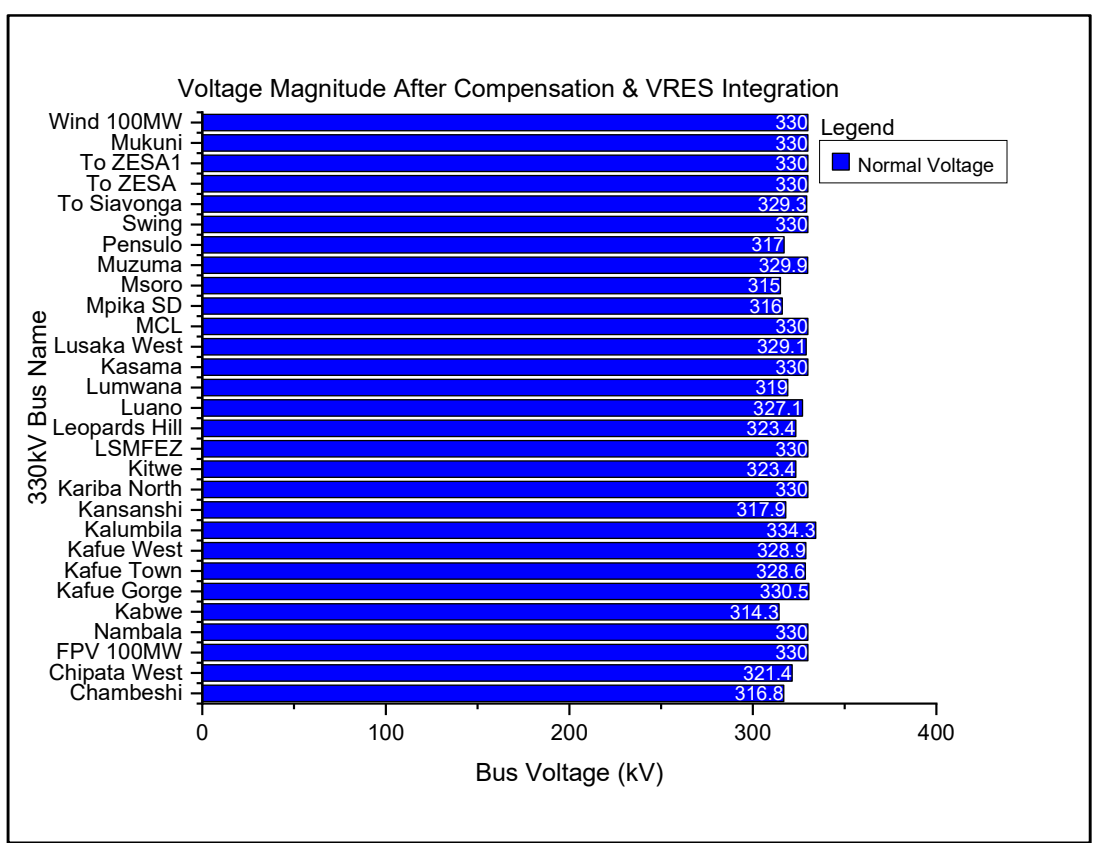

Figure 10. Showing bus voltage after adding network compensation and VRES.

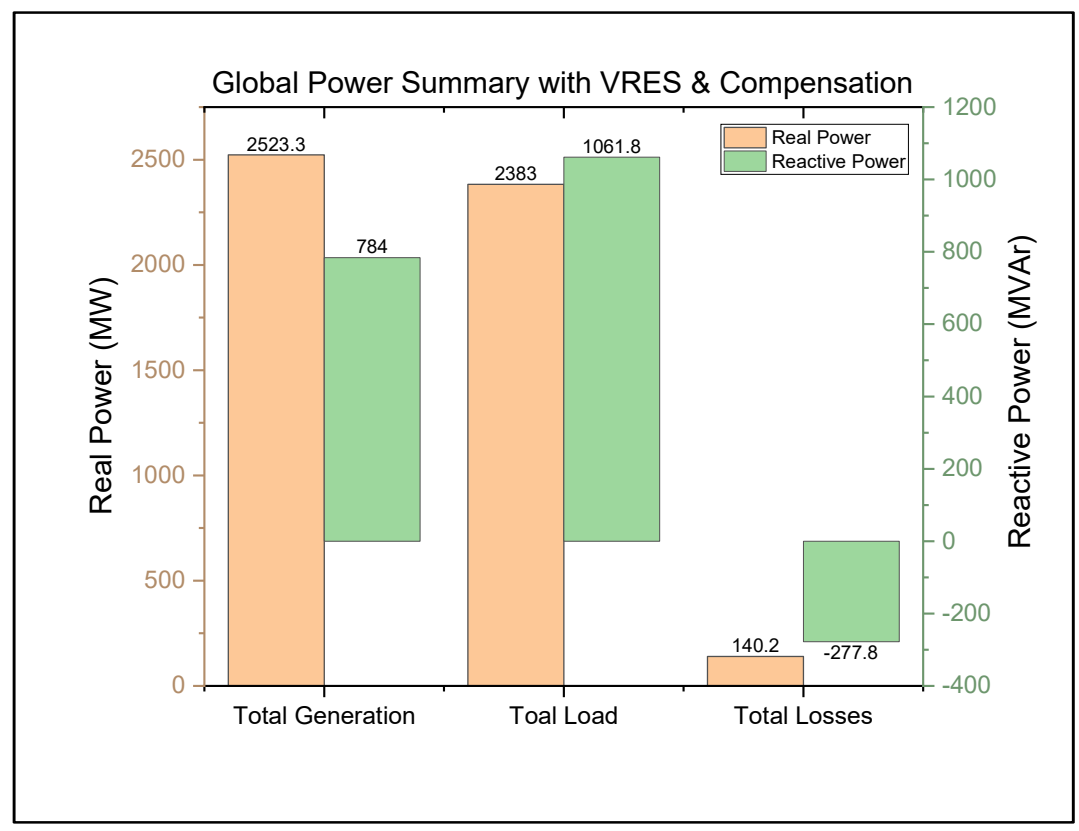

Figure 11. Showing power summary after VRES integration.

\subsubsection{Hydro Modeling Results Analysis at KGU}

The Kafue Gorge Upper hydro generation was modeled in iHoga using the power plant ratings provided by the national power utility (ZESCO Ltd. located in Zambia). The iHoga model for one turbine has $4 \%$ losses in penstock, $0 \%$ daily / hourly variability and $85 \%$ total turbine efficiency. The key summary results of the model taking a typical winter (i.e., June) and summer (i.e., November) month are presented in Figure 12a-d. In June, the maximum power output of the hydropower plant was $805 \mathrm{MW}$, corresponding to a discharge rate of $227.8 \mathrm{~m}^{3} / \mathrm{s}$ and reservoir level of $974.7 \mathrm{~m}$ above sea level, while the minimum generation output was $697 \mathrm{MW}$, corresponding to a discharge rate and level of $197.9 \mathrm{~m}^{3} / \mathrm{s}$ and $974.9 \mathrm{~m}$, respectively. In the month of November, hydro generation output ranged between 648 and $712 \mathrm{MW}$, corresponding to a discharge rate and level range of 
185-201 $\mathrm{m}^{3} / \mathrm{s}$ and $974.5-974.7 \mathrm{~m}$, respectively. Figure 12e shows the hydro-generation hourly time-series graphs, serving a fraction of the total national grid load for the first day of each month of January, March, June, September and November. On 1 January, KGU generated $10.69 \mathrm{GWh}$ of hydro, with an evening peak of $1.99 \mathrm{GWh}$, between 5 p.m. and 9 p.m., to serve about $27 \%$ of the total national grid demand for the day. KGU generated 15.6 GWh of hydropower on 1 March, with an evening peak of 3 GWh between 5 p.m. and 9 p.m., to serve about $46 \%$ of the total national electrical grid demand for the day. On 1 June, approximately 13.8 GWh of energy was generated, with an evening peak of $2.7 \mathrm{GWh}$ between 5 p.m. and 9 p.m., to serve about $34.4 \%$ of the total demand for the day. On 1 September, $14 \mathrm{GWh}$ of hydro-generation was produced, with an evening peak of $2.7 \mathrm{GWh}$ to serve $36 \%$ of the total grid demand for the day. Further, 1 November yielded 12.6 GWh of hydropower, with an evening peak of $2.4 \mathrm{GWh}$ between 5 p.m. and 9 p.m., to serve $29.6 \%$ of the grid demand for the day.

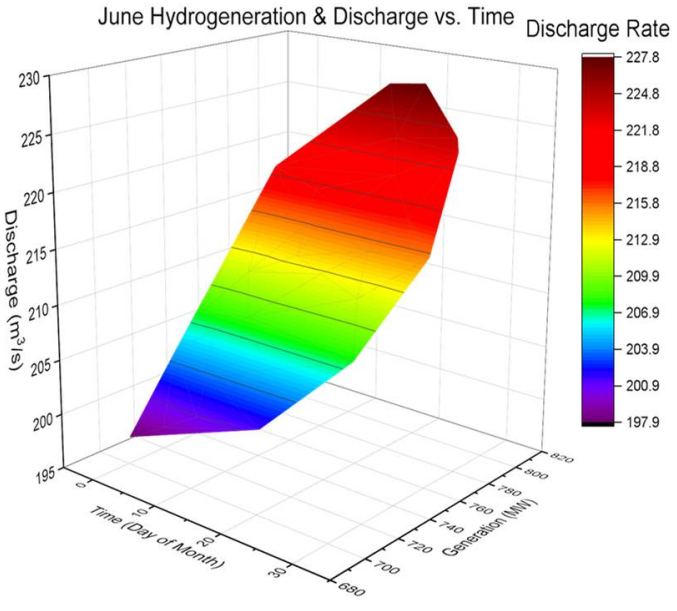

(a)

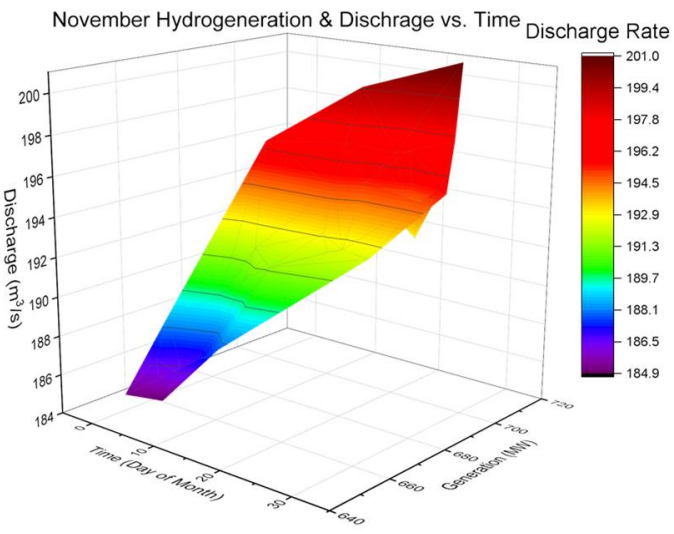

(c)

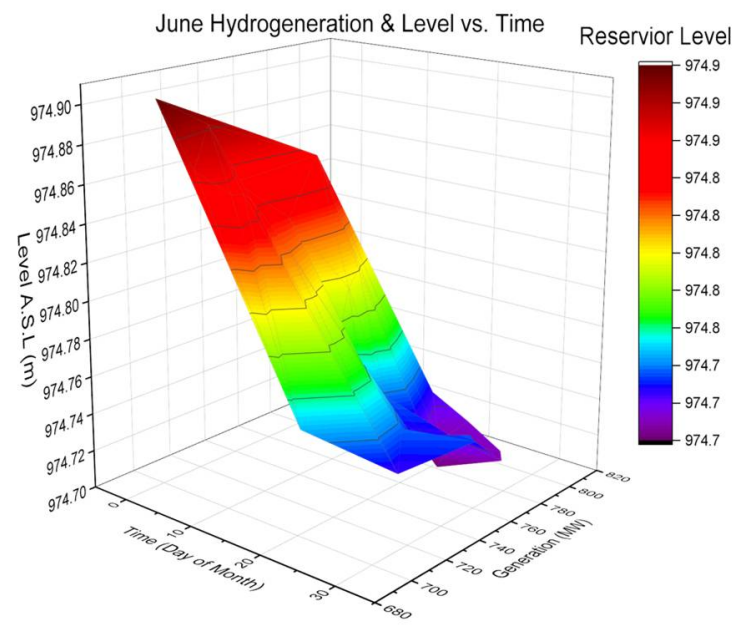

(b)

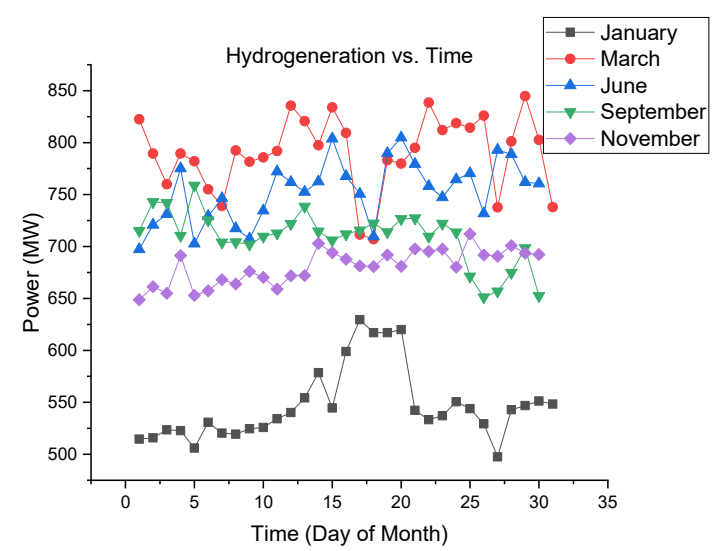

(d)

Figure 12. Cont. 


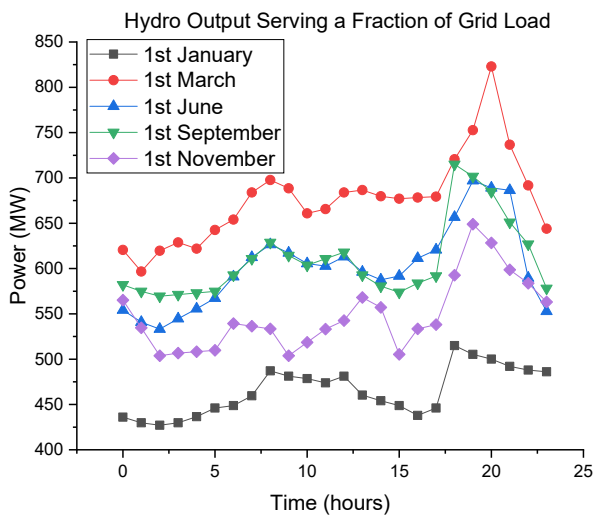

(e)

Figure 12. (a) Showing 3D June hydro-generation and discharge rate vs. time. (b) 3D June hydro-generation and reservoir level vs. time. (c) 3D November hydro-generation and discharge vs. time. (d) Day of month time series for hydro-generation vs. time. (e) Daily hydro output serving a fraction of grid load.

\subsubsection{VRES Modeling and Results Analysis}

Results analysis for the modeling and design of the 100 MWac onshore wind and 116MWdc floating photovoltaics at Kafue Gorge Upper hydropower plant is presented.

\section{Floating PV}

Detailed design and modeling of the FPV system were performed using the Photovoltaic System (PVSYST) software. A form factor (DC/AC ratio) of 1.16 was adopted for the project, based on industry practice for Southern Africa. The system design comprises a parallel connection of eight sub-arrays. Each sub-array comprises one hundred and twenty series-strings of seventeen PV solar modules (unit photovoltaic module rating of 285 watt-peak with 72 polycrystalline cells) connected to an inverter rated at $500 \mathrm{kWac}$, with the A/C combiner box linking twenty-five inverters in parallel for 1 sub-array. Firstly, the photovoltaic module and array characteristics were analyzed, based on the results in Figures 13 and 14. The average PV module running temperature of between 10 and $65{ }^{\circ} \mathrm{C}$ yielded a minimum of $60 \mathrm{~h}$ of operation throughout the year, with a design standard irradiation of $1 \mathrm{~kW} / \mathrm{m}^{2}$, an operating temperature range between 10 and $70{ }^{\circ} \mathrm{C}$, coupled with corresponding module efficiency between 15.8 and $11 \%$, respectively, at a given operating temperature range. However, at all irradiation levels, an increase in efficiency was observed with a decrease in temperature. Additionally, at $1 \mathrm{~kW} / \mathrm{m}^{2}$, the PV module power output at maximum power point (MPP) was found to be $229.1 \mathrm{~W}$ (20 percent decrease) and 305.3 W (7 percent increase) at the highest and lowest operating temperatures, respectively.

According to Figure 15, the annual energy yield injected into the grid from the FPV system was 214.4 GWh/year. August had the most FPV energy injection into the grid, with 21.29 GW, while January had the least, with 13.59 GWh. Moreover, August and October had the most average global horizontal irradiation of 187.6 and $193.4 \mathrm{kWh} / \mathrm{m}^{2}$, respectively, while January and February had the least, with 155.3 and $155.2 \mathrm{kWh} / \mathrm{m}^{2}$, respectively. October had the highest average ambient temperature of $25.61{ }^{\circ} \mathrm{C}$, while July had the least, at $16.78^{\circ} \mathrm{C}$. This corresponds to a monthly average system efficiency of 11.92 and 12.53 in the hottest and coldest months, respectively. 


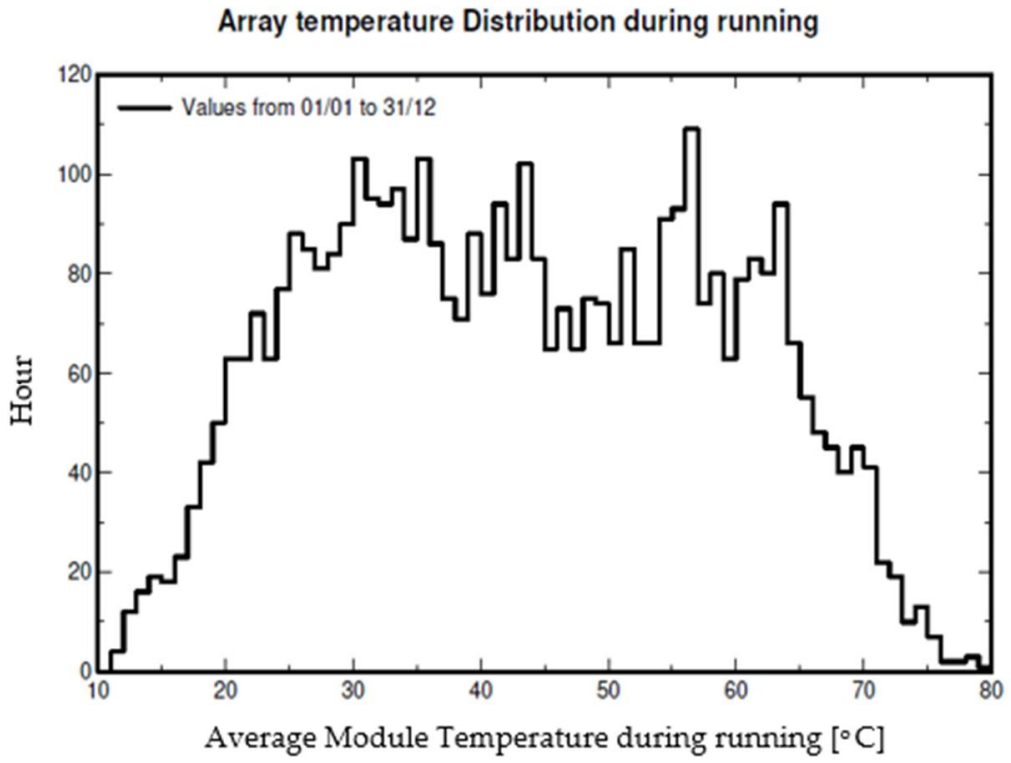

Figure 13. Showing FPV Array operational temperature.

PV module: Generic, Poly 285 Wp 72 cells

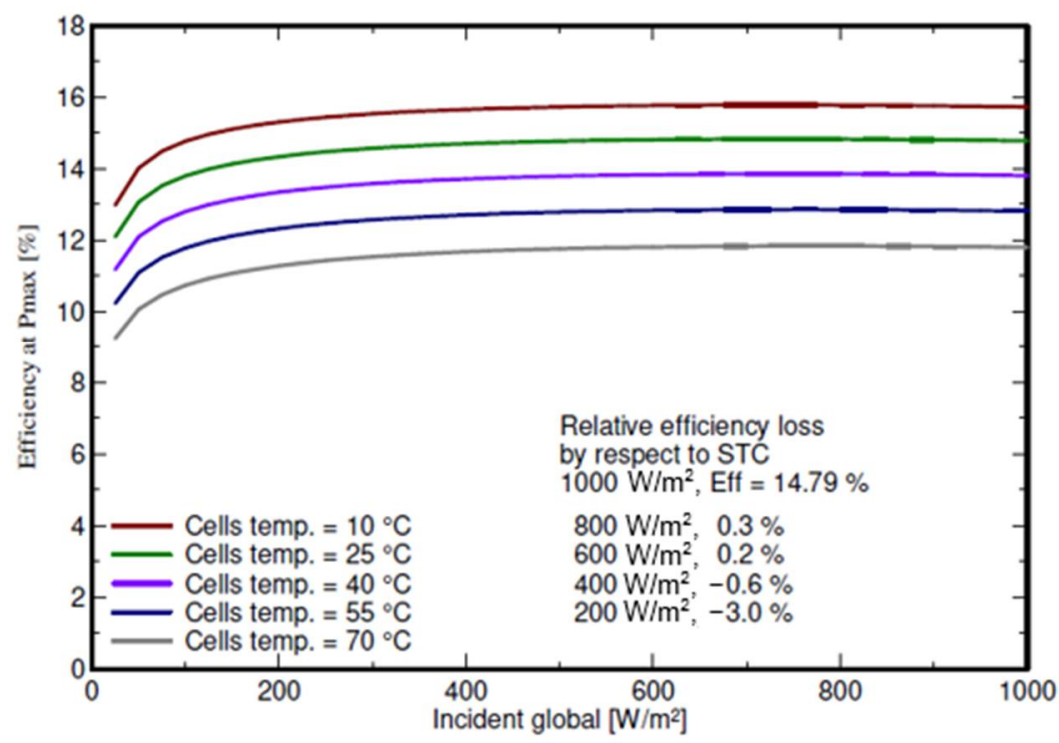

Figure 14. Figure showing FPV efficiency vs. irradiation curves. 


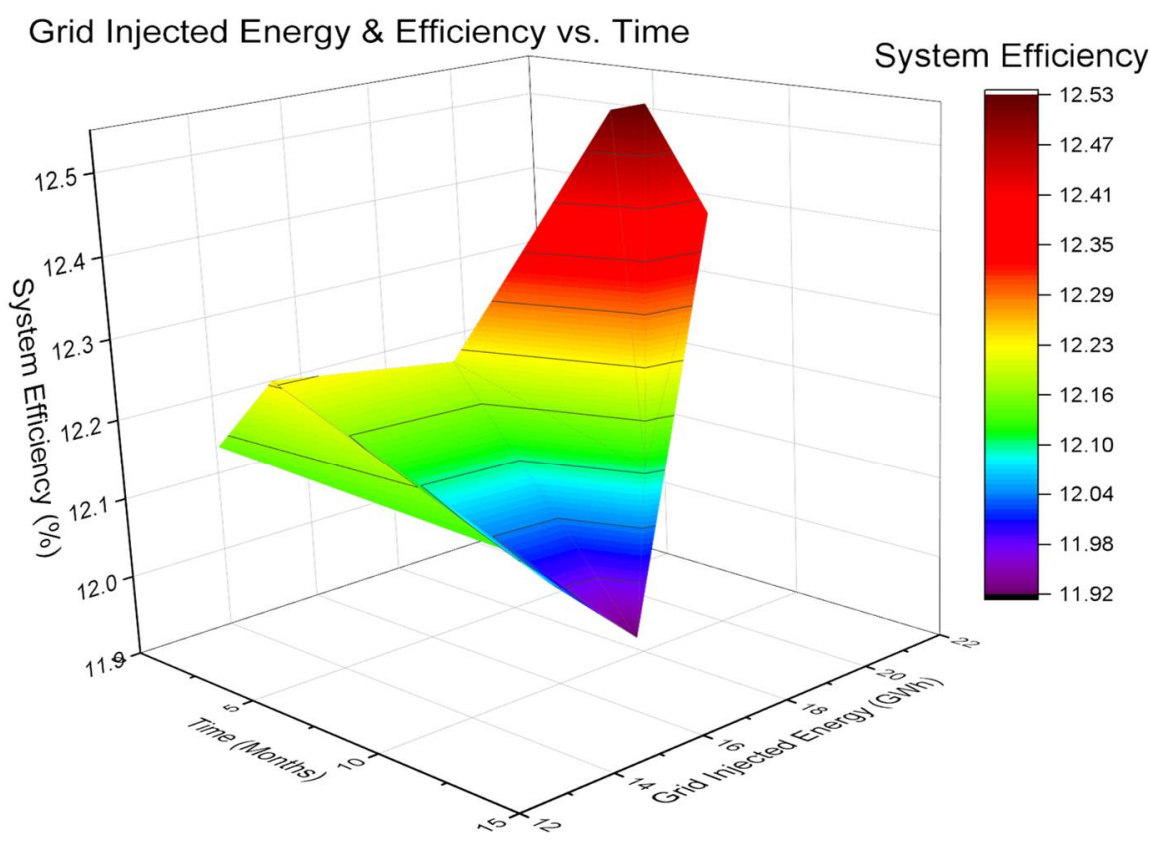

Figure 15. Figure showing FPV energy and efficiency vs. time (months).

It must be mentioned that in the case of generation power being greater than that injected, as indicated in Equation (17), the excess can still be injected as the local and regional demands are far higher. The case study only serves a fraction of the entire national demand; therefore, any excess can still be injected for local (Zambian) consumption or to meet part of the Southern African Power Pool's demand.

System optimization of the FPV system was performed by reviewing the impact of azimuth, pitch, tilt angle and ground-cover ratio (GCR) on grid-injected energy per year. The PVSYST embedded algorithm was used in the system optimization [129]. In the PVSYST software, after the case study location coordinates are entered, the meteorological data is selected from the list of databases. Thereafter, the design and system specifications are selected. The tilt angle values from 0 to 90 degrees are selected, with a sensitivity of $1^{\circ}$ intervals, at an azimuth of 0 degrees. The azimuth is then changed to $180^{\circ}$ while maintaining the same tilt angle inputs [129]. The objective function is maximizing the energy injected into the grid, which gives the simulation output in GWh. The embedded algorithm carries out a parametric analysis to search for the optimal point and plots the curves accordingly for all the input steps [129]. The ground cover ratio is optimized by looking at the ratio of the active area to the ground area. In PVsyst, the "active area" is the area of one module (length $\mathrm{x}$ width), multiplied by the number of modules, while the "ground area" is the area occupied by the PV array. PVSYST maximizes the injected output by tracking this ratio. The closer the ratio is to unity, the lower the injected energy into the grid. Regarding the "pitch", PVSYST will maximize the energy output by increasing the pitch. However, this requires sound engineering judgment in design by factoring in the land constraints for a particular project. Figure 16a shows a $2.6 \%$ increase in grid injected energy yield (from a base value of 214.4 to $220 \mathrm{GWh}$ ) at a GCR of $5 \%$, while there was a steep decrease in yield of between 80 and $100 \%$ of the GCR ratio. Figure $16 \mathrm{~b}$ shows that the maximum annual yield, between 214 and $215 \mathrm{GWh}$, is injected into the grid for tilt angles between 10 and $20^{\circ}$ for the location in question. Figure $16 \mathrm{c}$ reveals that more energy is injected into the grid with every step increase in pitch (i.e., a pitch of $15 \mathrm{~m}$ yielded more energy compared to the baseline design value of $3 \mathrm{~m}$ ). However, for practical considerations on space constraints, the scenario regarding pitch calls for careful analysis because, for a $400 \%$ increase (from $3 \mathrm{~m}$ to $15 \mathrm{~m}$ ) in pitch, only a corresponding $2.5 \%$ increase in grid injected energy was obtained. Furthermore, a negative and positive sensitivity analysis of the azimuth angle from a baseline value of $0^{\circ}$ yielded a reduction in grid-injected 
energy. This is because the baseline value was already at the optimized azimuth angle, as illustrated in Figure 16d. Additional analysis was able to compare the energy yield and performance ratio (PR) using the PVSYST software adjustments of the albedo and heat loss factor or U-value for floating photovoltaics $\left(0.1\right.$ albedo and U-value $31 \mathrm{~W} / \mathrm{m}^{2} \mathrm{~K}$ ) and ground-mounted $\left(0.2\right.$ and $\left.20 \mathrm{~W} / \mathrm{m}^{2} \mathrm{~K}\right)$ installations, in line with other research [72]. The results show that a floating PV has better performance (PR of $83.5 \%$ and energy yield of $214.4 \mathrm{GWh} / \mathrm{y}$ ) compared to a ground-mounted system (PR of $79.3 \%$ and energy yield of $204.4 \mathrm{GWh} / \mathrm{y}$ ) at the same location with similar design parameters (i.e., the tilt angle, azimuth, pitch, GCR). PVSYST was also used to evaluate the economics of the floating photovoltaic system. The analysis revealed that the cost of producing $214.4 \mathrm{GWh} /$ year of energy at an investment cost of GBP $0.68 / \mathrm{Wp}$ was GBP $0.04 / \mathrm{kWh}$, excluding operation and maintenance (O\&M) costs. This FPV LCOE is competitive, with a value of GBP $0.0342 / \mathrm{kWh}$ and GBP 0.0335/kWh, obtained by Maronga et al. [54] and RES4Africa [130], respectively, for ground-mounted PV. Homerpro gave a more conservative annual yield of $175 \mathrm{GWh}$ at an LCOE of GBP $0.067 / \mathrm{kWh}$ (including O\&M); however, this was without factoring in the water albedo and heat loss factor of the PV module's floating island. This goes to show that a reduction in annual energy yield by approximately $18.4 \%$ increases the LCOE by almost $40 \%$ for the PVSyst and Homerpro cases that are highlighted. The cost summary and energy yield distribution for FPV and wind are summarized in Table 5.
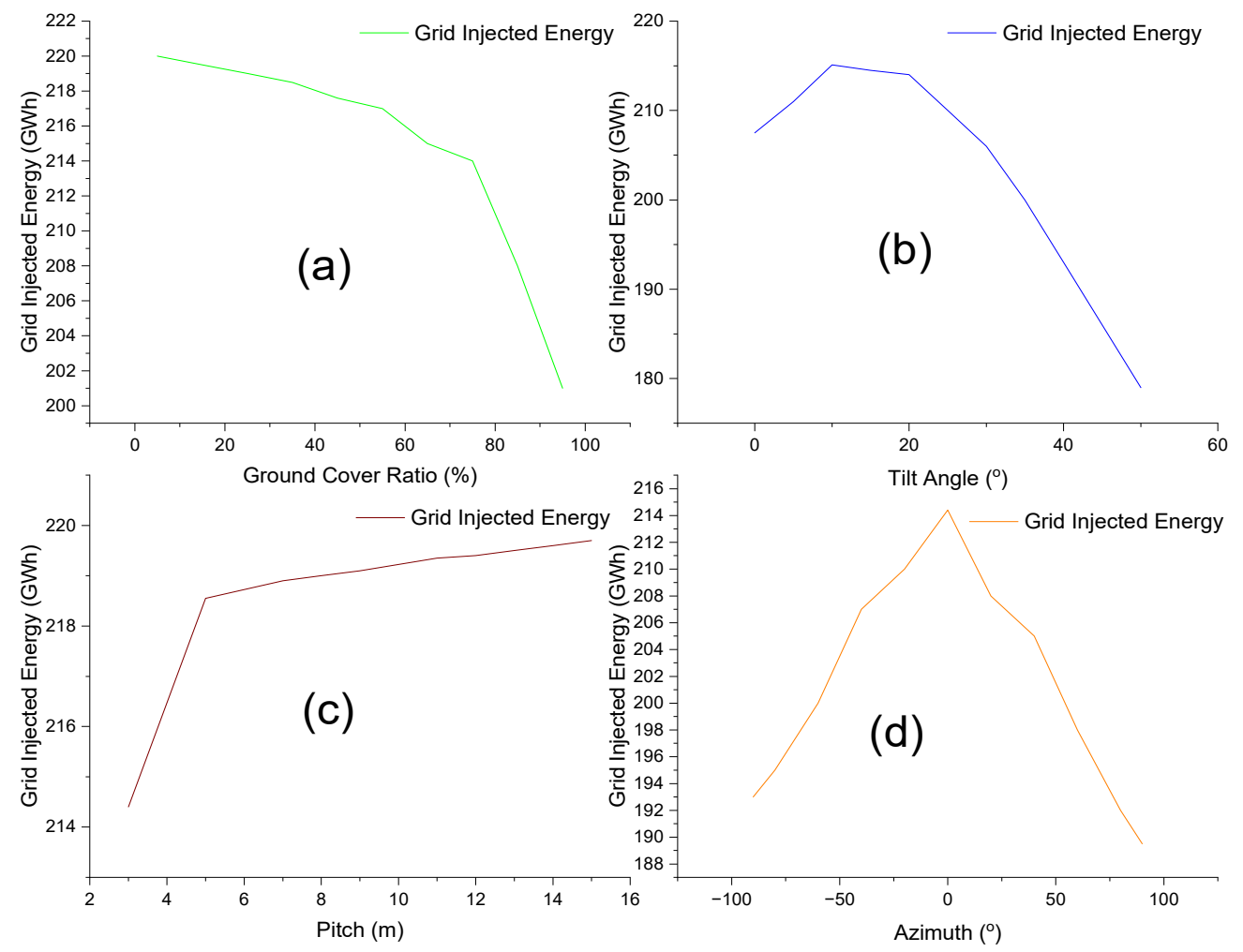

Figure 16. (a) Optimization of injected energy vs. ground cover ratio. (b) Energy vs. panel tilt angle. (c) Energy vs. pitch in meters. (d) Injected energy vs. azimuth angle. 
Table 5. Table showing the cost and energy production distribution (cost breakdown sources [130,131]).

\begin{tabular}{cccc}
\hline & FPV (116 MWpdc/100 MWac) & Wind (100 MWac) & FPV + Wind \\
\hline \multirow{2}{*}{ CAPEX } & GBP 80,233,200.00 & GBP 109,393,980.00 & GBP 189,627,180.00 \\
\cline { 2 - 4 } & GBP 0.69/kWp & GBP 1.09/kWp & GBP 0.88/kWp \\
\cline { 2 - 4 } OPEX & GBP 1,679,083.20 & GBP 2,00,000.00 & GBP 3,264,503.20 \\
\hline \multirow{2}{*}{ GWh/year } & GBP 0.017/kWp & GBP 0.02/kWp & G13 (PVSyst + Renewables Ninja). \\
& 214.4 (in PVSyst) @ & 295 (in Renewables Ninja) @ & 341 (in Homerpro) \\
\hline
\end{tabular}

Note: The hydro model in Homerpro had a capital cost of GBP 2.8/Wp with an operation and maintenance cost of GBP $0.017 / \mathrm{Wp}$.

Onshore Wind

Homerpro and Renewables Ninja were used in a complementary fashion in the analysis of the KGU wind-farm output. Owing to the wide coverage of its dataset, Renewables Ninja was used to simulate the output potential of each wind turbine, whose design characteristics included: $129 \mathrm{~m}$ hub height, $142 \mathrm{~m}$ rotor diameter and $4 \mathrm{MW}$ power rating per turbine. Thereafter, the Renewables Ninja wind speed output was exported to Homerpro to facilitate detailed analysis, to include the practical losses imposed on a typical wind farm with 25 by $4 \mathrm{MW}$ turbines (i.e., wake effects, curtailment losses etc.). With the wind farm capacity density of approximately $6.2 \mathrm{MW} / \mathrm{km}^{2}$, an optimistic annual energy yield of $294 \mathrm{GWh}$ was registered at the wind farm excluding system losses. However, Homerpro yielded a more conservative annual energy value, with a total of $8174 \mathrm{~h}$ of operation. In this scenario, about $167 \mathrm{GWh}$ /year of energy was produced at a competitive LCOE of about GBP $0.07 / \mathrm{kWh}$, as compared to the optimistic forecasted LCOE value of GBP $0.042 / \mathrm{kWh}$ obtained in the recent RES4Africa study about Zambia for the 2021/2022 benchmark [130]. The higher LCOE of wind compared to FPV is due to the fact that the resource potential for solar photovoltaics is pronounced, compared to wind in the Zambian context [30-32]. As illustrated from Figure 17a-c below, the total wind energy production on 1st January was $553.87 \mathrm{MWh}$ with a peak energy of 217.54 MWh between 4-8 a.m. On 1 March, the total wind energy generated was $983.18 \mathrm{MWh}$ with a peak energy of 186.1MWh between 6 a.m. and 10 a.m. and 207.2 MWh between 7 p.m. and 11 p.m. The 1st of June yielded 375.17 MWh of wind energy with a peak of 132.27 MWh between 7 a.m. and 12 p.m. and 98.2 MWh between 4 p.m. and 9 p.m. On 1 September, approximately $1654.2 \mathrm{MWh}$ was generated from wind with a peak of $422.2 \mathrm{MWh}$ between 6 a.m. and 11 a.m. Furthermore, 1809.66 MWh of wind was generated on 1 November, with a peak of 457.88 MWh between 6 a.m. and 11 a.m. and $385.8 \mathrm{MWh}$ between 2 p.m. and 7 p.m. Any excess power indicated in Equation (16) is treated in a similar manner to FPV and is injected to meet additional local or regional demand.

\subsubsection{Optimal Dispatch of Hydro and VRES Hybrid System Details}

With a Homerpro model (Figure 18) comprising customized virtual storage, a customized hydro initially modeled in iHoga, a PVSYST-based FPV system, and onshore wind values based on Renewables Ninja wind speed data, the following analysis can be made: the Homer Matlab Dispatch was implemented using a customized dispatch algorithm and utilized 5 hydro units, which is equivalent to $700 \mathrm{MW}, 100 \mathrm{MWp}$ of FPV, $100 \mathrm{MWp}$ of wind. The Matlab code was used to ascertain a customized dispatch with high VRES penetration. Homerpro calls the Matlab Dispatch at the beginning of each time step in the simulation. The Matlab Dispatch has three input variables, namely, simulation_state, simulation_parameters and custom_variables. The model virtual storage is dependent on available water in the dam and the floating PV and wind potential. 


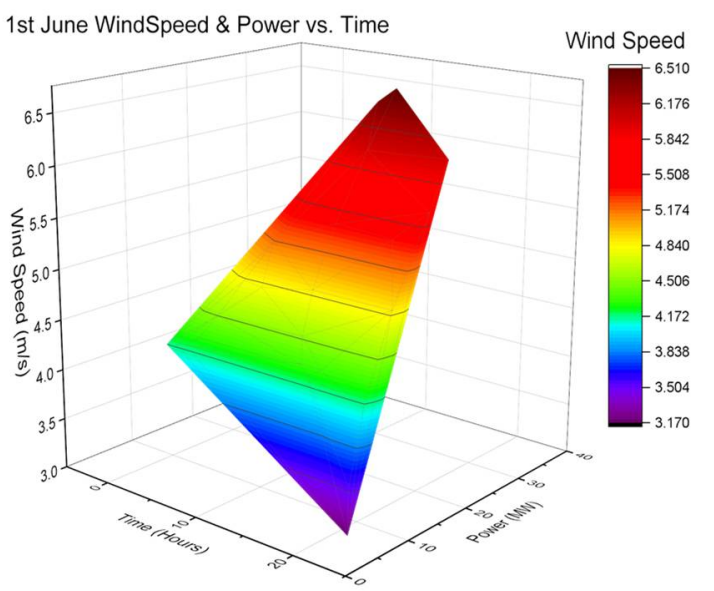

(a)

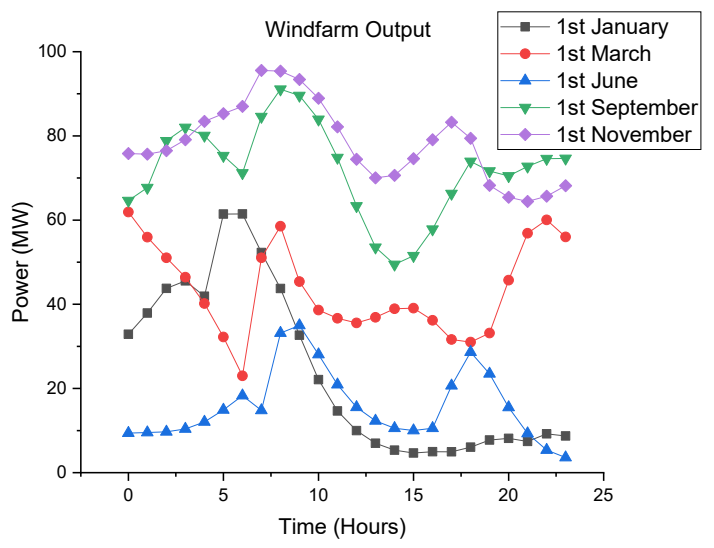

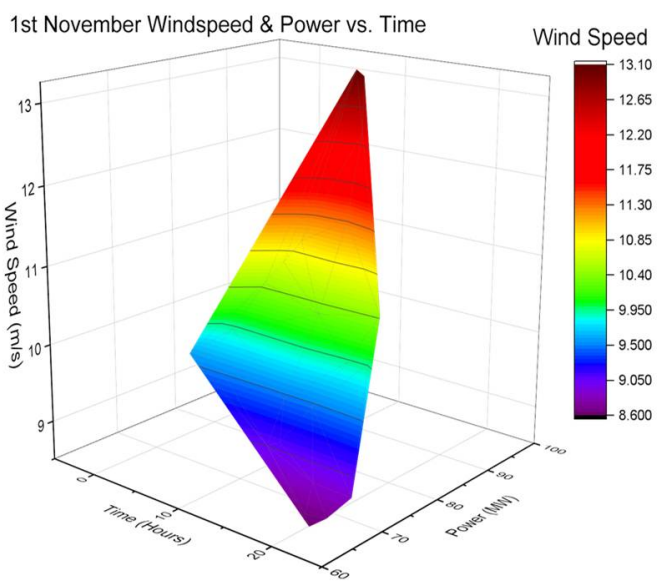

(b)

(c)

Figure 17. (a) June 3D wind speed and power vs. time. (b) November 3D wind speed and power vs. time. (c) Daily seasonal wind farm output.

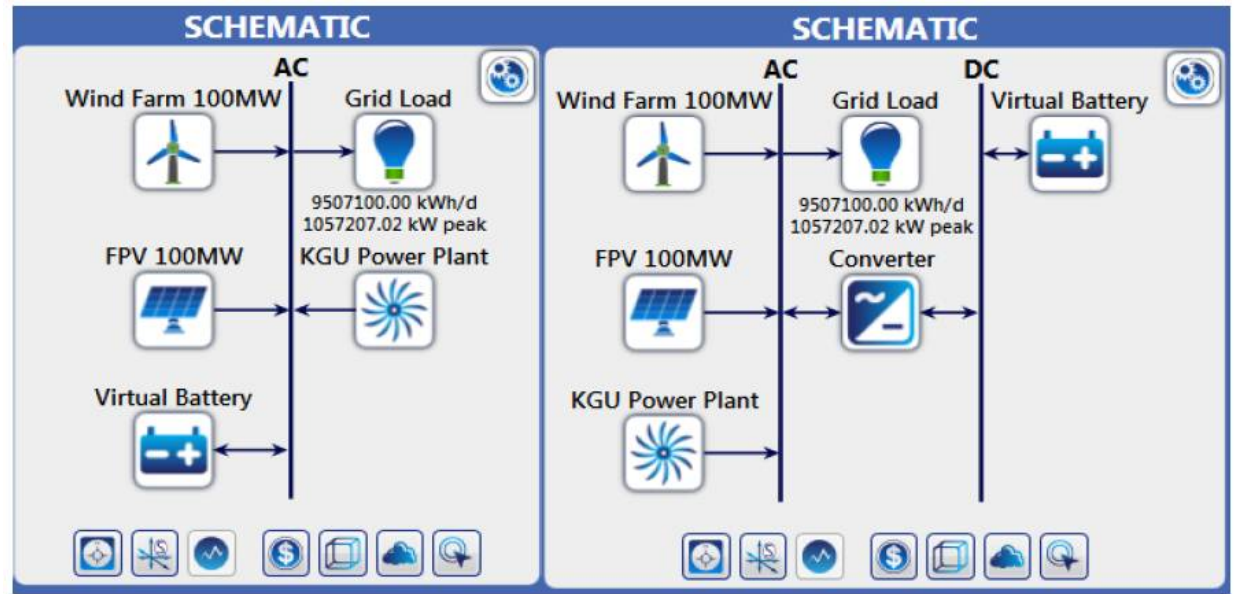

Figure 18. Graphic showing a hybrid energy system schematic in Homerpro.

The Custom Virtual Hydro Battery at Kafue Gorge has a reservoir that can store an assumed maximum capacity of 20 million cubic meters of water $(0.5 \mathrm{~m}$ rise, assuming it is operating at a minimum elevation of $974 \mathrm{~m}$ above sea level), which can discharge over a $173 \mathrm{~h}\left(20,000,000 \mathrm{~m}^{3} /\left(32 \mathrm{~m}^{3} / \mathrm{s} \times 60 \times 60\right)\right.$ period at a rate of $32 \mathrm{~m}^{3} / \mathrm{s}$. The effective head 
is $\sim 382 \mathrm{~m}$, and the generator efficiency is $\sim(85-90) \%$; the power and energy of the Virtual Hydro Battery system during discharging can be calculated as follows:

Discharging:

Power generated $=(\mathrm{p}) \times(\mathrm{g}) \times(\mathrm{v}) \times(\mathrm{h}) \times($ eff $)$

where $(\mathrm{p})$ is the density of water with a value of $1000 \mathrm{~kg} / \mathrm{m}^{3},(\mathrm{~g})$ is the gravitational constant of $9.81 \mathrm{~m} / \mathrm{s}^{2},(\mathrm{v})$ is the flow rate in $\mathrm{m}^{3} / \mathrm{s}$, (h) is the head of $382 \mathrm{~m}$, and (eff) is the generator efficiency value of $90 \%$.

Power Generated $=1000 \times 9.81 \times 32 \times 382 \times 0.9 \sim=108 \mathrm{MW}$.

For a 20-million-meter cube of water at a flow rate of $32 \mathrm{~m}^{3} / \mathrm{s}$, the water utilization duration is approximately $173 \mathrm{~h}$ for one turbine, based on the plant rating table shown above. However, if more turbines operate to consume the stored water, the duration would be proportional to the number of units in operation. The electrical energy generated over the $173 \mathrm{~h}$ is given below.

Energy generated $=$ Power generated $\times$ hours of usage

Energy generated $=108,000 \mathrm{~kW} \times 173 \mathrm{~h}=18,684,000 \mathrm{kWh}(\sim 18.7 \mathrm{GWh})$

Charging:

The initial charging assumes having a wet season and thus an abundant water supply, while other charging periods of the virtual battery system involve throttling down on the hydro when there is an availability of floating photovoltaics and onshore wind. The round-trip efficiency of the virtual battery is the efficiency of the turbogenerator unit, including friction losses in the penstock (assumed to be $90 \%$ total efficiency). The maximum capacity is the maximum electrical output, divided by the nominal voltage $=18,684,000 \times 1000 / 17,500=\sim 1,067,657 \mathrm{amp}$ hours, this assumes the utilization of a generation voltage of $17.5 \mathrm{kV}$ for storage calculations at KGU.

Optimal Daily Dispatch and Reservoir Water Saving

The optimal dispatch of the hybrid energy system at KGU involved the prioritizing of FPV and wind to serve the load and the excess met by hydropower. From Figure 19a below, 1.15 GWh of VRES generation dispatch translated into a reservoir water-saving potential of $9.5 \%$ (equivalent to $1.02 \mathrm{GWh}$ of generation) on 1 January. According to Figure 19b, a water-saving potential of $9.7 \%$ (equivalent to $1.52 \mathrm{GWh}$ of generation) was realized with a dispatch of 1.67 GWh of VRES on 1 March. Figure 19c shows a water-saving potential of $7.2 \%$ with a dispatch of 1.14 GWh of VRES on 1 June. Both 1 September and 1 November yielded better water-saving potentials of $16.8 \%$ and $18.7 \%$ with VRES dispatch of $2.52 \mathrm{GWh}$ and $2.35 \mathrm{GWh}$, respectively (Figure 19d,e). Therefore, using the customized Homer-Matlab dispatch code, 4.93 TWh of annual energy consumption was served, translating into 28 percent more demand served when compared to other default dispatch strategies embedded in Homerpro. This load was met by $166 \mathrm{GWh} /$ year of wind, $175 \mathrm{GWh}$ /year of floating photovoltaics, in the presence of 4.59 TWh of hydrogeneration (five out of six $140 \mathrm{MW}$ hydrogenator units with a $10 \%$ reserve operating margin per unit) and at a competitive levelized cost of energy of GBP $0.055 / \mathrm{kWh}$. The undispatched hydro unit presents a virtual storage potential of approximately $108 \mathrm{MW}$ by a $7.4 \%$ reduction in annual hydropower generation. Moreover, the water saving potential in this study excludes the added benefit of reduced evaporation owing to the presence of retrofitted solar PV panels on the hydro reservoir. 


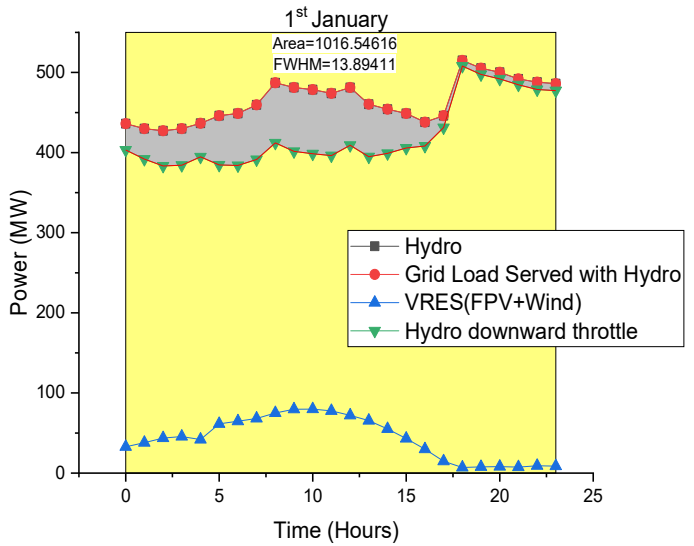

(a)

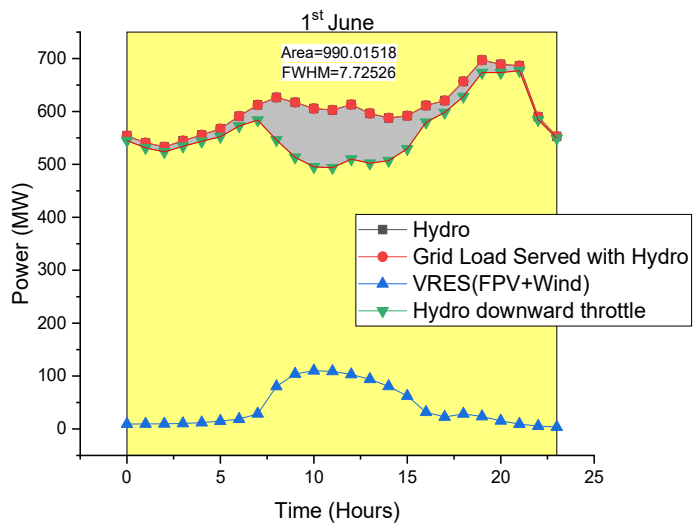

(c)

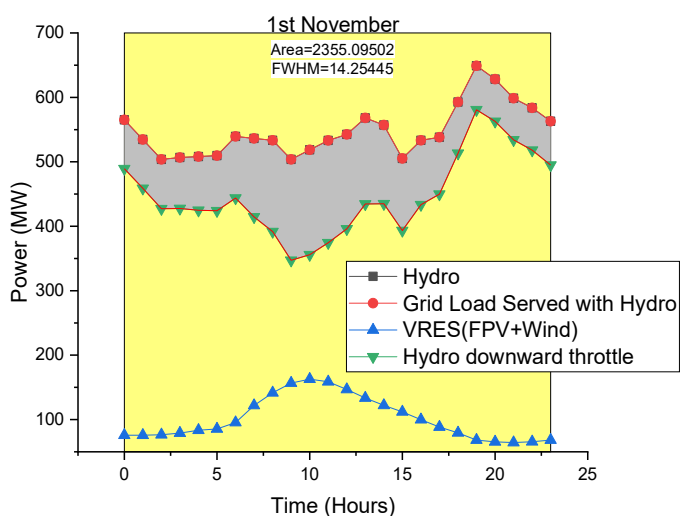

(e)

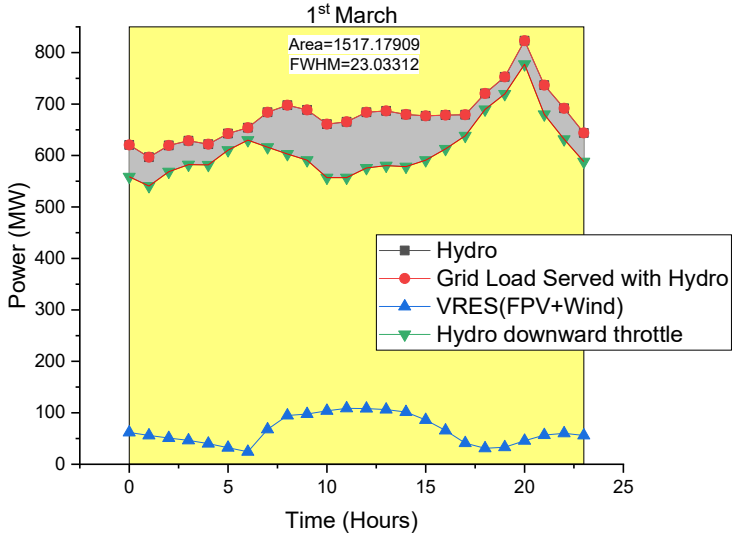

(b)

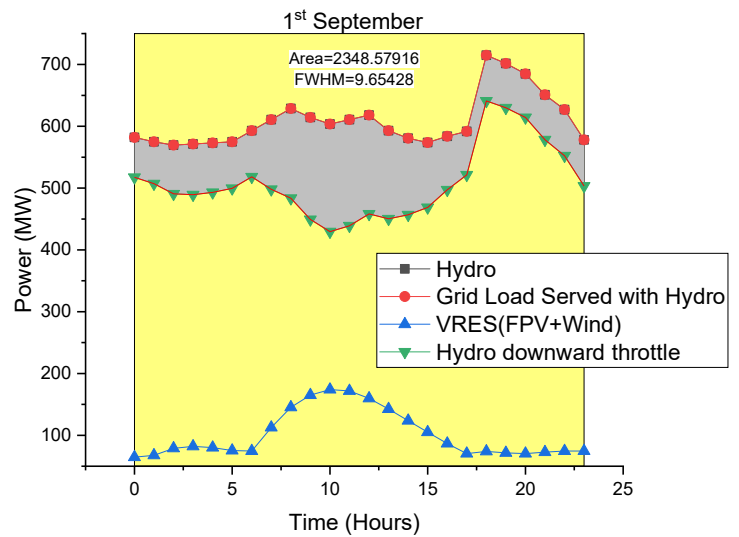

(d)

Figure 19. (a) Optimal daily dispatch of hydro, FPV and wind on 1 January to serve a fraction of the grid demand. (b) Optimal daily dispatch on 1 March. (c) Optimal daily dispatch on 1 June. (d) Dispatch on 1 September. (e) Dispatch on 1 November.

\section{Conclusions}

This study presented a comprehensive assessment of integrating onshore wind and floating photovoltaics that are adjacent to future and existing hydropower sites in Zambia. All the project objectives were successfully achieved, and these included site appraisal methodology formulation to score and rank possible hydropower sites for the potential addition of onshore wind and retrofitting of floating PV, development and scoping of a case study design methodology and its application. The authors presented an application of the devised screening and ranking multicriteria-based methodology for floating PV 
and onshore wind, near hydro sites. The extensive data collection for stage 1, filtered off 3 sites (Lunzua, Victoria and Zengamina), thereby presented the remaining 10 sites to the stage 2 scoring and ranking process. This ranking process was developed for three scenarios, which are the balanced hybrid, floating PV and onshore wind models. The three-level scoring and ranking procedure yielded the following results: the balanced ranking placed Itezhi-tezhi and Kafue Gorge Upper (KGU) at first- and second-rank, with total attribute values of $90 \%$ and $86.9 \%$, respectively; FPV ranking placed Itezhi-tezhi and Kafue Gorge Upper (KGU) at first- and second-rank, with total attribute values of $95 \%$ and 92.5\%, respectively; the wind ranking placed Kafue Gorge Lower (KGL) and Kafue Gorge Upper (KGU) at first- and second-rank, with total attribute values of $93.8 \%$ and $83.8 \%$, respectively. In all the three scoring and ranking levels, the Chishimba site was ranked the least. This study presents great insight for planners and prospective investors in floating photovoltaics and onshore wind as the factors influencing the suitability of the respective sites can easily be understood.

Moreover, the authors developed a scoping design methodology to be applied at any one of the 10 potential sites. The summarized methodology for the case study application includes assessing the technical parameters of the local electrical grid for integration of variable renewable energy sources (VRES), assessing current seasonal hydro generation and grid electrical demand in a year on an hour-by-hour basis, detailed assessment and design of the VRES (floating photovoltaics and onshore wind) for the chosen case study, assessing the storage potential (implied by throttling down hydro in the presence of VRES for the reservoir type), optimizing daily energy production of the system within grid constraints and ascertaining the levelized cost of the energy of the system.

The results of the case study at Kafue Gorge Upper were promising, with VRES integration potential within grid limits of 341 GWh and 508 GWh per annum, for the conservative and optimistic case, respectively. Furthermore, it is worth noting that the floating PV is not being presented as a competitor to ground-mounted systems, but rather as a complementary technology in specific applications (i.e., retrofitting on hydro reservoirs). Along with providing such benefits as reduced evaporation and algae growth, FPV systems have lower operating temperatures and potentially reduce the costs of solar energy generation. To put this into perspective, the current study using PVSYST showed that floating photovoltaics have a better energy yield compared to a ground-mounted system, as evidenced by a $7.4 \%, 5.8 \%$ and $4.9 \%$ increase in energy production for the freestanding, small-footprint and large-footprint FPV configurations, respectively, at a reduced generation cost of GBP $0.04 / \mathrm{kWh}$.

Therefore, floating PV and onshore wind integration could present added technoeconomic benefits by fast-tracking new capacity development with opportunities for private investments (IPPs), new opportunities for the Zambian service and manufacturing sectors, power structure decentralization, owing to the wide spread of the renewable resources in the country (i.e., solar PV and wind are more diffused) compared to localized hydropower projects (usually located near large lakes and rivers).

\section{Recommendations}

The following future work is recommended to add more value and traction to the project research:

- An opportunity to conduct detailed financial and uncertainty analysis to cement project bankability.

- The conducting of pre-feasibility studies (i.e., bathymetry, environmental impact assessment, geotechnical and soil analysis of the reservoir/dam).

- The potential to widen the study scope to include all viable water bodies in the country (both natural and man-made).

- An opportunity to assess the grid impact at the other 9 ranked sites to ascertain overall impact on voltage stability and magnitude profile, network power losses, operating cost differential for different unit commitment scenarios. Moreover, there 
is the potential to conduct detailed network analysis to cover: N-1static security assessment, network fault level analysis and protection coordination, short-term and long-term frequency response, the effects of a spinning reserve, transient and dynamic stability performance, and voltage regulation during transience. Consequently, these studies will further provide the necessary technical requirements in the national grid code for large-scale VRES integration.

- Additionally, this study will pave the way for future research in optimizing the dispatch of VRES through an enhanced forecasting model for wind and PV (with the utilization of artificial intelligence and machine learning such as deep neural networks). This will help reduce power balancing costs for large-scale VRES integration.

Author Contributions: Conceptualization, K.J.N. and P.G.T.; software, K.J.N.; methodology, K.J.N. and P.G.T.; formal analysis, K.J.N.; writing - original draft preparation (based on M.Sc. dissertation), K.J.N.; writing—review and editing, A.M., P.G.T. and A.S. All authors have read and agreed to the published version of the manuscript.

Funding: K.J.N. received a scholarship to study for an M.Sc. in Sustainable Engineering: Renewable Energy Systems and the Environment at the University of Strathclyde from the Commonwealth Scholarship Commission (Scholar ID: ZMCS-2019-760).

Institutional Review Board Statement: Not applicable.

Informed Consent Statement: Not applicable.

Data Availability Statement: The data presented in this study is available on request from the corresponding authors.

Acknowledgments: We are grateful for the support and data obtained from industry and would like to acknowledge the contribution of the following: ZESCO Ltd. (Chief Engineer System Studies and Project Design under Distribution Development-George Muyunda and Hydrology EngineerKelvin Kabwe) and the Rural Electrification Authority (Chief Executive Officer-Clement Silavwe). Part of this work was conducted under the Energy Systems Research Unit at the University of Strathclyde, Glasgow.

Conflicts of Interest: The author declares no conflict of interest but also acknowledges a Master of Science scholarship from the Commonwealth Scholarship Commission that made it possible to conduct this study. 


\section{Appendix A}

Appraisal and Ranking Methodology.

Table A1. Showing the site attribute score for FPV, Wind and Hybrid

\begin{tabular}{|c|c|c|c|c|c|c|c|c|c|c|c|c|}
\hline $\begin{array}{l}\text { Suitability } \\
\text { Score }\end{array}$ & & & & & & & & & & & & \\
\hline \multicolumn{13}{|c|}{ Part 1: Balanced Score Attribute Distribution [70,75-78,94-103]. } \\
\hline & \multicolumn{3}{|c|}{ Wind Potential (25\% Relative Weight) } & \multicolumn{2}{|c|}{$\begin{array}{c}\text { FPV Potential (35\% Relative } \\
\text { Weight) }\end{array}$} & \multicolumn{3}{|c|}{ Energy Export (20\% Relative Weight) } & \multicolumn{3}{|c|}{ Ease of Access (15\% Relative Weight) } & \multirow{2}{*}{$\begin{array}{c}\text { Demand (5\% } \\
\text { Rel. Weight) } \\
\begin{array}{c}\text { Distance to } \\
\text { Demand } \\
(\mathbf{k m})\end{array}\end{array}$} \\
\hline & $\begin{array}{l}\text { Number of } \\
\text { Turbines }\end{array}$ & $\begin{array}{l}\text { Capacity } \\
\text { Factor }(\%)\end{array}$ & Slope $(\%)$ & Area $\left(\mathrm{km}^{2}\right)$ & $\begin{array}{l}\text { Capacity } \\
\text { Factor }(\%)\end{array}$ & $\begin{array}{c}\text { FPV } \\
\text { Distance to } \\
\text { Grid (km) }\end{array}$ & $\begin{array}{c}\text { Wind } \\
\text { Distance to } \\
\text { Grid (km) }\end{array}$ & $\begin{array}{c}\text { Grid } \\
\text { Capacity } \\
\text { (MVA) }\end{array}$ & Land Use & $\begin{array}{c}\text { Land } \\
\text { Ownership }\end{array}$ & $\begin{array}{l}\text { Distance to } \\
\text { Road (km) }\end{array}$ & \\
\hline High $(100 \%)$ & $>20$ & $>=40$ & $0-<7$ & $>=10$ & $>=14$ & $<=2$ & $0-<=15$ & $>=700$ & No current use & $\begin{array}{l}\text { Customary } \\
\text { /State }\end{array}$ & $0-4$ & $<=50$ \\
\hline $\begin{array}{l}\text { Medium } \\
(75 \%)\end{array}$ & $>10-<=20$ & $>=35,<40$ & $>=7-<14$ & $>=1,<10$ & - & $>=5,<2$ & $>15-<=30$ & $<700->=400$ & - & - & $4-8$. & $50-100$ \\
\hline Low $(50 \%)$ & $>5-<=10$ & $>=30,<35$ & $>=14-<20$ & $>=0.1,<1$ & - & $>=7.5,<5$ & $>30-<=45$ & $<400->=100$ & - & - & $8-12$. & $100-150$ \\
\hline Lowest (25\%) & $>=1-<5$ & $>=26,<30$ & $>=20-<=30$ & $>=0.004,<0.1$ & - & $<=10,<7.5$ & $>45-<=60$ & $<100->=1$ & Agriculture & Private & $12-16$. & $150-200$ \\
\hline Unsuitable & 0 & $<26$ & $>30$ & $<0.004$ & & $>10$ & $>60$ & $<1$ & $\begin{array}{l}\text { Protected/sensitive } \\
\quad \text { land }\end{array}$ & - & - & $>=200$ \\
\hline \multicolumn{13}{|c|}{ Part 2: Floating Photovoltaic (FPV) Attribute Score Distribution $[70,75-78,94-103]}$. \\
\hline & \multicolumn{2}{|c|}{ Area $\left(\mathrm{km}^{2}\right)$} & $\begin{array}{l}\text { Capacity } \\
\text { Factor }(\%)\end{array}$ & \multicolumn{2}{|c|}{ FPV Distance to Grid (km) } & $\begin{array}{c}\text { Grid } \\
\text { Capacity } \\
\text { (MVA) }\end{array}$ & Land Use & $\begin{array}{c}\text { Land } \\
\text { Ownership }\end{array}$ & $\begin{array}{l}\text { Distance to } \\
\text { Road (km) }\end{array}$ & \multicolumn{3}{|c|}{ Distance to Demand (km) } \\
\hline High $(100 \%)$ & \multicolumn{2}{|c|}{$>=10$} & $>=14$ & \multicolumn{2}{|c|}{$<=2$} & $>=700$ & No current use & Customary/State & $0-<=4$ & \multicolumn{3}{|c|}{$<=50$} \\
\hline $\begin{array}{l}\text { Medium } \\
(75 \%)\end{array}$ & \multicolumn{2}{|c|}{$>=1,<10$} & & \multicolumn{2}{|c|}{$>=5,<2$} & $<700->=400$ & - & - & $>4-<=8$ & \multicolumn{3}{|c|}{$>50-<=100$} \\
\hline Low $(50 \%)$ & \multicolumn{2}{|c|}{$>=0.1,<1$} & & \multicolumn{2}{|c|}{$>=7.5,<5$} & $<400->=100$ & - & - & $>8-<=12$ & \multicolumn{3}{|c|}{$>100-<=150$} \\
\hline Lowest $(25 \%)$ & \multicolumn{2}{|c|}{$>=0.004,<0.1$} & & \multicolumn{2}{|c|}{$<=10,<7.5$} & $<100->=1$ & Agriculture & Private & $>12-<=16$ & \multicolumn{3}{|c|}{$>150-<=200$} \\
\hline Unsuitable & \multicolumn{2}{|c|}{$<0.004$} & & \multicolumn{2}{|c|}{$>10$} & $<1$ & \multicolumn{2}{|l|}{$\begin{array}{l}\text { Protected/sensitive } \\
\quad \text { land }\end{array}$} & - & \multicolumn{3}{|c|}{$>200$} \\
\hline
\end{tabular}


Table A1. Cont.

Part 3: Onshore Wind Attribute Score Distribution [70,75-78,94-103].

\begin{tabular}{|c|c|c|c|c|c|c|c|c|c|}
\hline & \multicolumn{3}{|c|}{ Wind Potential (60\% Relative Weight) } & \multicolumn{2}{|c|}{$\begin{array}{c}\text { Energy Export (20\% Relative } \\
\text { Weight) }\end{array}$} & \multicolumn{3}{|c|}{ Ease of Access (15\% Relative Weight) } & \multirow{2}{*}{$\begin{array}{c}\begin{array}{c}\text { Demand (5\% Relative } \\
\text { Weight) }\end{array} \\
\text { Distance to Demand (km) }\end{array}$} \\
\hline & Number of Turbines & $\begin{array}{c}\text { Capacity } \\
\text { Factor }(\%)\end{array}$ & Slope $(\%)$ & $\begin{array}{l}\text { Wind } \\
\text { Distance to } \\
\text { Grid (km) }\end{array}$ & $\begin{array}{c}\text { Grid } \\
\text { Capacity } \\
\text { (MVA) }\end{array}$ & Land Use & $\begin{array}{c}\text { Land } \\
\text { Ownership }\end{array}$ & $\begin{array}{l}\text { Distance to } \\
\text { Road (km) }\end{array}$ & \\
\hline High $(100 \%)$ & $>20$ & $>=40$ & $0-<7$ & $0-<=15$ & $>=700$ & No current use & Customary/State & $0-<=4$ & $<=50$ \\
\hline $\begin{array}{l}\text { Medium } \\
(75 \%)\end{array}$ & $>10-<=20$ & $>=35,<40$ & $>=7-<14$ & $>15-<=30$ & $<700->=400$ & - & - & $>4-<=8$ & $50-100$ \\
\hline Low $(50 \%)$ & $>5-<=10$ & $>=30,<35$ & $>=14-<20$ & $>30-<=45$ & $<400->=100$ & - & - & $>8-<=12$ & $100-150$ \\
\hline Unsuitable & 0 & $<26$ & $>30$ & $>60$ & $<1$ & $\begin{array}{l}\text { Protected/sensitive } \\
\quad \text { land }\end{array}$ & - & - & $>=200$ \\
\hline
\end{tabular}

Table A2. Showing balanced scoring and ranking matrix results.

\begin{tabular}{|c|c|c|c|c|c|c|c|c|}
\hline & & \multicolumn{4}{|c|}{ Wind Potential (25\% Weight) } & \multicolumn{3}{|c|}{ FPV Potential ( $35 \%$ weight) } \\
\hline & & $\begin{array}{c}\text { Score * Weight } \\
(\mathbf{1 0} \%)\end{array}$ & $\begin{array}{c}\text { Score * Weight } \\
(10 \%)\end{array}$ & Score * Weight $(5 \%)$ & $\sum$ & $\begin{array}{c}\text { Score * Weight } \\
(17.5 \%)\end{array}$ & $\begin{array}{c}\text { Score * Weight } \\
(\mathbf{1 7 . 5 \% )}\end{array}$ & $\Sigma$ \\
\hline Rank \# & Name of Site & $\begin{array}{l}\text { Number of } \\
\text { Turbines }\end{array}$ & Capacity Factor & Slope & Wind Total & Area & Capacity Factor & FPV Total \\
\hline$=\mathbf{1}^{\prime}$ & Itezhi-tezhi FPV/wind site & $10.0 \%$ & $7.5 \%$ & $5.0 \%$ & $22.5 \%$ & $17.5 \%$ & $17.5 \%$ & $35.0 \%$ \\
\hline$=2^{\prime}$ & KGU FPV/wind site & $10.0 \%$ & $7.5 \%$ & $3.8 \%$ & $21.3 \%$ & $13.1 \%$ & $17.5 \%$ & $30.6 \%$ \\
\hline$=3^{\prime}$ & KGL FPV/wind site & $10.0 \%$ & $10.0 \%$ & $5.0 \%$ & $25.0 \%$ & $8.8 \%$ & $17.5 \%$ & $26.3 \%$ \\
\hline$=3^{\prime}$ & Lusiwasi FPV/ wind site & $10.0 \%$ & $5.0 \%$ & $5.0 \%$ & $20.0 \%$ & $17.5 \%$ & $17.5 \%$ & $35.0 \%$ \\
\hline$=6^{\prime}$ & Musonda FPV/wind site & $10.0 \%$ & $7.5 \%$ & $5.0 \%$ & $22.5 \%$ & $13.1 \%$ & $17.5 \%$ & $30.6 \%$ \\
\hline$=6^{\prime}$ & Mulungushi FPV/wind site & $10.0 \%$ & $7.5 \%$ & $5.0 \%$ & $22.5 \%$ & $13.1 \%$ & $17.5 \%$ & $30.6 \%$ \\
\hline$=8^{\prime}$ & Shiwangangu FPV/ wind site & $10.0 \%$ & $7.5 \%$ & $3.8 \%$ & $21.3 \%$ & $8.8 \%$ & $17.5 \%$ & $26.3 \%$ \\
\hline$=9^{\prime}$ & Lunsemfwa FPV/wind site & $10.0 \%$ & $10.0 \%$ & $5.0 \%$ & $25.0 \%$ & $4.4 \%$ & $17.5 \%$ & $21.9 \%$ \\
\hline$=10^{\prime}$ & Chishimba FPV/wind site & $10.0 \%$ & $5.0 \%$ & $5.0 \%$ & $20.0 \%$ & $4.4 \%$ & $17.5 \%$ & $21.9 \%$ \\
\hline
\end{tabular}


Table A3. Showing continuation of balanced scoring and ranking matrix results.

\begin{tabular}{|c|c|c|c|c|c|c|c|c|c|c|c|c|}
\hline & & \multicolumn{4}{|c|}{ Energy Export (20\% Weight) } & \multicolumn{4}{|c|}{ Ease of Access (15\% Weight) } & \multirow{2}{*}{$\begin{array}{c}\begin{array}{c}\text { Demand (5\% } \\
\text { Weight) }\end{array} \\
\begin{array}{c}\text { Score * } \\
\text { Weight (5\%) }\end{array}\end{array}$} & \multirow[b]{2}{*}{$\Sigma$} & \multirow{2}{*}{$\begin{array}{c}\begin{array}{c}\text { Site Tota } \\
(\mathbf{1 0 0 \%} \\
\text { Weight })\end{array} \\
\sum\end{array}$} \\
\hline & & $\begin{array}{c}\text { Score * } \\
\text { Weight (5\%) }\end{array}$ & $\begin{array}{c}\text { Score * } \\
\text { Weight (5\%) }\end{array}$ & $\begin{array}{l}\text { Score * } \\
\text { Weight } \\
(10 \%)\end{array}$ & $\sum$ & $\begin{array}{c}\text { Score * } \\
\text { Weight (5\%) }\end{array}$ & $\begin{array}{c}\text { Score * } \\
\text { Weight (5\%) }\end{array}$ & $\begin{array}{c}\text { Score * } \\
\text { Weight (5\%) }\end{array}$ & $\sum$ & & & \\
\hline Rank\# & Name of Site & $\begin{array}{c}\text { FPV } \\
\text { Distance to } \\
\text { Grid }\end{array}$ & $\begin{array}{l}\text { Wind } \\
\text { Distance to } \\
\text { Grid }\end{array}$ & $\begin{array}{c}\text { Grid } \\
\text { Capacity } \\
(10 \%)\end{array}$ & Total & $\begin{array}{l}\text { Land Use } \\
\quad(5 \%)\end{array}$ & $\begin{array}{c}\text { Land } \\
\text { Ownership }\end{array}$ & $\begin{array}{l}\text { Distance to } \\
\text { Road }\end{array}$ & Total & $\begin{array}{l}\text { Distance to } \\
\text { Demand }\end{array}$ & $\begin{array}{l}\text { Demand } \\
\text { Total }\end{array}$ & $\begin{array}{l}\text { Score * } \\
\text { Weight }\end{array}$ \\
\hline$=\mathbf{1}^{\prime}$ & Itezhi-tezhi FPV/wind site & $5.0 \%$ & $2.5 \%$ & $5.0 \%$ & $12.5 \%$ & $5.0 \%$ & $5.0 \%$ & $5.0 \%$ & $15.0 \%$ & $5.0 \%$ & $5.0 \%$ & $90.0 \%$ \\
\hline$=2^{\prime}$ & KGU FPV/wind site & $5.0 \%$ & $3.8 \%$ & $10.0 \%$ & $18.8 \%$ & $5.0 \%$ & $5.0 \%$ & $1.3 \%$ & $11.3 \%$ & $5.0 \%$ & $5.0 \%$ & $86.9 \%$ \\
\hline$=3^{\prime}$ & KGL FPV/wind site & $2.5 \%$ & $2.5 \%$ & $10.0 \%$ & $15.0 \%$ & $5.0 \%$ & $5.0 \%$ & $3.8 \%$ & $13.8 \%$ & $5.0 \%$ & $5.0 \%$ & $85.0 \%$ \\
\hline$=3^{\prime}$ & Kariba FPV/wind site & $5.0 \%$ & $5.0 \%$ & $10.0 \%$ & $20.0 \%$ & $5.0 \%$ & $5.0 \%$ & $5.0 \%$ & $15.0 \%$ & $5.0 \%$ & $5.0 \%$ & $85.0 \%$ \\
\hline$=3^{\prime}$ & Lusiwasi FPV/ wind site & $5.0 \%$ & $5.0 \%$ & $2.5 \%$ & $12.5 \%$ & $5.0 \%$ & $5.0 \%$ & $5.0 \%$ & $15.0 \%$ & $2.5 \%$ & $2.5 \%$ & $85.0 \%$ \\
\hline$=6^{\prime}$ & Musonda FPV/wind site & $1.3 \%$ & $5.0 \%$ & $2.5 \%$ & $8.8 \%$ & $5.0 \%$ & $5.0 \%$ & $5.0 \%$ & $15.0 \%$ & $2.5 \%$ & $2.5 \%$ & $79.4 \%$ \\
\hline$=6^{\prime}$ & Mulungushi FPV/wind site & $2.5 \%$ & $5.0 \%$ & $2.5 \%$ & $10.0 \%$ & $5.0 \%$ & $5.0 \%$ & $3.8 \%$ & $13.8 \%$ & $2.5 \%$ & $2.5 \%$ & $79.4 \%$ \\
\hline$=8^{\prime}$ & Shiwangangu FPV/ wind site & $5.0 \%$ & $5.0 \%$ & $2.5 \%$ & $12.5 \%$ & $5.0 \%$ & $5.0 \%$ & $3.8 \%$ & $13.8 \%$ & $2.5 \%$ & $2.5 \%$ & $76.3 \%$ \\
\hline$=10^{\prime}$ & Chishimba FPV/wind site & $5.0 \%$ & $3.8 \%$ & $2.5 \%$ & $11.3 \%$ & $5.0 \%$ & $5.0 \%$ & $5.0 \%$ & $15.0 \%$ & $2.5 \%$ & $2.5 \%$ & $70.6 \%$ \\
\hline
\end{tabular}




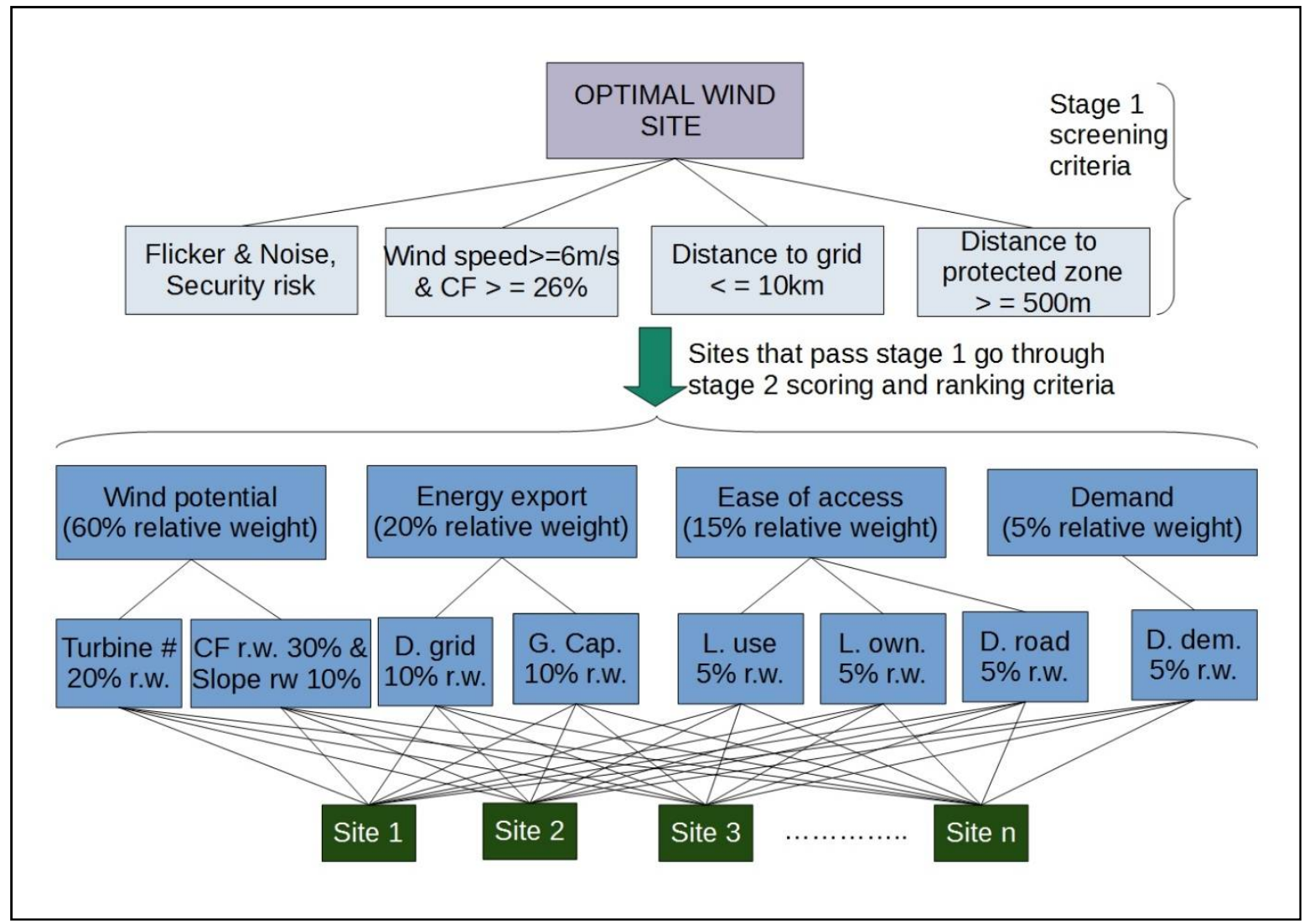

Figure A1. Graphic showing the 2-stage hierarchy structure for optimal onshore wind site selection. Abbreviations: Turbines\#—number of turbines, CF—capacity factor, r.w.—relative weight, D. grid—distance to grid, G. cap.—grid capacity, L. use-land use, L. own-land ownership, D. road-distance to road, D. dem.-distance to demand center, r.w.-relative weight.

\section{Appendix B}

ZESCO Power System Analysis Toolbox Models.

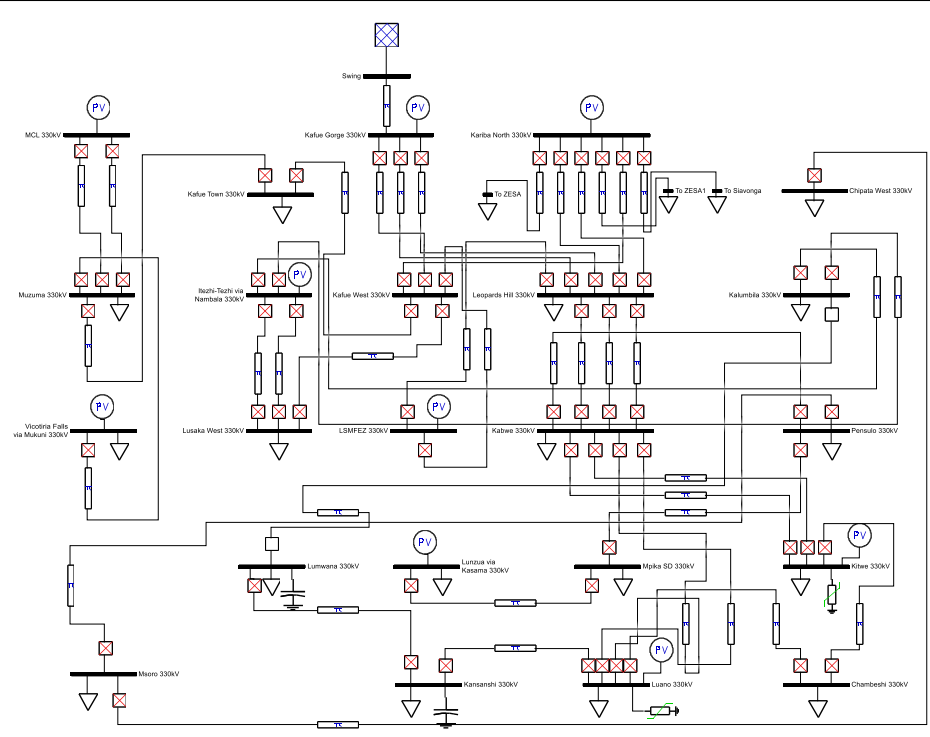

Figure A2. Layout showing the PSAT model for the existing $330 \mathrm{kV}$ Zambian network. 


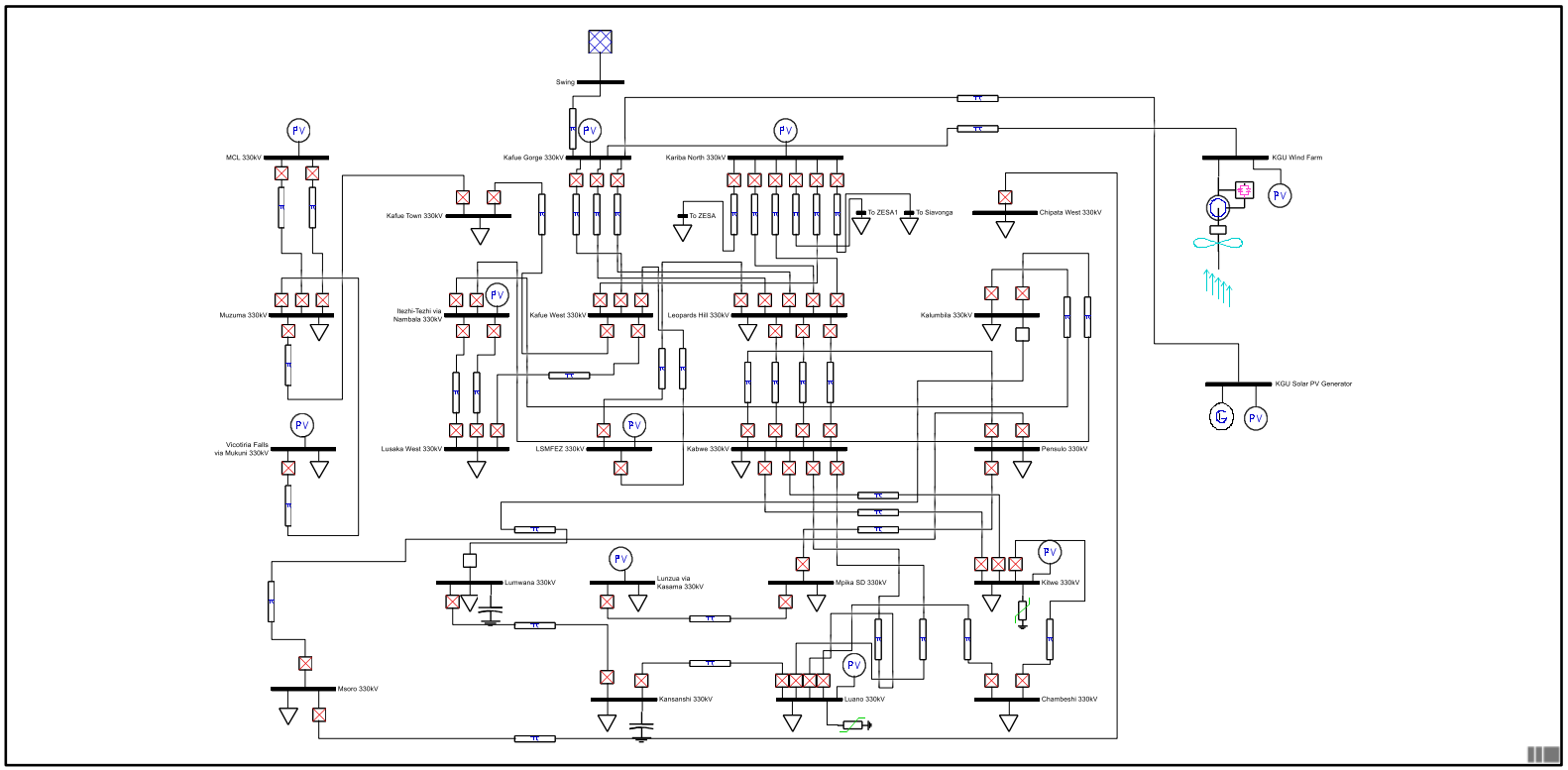

Figure A3. Layout showing the PSAT FPV and wind integration model for the $330 \mathrm{kV}$ Zambian network.

Table A4. Showing the power system modeling data.

\begin{tabular}{|c|c|c|c|c|c|c|c|}
\hline \multirow[t]{2}{*}{ Base MVA } & \multirow[t]{2}{*}{100} & & & \multicolumn{4}{|c|}{ Shunt Compensation } \\
\hline & & & & & Station & $\begin{array}{l}\text { Rating } \\
\text { (MVAr) }\end{array}$ & \\
\hline & & & & & Kitwe & 20 & \\
\hline \multicolumn{2}{|c|}{ 330kV Line Parameters } & & & & Lumwana & 20 & \\
\hline $\mathrm{R}(\mathrm{p} . \mathrm{u} / \mathrm{km})$ & $X(p \cdot u / k m)$ & B (p.u/km) & & & Kansanshi & 20 & \\
\hline \multirow[t]{2}{*}{0.00004} & 0.000315 & 0.003708 & & & & & \\
\hline & & & & & SVCs & & \\
\hline \multicolumn{3}{|c|}{ 220kV Line Parameters } & & & Station & $\begin{array}{l}\text { Rating } \\
\text { (MVA) }\end{array}$ & \\
\hline $\mathrm{R}(\mathrm{p} \cdot \mathrm{u} / \mathrm{km})$ & $X(p . u / k m)$ & B (p.u/km) & & & Kitwe & 35 & \\
\hline 0.000115 & 0.000682 & 0.001701 & & & Luano & 80 & \\
\hline \multicolumn{3}{|c|}{ 132kV Line Parameters } & & & & & \\
\hline $\mathrm{R}(\mathrm{p} . \mathrm{u} / \mathrm{km})$ & $X(\mathrm{p} . \mathrm{u} / \mathrm{km})$ & B (p.u/km) & & & & & \\
\hline 0.001224 & 0.002365 & 0.000486 & & & & & \\
\hline FROM & TO & $\mathrm{km}$ & $\mathrm{R}(\mathrm{p} . \mathrm{u})$ & $X(p \cdot u)$ & $B(p . u)$ & $\begin{array}{c}\text { Voltage Level } \\
\qquad(\mathrm{kV})\end{array}$ & $\begin{array}{l}\text { Rating } \\
\text { (MVA) }\end{array}$ \\
\hline Kafue Gorge & $\begin{array}{c}\text { Leopards } \\
\text { Hill }\end{array}$ & 47 & 0.00188 & 0.014805 & 0.174276 & 330 & 700 \\
\hline Kafue Gorge & Kafue West & 43 & 0.00172 & 0.013545 & 0.159444 & 330 & 700 \\
\hline Kariba North & $\begin{array}{c}\text { Leopards } \\
\text { Hill }\end{array}$ & 123 & 0.00492 & 0.038745 & 0.456084 & 330 & 700 \\
\hline $\begin{array}{c}\text { Leopards } \\
\text { Hill }\end{array}$ & Kabwe & 97 & 0.00388 & 0.030555 & 0.359676 & 330 & 700 \\
\hline
\end{tabular}


Table A4. Cont.

\begin{tabular}{|c|c|c|c|c|c|c|c|}
\hline Kabwe & Kitwe & 211 & 0.00844 & 0.066465 & 0.782388 & 330 & 700 \\
\hline Kabwe & Luano & 247 & 0.00988 & 0.077805 & 0.915876 & 330 & 700 \\
\hline Kabwe & Pensulo & 298 & 0.01192 & 0.09387 & 1.104984 & 330 & 700 \\
\hline Kitwe & Luano & 40 & 0.0016 & 0.0126 & 0.14832 & 330 & 700 \\
\hline Kitwe & Chambishi & 21.5 & 0.00086 & 0.0067725 & 0.079722 & 330 & 700 \\
\hline Chambishi & Luano & 21.5 & 0.00086 & 0.0067725 & 0.079722 & 330 & 700 \\
\hline Luano & Kansanshi & 196 & 0.00784 & 0.06174 & 0.726768 & 330 & 700 \\
\hline Kansanshi & Lumwana & 72 & 0.00288 & 0.02268 & 0.266976 & 330 & 700 \\
\hline Kafue West & Lusaka West & 51 & 0.00204 & 0.016065 & 0.189108 & 330 & 700 \\
\hline Kafue West & Kafue Town & 3 & 0.00012 & 0.000945 & 0.011124 & 330 & 700 \\
\hline Kafue West & $\begin{array}{c}\text { Leopards } \\
\text { Hill }\end{array}$ & 53 & 0.00212 & 0.016695 & 0.196524 & 330 & 700 \\
\hline VicFalls & Muzuma & 159 & 0.018285 & 0.108438 & 0.270459 & 220 & 230 \\
\hline Muzuma & Kafue Town & 189 & 0.021735 & 0.128898 & 0.321489 & 220 & 230 \\
\hline Luano & Michelo & 44 & 0.00506 & 0.030008 & 0.074844 & 220 & 375 \\
\hline Michelo & Karavia & 8 & 0.00092 & 0.005456 & 0.013608 & 220 & 375 \\
\hline $\begin{array}{c}\text { Leopards } \\
\text { Hill }\end{array}$ & Roma & 28 & 0.034272 & 0.06622 & 0.013608 & 132 & 85 \\
\hline $\begin{array}{c}\text { Leopards } \\
\text { Hill }\end{array}$ & Coventry & 28 & 0.034272 & 0.06622 & 0.013608 & 132 & 85 \\
\hline Roma & Lusaka West & 21 & 0.025704 & 0.049665 & 0.010206 & 132 & 85 \\
\hline Lusaka West & Roma & 21 & 0.025704 & 0.049665 & 0.010206 & 132 & 85 \\
\hline \multicolumn{8}{|l|}{ Transformers } \\
\hline Station & Qty & $x(p \cdot u)$ & Rating & Ratio & & & \\
\hline Kafue Town & 1 & 0.185 & 60 & $220 / 88$ & & & \\
\hline Kafue Town & 1 & 0.1707 & 60 & $330 / 88$ & & & \\
\hline Lusaka West & 1 & 0.056 & 125 & $330 / 132$ & & & \\
\hline Leopard Hill & 2 & 0.056 & 125 & $330 / 132$ & & & \\
\hline Kitwe & 6 & 0.042 & 125 & $330 / 220$ & & & \\
\hline Luano & 4 & 0.042 & 125 & $330 / 220$ & & & \\
\hline
\end{tabular}

\section{References}

1. World Bank Group, ESMAP, and SERIS. Where Sun Meets Water: Floating Solar Handbook for Practitioners; World Bank: Washington, DC, USA, 2019. Available online: https://www.esmap.org/where_sun_meets_water_handbook (accessed on 10 September 2020).

2. Obane, H.; Nagai, Y.; Asano, K. Assessing land use and potential conflict in solar and onshore wind energy in Japan. Renew. Energy 2020, 160, 842-851. [CrossRef]

3. Thi, N.D.A. The Evolution of Floating Solar Photovoltaics; Research Gate: Berlin, Germany, 2017.

4. Trapani, K.; Santafé, M.R. A review of floating photovoltaic installations: 2007-2013. Prog. Photovolt. Res. Appl. 2014, $23,524-532$. [CrossRef]

5. $\quad$ Ferrer-Gisbert, C.; Ferrán-Gozálvez, J.J.; Redón-Santafé, M.; Gisbert, P.F.; Sanchez-Romero, F.-J.; Torregrosa-Soler, J.B. A new photovoltaic floating cover system for water reservoirs. Renew. Energy 2013, 60, 63-70. [CrossRef]

6. Mesbahi, M.; Minamino, S. Top 70 Floating Solar PV Plants. Available online: https://www.solarplaza.com/channels/top-10s/ 11761/top-70-floating-solar-pv-plants / (accessed on 20 June 2020).

7. Tsanova, T. Floating solar installs to top $1.5 \mathrm{GW}$ in 2019. Available online: https://renewablesnow.com/news/to-the-pointfloatingsolar-installs-to-top-15-gw-in-2019-613278 / (accessed on 27 May 2021).

8. Ranjbaran, P.; Yousefi, H.; Gharehpetian, G.B.; Astaraei, F.R. A review on floating photovoltaic (FPV) power generation units. Renew. Sustain. Energy Rev. 2019, 110, 332-347. [CrossRef] 
9. Sulaeman, S.; Brown, E.; Quispe-Abad, R.; Müller, N. Floating PV system as an alternative pathway to the amazon dam underproduction. Renew. Sustain. Energy Rev. 2020, 135, 110082. [CrossRef]

10. Oliveira-Pinto, S.; Stokkermans, J. Assessment of the potential of different floating solar technologies-Overview and analysis of different case studies. Energy Convers. Manag. 2020, 211, 112747. [CrossRef]

11. Rosa-Clot, M. Floating PV Plants; Academic Press: Cambridge, MA, USA, 2020.

12. Liu, H.; Krishna, V.; Leung, J.L.; Reindl, T.; Zhao, L. Field experience and performance analysis of floating PV technologies in the tropics. Prog. Photovolt. Res. Appl. 2018, 26, 957-967. [CrossRef]

13. ZESCO Limited. Statement on Electricity Deficit. 2020. Available online: https://www.reuters.com/article/zambia-electricity/ update-1-zambian-power-firm-zesco-says-electricity-deficit-growing-idUSL8N2B626D (accessed on 11 September 2020).

14. Ministry of Energy (MOE). Official Opening of the Fifth Session of the Twelfth National Assembly by His Excellency, Mr. Edgar Chagwa Lungu, President of the Republic of Zambia on Friday 11 September 2020. Available online: https://www.moe.gov.zm/ ?wpfb_dl=82 (accessed on 11 September 2020).

15. Stiubiener, U.; da Silva, T.C.; Trigoso, F.B.M.; Benedito, R.D.S.; Teixeira, J.C. PV power generation on hydro dam's reservoirs in Brazil: A way to improve operational flexibility. Renew. Energy 2020, 150, 765-776. [CrossRef]

16. Farfan, J.; Breyer, C. Combining Floating Solar Photovoltaic Power Plants and Hydropower Reservoirs: A Virtual Battery of Great Global Potential. Energy Procedia 2018, 155, 403-411. [CrossRef]

17. Nordmann, T.; Vontobel, T.; Clavadetscher, L.; Boström, T.; Remlo, H. Large Scale Hybrid PV Hydro Electricity Production in Floating Devices on Water. Forest 2009, 1, 4189-4192. [CrossRef]

18. Ming, B.; Liu, P.; Cheng, L.; Zhou, Y.; Wang, X. Optimal daily generation scheduling of large hydro-photovoltaic hybrid power plants. Energy Convers. Manag. 2018, 171, 528-540. [CrossRef]

19. Spencer, R.S.; Macknick, J.; Aznar, A.; Warren, A.; Reese, M.O. Floating Photovoltaic Systems: Assessing the Technical Potential of Photovoltaic Systems on Man-Made Water Bodies in the Continental United States. Environ. Sci. Technol. 2018, 53, 1680-1689. [CrossRef]

20. Serrano-González, J.; Lacal-Arántegui, R. Technological evolution of onshore wind turbines-A market-based analysis. Wind. Energy 2016, 19, 2171-2187. [CrossRef]

21. Sliz-Szkliniarz, B.; Eberbach, J.; Hoffmann, B.; Fortin, M. Assessing the cost of onshore wind development scenarios: Modelling of spatial and temporal distribution of wind power for the case of Poland. Renew. Sustain. Energy Rev. 2019, 109, 514-531. [CrossRef]

22. Ladenburg, J.; Hevia-Koch, P.; Petrović, S.; Knapp, L. The offshore-onshore conundrum: Preferences for wind energy considering spatial data in Denmark. Renew. Sustain. Energy Rev. 2020, 121, 109711. [CrossRef]

23. Jin, X.; Rong, Y.; Zhong, X. Wind turbine manufacturing industry in China: Current situation and problems. Renew. Sustain. Energy Rev. 2014, 33, 729-735. [CrossRef]

24. Hughes, F.M.; Anaya-Lara, O.; Ramtharan, G.; Jenkins, N.; Strbac, G. Influence of tower shadow and wind turbulence on the performance of power system stabilizers for DFIG-based wind farms. IEEE Trans. Energy Convers. 2008, 23, 519-528. [CrossRef]

25. Liu, C.; Xu, D.; Zhu, N.; Blaabjerg, F.; Chen, M. DC-Voltage Fluctuation Elimination Through a DC-Capacitor Current Control for DFIG Converters Under Unbalanced Grid Voltage Conditions. IEEE Trans. Power Electron. 2012, 28, 3206-3218. [CrossRef]

26. Jiang, L.; Chi, Y.; Qin, H.; Pei, Z.; Li, Q.; Liu, M.; Bai, J.; Wang, W.; Feng, S.; Kong, W.; et al. Wind energy in China. IEEE Power Energy Mag. 2011, 9, 36-46. [CrossRef]

27. Feng, Y.; Lin, H.; Ho, S.L.; Yan, J.; Dong, J.; Fang, S.; Huang, Y. Overview of wind power generation in China: Status and development. Renew. Sustain. Energy Rev. 2015, 50, 847-858. [CrossRef]

28. Vittal, E.; O’Malley, M.; Keane, A. Rotor Angle Stability with High Penetrations of Wind Generation. IEEE Trans. Power Syst. 2011, 27, 353-362. [CrossRef]

29. Swarna, K.S.V.; Vinayagam, A.; Yang Khoo, S.; Stojcevski, A. Impacts of Integration of Wind and Solar PV in a Typical Power Network. In Proceedings of the 2015 International Conference on Sustainable Energy and Environmental Engineering, Shenzhen, China, 20-21 December 2015.

30. International Renewable Energy Agency (IRENA). Renewables Readiness Assessment (RRA); IRENA: New York, NY, USA, 2013.

31. ESMAP (World Bank). Wind Resource Mapping in Zambia-Mesoscale Wind Modelling Report, July 2015; World Bank: Washington, DC, USA, 2015.

32. ESMAP (World Bank). Wind Resource Mapping in Zambia-12 Month Site Resource Report, May 2018; World Bank: Washington, DC, USA, 2018.

33. CSO-Central Statistical Office, Republic of Zambia. 2019. Available online: https://knoema.com/atlas/sources/CSO-ZM (accessed on 27 May 2021).

34. USAID Southern Africa Energy Program. Zambia Power Sector Assessment; USAID: Pretoria, South Africa, 2018.

35. Chidumayo, E.N. Handbook on Miombo Ecology and Management; Stockholm Environmental Institute: Stockholm, Sweden, 1996.

36. Shane, A.; Gheewala, S.H.; Fungtammasan, B.; Silalertruksa, T.; Bonnet, S.; Phiri, S. Bioenergy resource assessment for Zambia. Renew. Sustain. Energy Rev. 2016, 53, 93-104. [CrossRef]

37. ZESCO. Zambia Electricity Supply Corporation. 2020. Available online: https:/ /www.zesco.co.zm/ (accessed on 20 May 2021).

38. Shah, R.; Mithulananthan, N.; Bansal, R.; Ramachandaramurthy, V. A review of key power system stability challenges for large-scale PV integration. Renew. Sustain. Energy Rev. 2015, 41, 1423-1436. [CrossRef] 
39. Ding, M.; Xu, Z.; Wang, W.; Wang, X.; Song, Y.; Chen, D. A review on China's large-scale PV integration: Progress, challenges and recommendations. Renew. Sustain. Energy Rev. 2016, 53, 639-652. [CrossRef]

40. Mararakanye, N.; Bekker, B. Renewable energy integration impacts within the context of generator type, penetration level and grid characteristics. Renew. Sustain. Energy Rev. 2019, 108, 441-451. [CrossRef]

41. Li, J.; Liu, F.; Li, Z.; Shao, C.; Liu, X. Grid-side flexibility of power systems in integrating large-scale renewable generations: A critical review on concepts, formulations and solution approaches. Renew. Sustain. Energy Rev. 2018, 93, 272-284. [CrossRef]

42. Matschoss, P.; Bayer, B.; Thomas, H.; Marian, A. The German incentive regulation and its practical impact on the grid integration of renewable energy systems. Renew. Energy 2018, 134, 727-738. [CrossRef]

43. Rauf, H.; Gull, M.S.; Arshad, N. Complementing hydroelectric power with floating solar PV for daytime peak electricity demand. Renew. Energy 2020, 162, 1227-1242. [CrossRef]

44. Chen, Y.; Wei, W.; Liu, F.; Mei, S. Distributionally robust hydro-thermal-wind economic dispatch. Appl. Energy 2016, 173, 511-519. [CrossRef]

45. Deshmukh, M.; Deshmukh, S. Modeling of hybrid renewable energy systems. Renew. Sustain. Energy Rev. 2008, 12, 235-249. [CrossRef]

46. Paska, J.; Biczel, P.; Kłos, M. Hybrid power systems-An effective way of utilising primary energy sources. Renew. Energy 2009, 34, 2414-2421. [CrossRef]

47. Campana, P.E.; Li, H.; Yan, J. Dynamic modelling of a PV pumping system with special consideration on water demand. Appl. Energy 2013, 112, 635-645. [CrossRef]

48. Glasnovic, Z.; Margeta, J. Optimal sizing of photovoltaic-hydro power plant. Prog. Photovolt. Res. Appl. 2009, 17, 542-553. [CrossRef]

49. Chen, J.; Zhuang, Y.; Li, Y.; Wang, P.; Zhao, Y.; Zhang, C. Risk-aware short term hydro-wind-thermal scheduling using a probability interval optimization model. Appl. Energy 2017, 189, 534-554. [CrossRef]

50. Bayón, L.; Grau, J.M.; Ruiz, M.; Suárez, P. A comparative economic study of two configurations of hydro-wind power plants. Energy 2016, 112, 8-16. [CrossRef]

51. Portero, U.; Velázquez, S.; Carta, J.A. Sizing of a wind-hydro system using a reversible hydraulic facility with seawater. A case study in the Canary Islands. Energy Convers. Manag. 2015, 106, 1251-1263. [CrossRef]

52. Wang, X.; Mei, Y.; Kong, Y.; Lin, Y.; Wang, H. Improved multi-objective model and analysis of the coordinated operation of a hydro-wind-photovoltaic system. Energy 2017, 134, 813-839. [CrossRef]

53. Liu, Y.; Tan, S.; Jiang, C. Interval optimal scheduling of hydro-PV-wind hybrid system considering firm generation coordination IET Renew. Power Gener. 2016, 11, 63-72. [CrossRef]

54. Maronga, A.; Nyoni, K.J.; Tuohy, P.; Shane, A. Modelling and assessing CSP and PV systems technical and economic performances to supply power to a mining context in Zimbabwe. Energies 2021, 14, 3740. [CrossRef]

55. Shabani, M.; Mahmoudimehr, J. Techno-economic role of PV tracking technology in a hybrid PV-hydroelectric standalone power system. Appl. Energy 2018, 212, 84-108. [CrossRef]

56. Beluco, A.; de Souza, P.K.; Krenzinger, A. A method to evaluate the effect of complementarity in time between hydro and solar energy on the performance of hybrid hydro PV generating plants. Renew. Energy 2012, 45, 24-30. [CrossRef]

57. François, B.; Borga, M.; Creutin, J.; Hingray, B.; Raynaud, D.; Sauterleute, J. Complementarity between solar and hydro power: Sensitivity study to climate characteristics in Northern-Italy. Renew. Energy 2016, 86, 543-553. [CrossRef]

58. Kougias, I.; Szabo, S.; Monforti-Ferrario, F.; Huld, T.; Bodis, K. A methodology for optimization of the complementarity between small-hydropower plants and solar PV systems. Renew. Energy 2016, 87, 1023-1030. [CrossRef]

59. Jurasz, J.; Ciapała, B. Integrating photovoltaics into energy systems by using a run-off-river power plant with pondage to smooth energy exchange with the power gird. Appl. Energy 2017, 198, 21-35. [CrossRef]

60. Fang, W.; Huang, Q.; Huang, S.; Yang, J.; Meng, E.; Li, Y. Optimal sizing of utility-scale photovoltaic power generation complementarily operating with hydropower: A case study of the world's largest hydro-photovoltaic plant. Energy Convers. Manag. 2017, 136, 161-172. [CrossRef]

61. Chen, L.; Liu, Y. Scheduling strategy of hybrid wind-photovoltaic-hydro power generation system. In Proceedings of the International Conference on Sustainable Power Generation and Supply (SUPERGEN 2012), Hangzhou, China, 8-9 September 2012.

62. Yang, X.; Wang, W.; Xue, B.; Huang, Q. On short-term united optimal operation of wind power, thermal power and waterpower. J. Hydroelectr. Eng. 2013, 4, 199-203.

63. Yang, X.; Chen, Q.; Wang, M.; Zhang, L. Cooperating control for wind farm and hydro power plant based on the fruit fly optimization. Proc. Chin. Soc. Electr. Eng. 2017, 37, 5286-5293.

64. Wei, P.; Liu, Y. The Integration of Wind-Solar-Hydropower Generation in Enabling Economic Robust Dispatch. Math. Probl. Eng. 2019, 2019, 4634131. [CrossRef]

65. Dong, W.; Wang, Q.; Yang, L. A coordinated dispatching model for a distribution utility and virtual power plants with wind/photovoltaic/hydro generators. Autom. Electr. Power Syst. 2015, 39, 75-81.

66. Zou, Y.; Yang, L. Synergetic dispatch models of a wind/PV/hydro virtual power plant based on representative scenario set. Power Syst. Technol. 2015, 39, 1855-1859.

67. Liu, Y.; Guo, L.; Wang, C. Economic dispatch of microgrid based on two stage robust optimization. Proc. CSEE 2018, 38, 4013-4022. 
68. Reddy, S.S. Optimal scheduling of wind-thermal power system using clustered adaptive teaching learning based optimization. Electr. Eng. 2017, 99, 535-550. [CrossRef]

69. Reddy, S.S.; Bijwe, P. Real time economic dispatch considering renewable energy resources. Renew. Energy 2015, 83, 1215-1226. [CrossRef]

70. Ali, S.; Taweekun, J.; Techato, K.; Waewsak, J.; Gyawali, S. GIS based site suitability assessment for wind and solar farms in Songkhla, Thailand. Renew. Energy 2018, 132, 1360-1372. [CrossRef]

71. Harper, M.; Anderson, B.; James, P.; Bahaj, A. Identifying suitable locations for onshore wind turbines using a GIS-MCDA approach. In Proceedings of the 16th International Conference on Sustainable Energy Technologies, Bologna, Italy, 17-20 July 2017.

72. Sunak, Y.; Höfer, T.; Siddique, H.; Madlener, R.; De Doncker, R.W. A GIS-Based Decision Support System for the Optimal Siting of Wind Farm Projects; E.ON Energy Research Center: Aachen, Germany, 2015.

73. Malczewski, J. GIS-based land-use suitability analysis: A critical overview. Prog. Plan. 2004, 62, 3-65. [CrossRef]

74. Voivontas, D.; Assimacopoulos, D.; Mourelatos, A.; Corominas, J. Evaluation of Renewable Energy potential using a GIS decision support system. Renew. Energy 1998, 13, 333-344. [CrossRef]

75. Baban, S.M.; Parry, T. Developing and applying a GIS-assisted approach to locating wind farms in the UK. Renew. Energy 2001, 24, 59-71. [CrossRef]

76. Gigović, L.; Pamučar, D.; Božanić, D.; Ljubojević, S. Application of the GIS-DANP-MABAC multi-criteria model for selecting the location of wind farms: A case study of Vojvodina, Serbia. Renew. Energy 2017, 103, 501-521. [CrossRef]

77. Watson, J.J.; Hudson, M.D. Regional Scale wind farm and solar farm suitability assessment using GIS-assisted multi-criteria evaluation. Landsc. Urban Plan. 2015, 138, 20-31. [CrossRef]

78. Höfer, T.; Sunak, Y.; Siddique, H.; Madlener, R. Wind farm siting using a spatial Analytic Hierarchy Process approach: A case study of the Städteregion Aachen. Appl. Energy 2016, 163, 222-243. [CrossRef]

79. Latinopoulos, D.; Kechagia, K. A GIS-based multi-criteria evaluation for wind farm site selection. A regional scale application in Greece. Renew. Energy 2015, 78, 550-560. [CrossRef]

80. Uyan, M. GIS-based solar farms site selection using analytic hierarchy process (AHP) in Karapinar region, Konya/Turkey. Renew. Sustain. Energy Rev. 2013, 28, 11-17. [CrossRef]

81. Aragonés-Beltrán, P.; Chaparro-González, F.; Pastor-Ferrando, J.; Rodríguez-Pozo, F. An ANP-based approach for the selection of photovoltaic solar power plant investment projects. Renew. Sustain. Energy Rev. 2010, 14, 249-264. [CrossRef]

82. Rojas-Zerpa, J.C.; Yusta, J.M. Application of multicriteria decision methods for electric supply planning in rural and remote areas Renew. Sustain. Energy Rev. 2015, 52, 557-571. [CrossRef]

83. Campos-Guzmán, V.; García-Cáscales, M.S.; Espinosa, N.; Urbina, A. Life Cycle Analysis with Multi-Criteria Decision Making: A review of approaches for the sustainability evaluation of renewable energy technologies. Renew. Sustain. Energy Rev. 2019, 104, 343-366. [CrossRef]

84. Rediske, G.; Siluk, J.C.M.; Michels, L.; Rigo, P.; Rosa, C.B.; Cugler, G. Multi-criteria decision-making model for assessment of large photovoltaic farms in Brazil. Energy 2020, 197, 117167. [CrossRef]

85. Ridha, H.M.; Gomes, C.; Hizam, H.; Ahmadipour, M.; Heidari, A.A.; Chen, H. Multi-objective optimization and multi-criteria decision-making methods for optimal design of standalone photovoltaic system: A comprehensive review. Renew. Sustain. Energy Rev. 2011, 135, 110202. [CrossRef]

86. Charabi, Y.; Gastli, A. PV site suitability analysis using GIS-based spatial fuzzy multi-criteria evaluation. Renew. Energy 2011, 36, 2554-2561. [CrossRef]

87. Kim, S.; Lee, Y.; Moon, H.-R. Siting criteria and feasibility analysis for PV power generation projects using road facilities. Renew. Sustain. Energy Rev. 2018, 81, 3061-3069. [CrossRef]

88. Dhiman, H.S.; Deb, D. Fuzzy TOPSIS and fuzzy COPRAS based multi-criteria decision making for hybrid wind farms. Energy 2020, 202, 117755. [CrossRef]

89. Deveci, M.; Cali, U.; Kucuksari, S.; Erdogan, N. Interval type-2 fuzzy sets based multi-criteria decision-making model for offshore wind farm development in Ireland. Energy 2020, 198, 117317. [CrossRef]

90. Mahdy, M.; Bahaj, A. Multi criteria decision analysis for offshore wind energy potential in Egypt. Renew. Energy 2018, 118, 278-289. [CrossRef]

91. Noorollahi, Y.; Yousefi, H.; Mohammadi, M. Multi-criteria decision support system for wind farm site selection using GIS. Sustain Energy Technol. Assess. 2016, 13, 38-50. [CrossRef]

92. Moradi, S.; Yousefi, H.; Noorollahi, Y.; Rosso, D. Multi-criteria decision support system for wind farm site selection and sensitivity analysis: Case study of Alborz Province, Iran. Energy Strat. Rev. 2020, 29, 100478. [CrossRef]

93. Cunden, T.S.; Doorga, J.; Lollchund, M.R.; Rughooputh, S.D. Multi-level constraints wind farms siting for a complex terrain in a tropical region using MCDM approach coupled with GIS. Energy 2020, 211, 118533. [CrossRef]

94. Supciller, A.A.; Toprak, F. Selection of wind turbines with multi-criteria decision making techniques involving neutrosophic numbers: A case from Turkey. Energy 2020, 207, 118237. [CrossRef]

95. Xu, Y.; Li, Y.; Zheng, L.; Cui, L.; Li, S.; Li, W.; Cai, Y. Site selection of wind farms using GIS and multi-criteria decision making method in Wafangdian, China. Energy 2020, 207, 118222. [CrossRef] 
96. Jangid, J.; Bera, A.K.; Joseph, M.; Singh, V.; Singh, T.; Pradhan, B.; Das, S. Potential zones identification for harvesting wind energy resources in desert region of India-A multi criteria evaluation approach using remote sensing and GIS. Renew. Sustain. Energy Rev. 2016, 65, 1-10. [CrossRef]

97. Janke, J.R. Multicriteria GIS modeling of wind and solar farms in Colorado. Renew. Energy 2010, 35, 2228-2234. [CrossRef]

98. Chimres, N.; Wongwises, S. Critical review of the current status of solar energy in Thailand. Renew. Sustain. Energy Rev. 2016, 58, 198-207. [CrossRef]

99. Al Garni, H.Z.; Awasthi, A. Solar PV power plant site selection using a GIS-AHP based approach with application in Saudi Arabia. Appl. Energy 2017, 206, 1225-1240. [CrossRef]

100. Krewitt, W.; Nitsch, J. The potential for electricity generation from on-shore wind energy under the constraints of nature conservation: A case study for two regions in Germany. Renew. Energy 2003, 28, 1645-1655. [CrossRef]

101. Ho, C.; Sims, C.; Christian, J. Evaluation of Glare at the Ivanpah Solar Electric Generating System. Energy Procedia 2015, 69, 1296-1305. [CrossRef]

102. Yue, C.-D.; Wang, S.-S. GIS-based evaluation of multifarious local renewable energy sources: A case study of the Chigu area of southwestern Taiwan. Energy Policy 2006, 34, 730-742. [CrossRef]

103. Tanavud, C.; Yongchalermchai, C.; Bennui, A.; Densreeserekul, O. Assessment of flood risk in Hat Yai Municipality, Southern Thailand, using GIS. J. Nat. Disaster Sci. 2004, 26, 1-14. [CrossRef]

104. Ghenai, C.; Albawab, M.; Bettayeb, M. Sustainability indicators for renewable energy systems using multi-criteria decision-making model and extended SWARA/ARAS hybrid method. Renew. Energy 2019, 146, 580-597. [CrossRef]

105. Shao, M.; Han, Z.; Sun, J.; Xiao, C.; Zhang, S.; Zhao, Y. A review of multi-criteria decision making applications for renewable energy site selection. Renew. Energy 2020, 157, 377-403. [CrossRef]

106. Van Rensburg, T.M.; Kelley, H.; Jeserich, N. What influences the probability of wind farm planning approval: Evidence from Ireland. Ecol. Econ. 2015, 111, 12-22. [CrossRef]

107. Sichilalu, S.; Wamalwa, F.; Akinlabi, E.T. Optimal control of wind-hydrokinetic pumpback hydropower plant con-strained with ecological water flows. Renew. Energy 2019, 138, 54-69. [CrossRef]

108. Asaduz-Zaman, M.; Rahaman, M.H.; Reza, M.S.; Islam, M.M. A Method for Distributed Generator Dispatch Strategy in Distribution Network. J. Electr. Eng. 2018, 6, 261-270. [CrossRef]

109. Emmanuel, M.; Rayudu, R. Evolution of dispatchable photovoltaic system integration with the electric power network for smart grid applications: A review. Renew. Sustain. Energy Rev. 2017, 67, 207-224. [CrossRef]

110. Loudiyi, K.; Berrada, A.; Svendsen, H.G.; Mentesidi, K. Grid code status for wind farms interconnection in Northern Africa and Spain: Descriptions and recommendations for Northern Africa. Renew. Sustain. Energy Rev. 2018, 81, 2584-2598. [CrossRef]

111. Shafiullah, G.; Oo, A.M.; Ali, A.S.; Wolfs, P. Potential challenges of integrating large-scale wind energy into the power grid-A review. Renew. Sustain. Energy Rev. 2013, 20, 306-321. [CrossRef]

112. Saqib, M.A.; Saleem, A.Z. Power-quality issues and the need for reactive-power compensation in the grid integration of wind power. Renew. Sustain. Energy Rev. 2015, 43, 51-64. [CrossRef]

113. Rona, B.; Güler, O. Power system integration of wind farms and analysis of grid code requirements. Renew. Sustain. Energy Rev. 2015, 49, 100-107. [CrossRef]

114. Mohseni, M.; Islam, S. Review of international grid codes for wind power integration: Diversity, technology and a case for global standard. Renew. Sustain. Energy Rev. 2012, 16, 3876-3890. [CrossRef]

115. Shaker, H.; Zareipour, H.; Wood, D. Impacts of large-scale wind and solar power integration on California's net electrical load. Renew. Sustain. Energy Rev. 2016, 58,761-774. [CrossRef]

116. Zappa, W.; Broek, M.V.D. Analysing the potential of integrating wind and solar power in Europe using spatial optimisation under various scenarios. Renew. Sustain. Energy Rev. 2018, 94, 1192-1216. [CrossRef]

117. Viviescas, C.; Lima, L.; Diuana, F.A.; Vasquez, E.; Ludovique, C.; Silva, G.N.; Huback, V.; Magalar, L.; Szklo, A.; Lucena, A.F.; et al. Contribution of Variable Renewable Energy to increase energy security in Latin America: Complementarity and climate change impacts on wind and solar resources. Renew. Sustain. Energy Rev. 2019, 113, 109232. [CrossRef]

118. Liu, L.; Wang, Z.; Wang, Y.; Wang, J.; Chang, R.; He, G.; Tang, W.; Gao, Z.; Li, J.; Liu, C.; et al. Optimizing wind/solar combinations at finer scales to mitigate renewable energy variability in China. Renew. Sustain. Energy Rev. 2020, 132, 110151. [CrossRef]

119. Sterl, S.; Donk, P.; Willems, P.; Thiery, W. Turbines of the Caribbean: Decarbonising Suriname's electricity mix through hydrosupported integration of wind power. Renew. Sustain. Energy Rev. 2020, 134, 110352. [CrossRef]

120. Nghitevelekwa, K.; Bansal, R. A review of generation dispatch with large-scale photovoltaic systems. Renew. Sustain. Energy Rev. 2018, 81, 615-624. [CrossRef]

121. Boqiang, R.; Chuanwen, J. A review on the economic dispatch and risk management considering wind power in the power market. Renew. Sustain. Energy Rev. 2009, 13, 2169-2174. [CrossRef]

122. Cheng, C.; Liu, B.; Chau, K.-W.; Li, G.; Liao, S. China's small hydropower and its dispatching management. Renew. Sustain. Energy Rev. 2015, 42, 43-55. [CrossRef]

123. Das, H.S.; Yatim, A.; Tan, C.W.; Lau, K.Y. Proposition of a PV/tidal powered micro-hydro and diesel hybrid system: A southern Bangladesh focus. Renew. Sustain. Energy Rev. 2016, 53, 1137-1148. [CrossRef] 
124. Dallinger, B.; Schwabeneder, D.; Lettner, G.; Auer, H. Socio-economic benefit and profitability analyses of Austrian hydro storage power plants supporting increasing renewable electricity generation in Central Europe. Renew. Sustain. Energy Rev. 2019, 107, 482-496. [CrossRef]

125. Schmidt, J.; Cancella, R.; Junior, A.O.P. The effect of windpower on long-term variability of combined hydro-wind resources: The case of Brazil. Renew. Sustain. Energy Rev. 2016, 55, 131-141. [CrossRef]

126. Upadhyay, S.; Sharma, M. A review on configurations, control and sizing methodologies of hybrid energy systems. Renew. Sustain. Energy Rev. 2014, 38, 47-63. [CrossRef]

127. Mukhopadhyay, B.; Das, D. Multi-objective dynamic and static reconfiguration with optimized allocation of PV-DG and battery energy storage system. Renew. Sustain. Energy Rev. 2020, 124, 109777. [CrossRef]

128. Bird, L.; Lew, D.; Milligan, M.; Carlini, E.M.; Estanqueiro, A.; Flynn, D.; Gomez-Lazaro, E.; Holttinen, H.; Menemenlis, N.; Orths, A.; et al. Wind and solar energy curtailment: A review of international experience. Renew. Sustain. Energy Rev. 2016, 65, 577-586. [CrossRef]

129. PVSyst Help Manual. Available online: https:/ / www.pvsyst.com/help/ (accessed on 1 July 2020).

130. RES4Africa. Integration of Variable Renewable Energy Sources in the National Electric System of Zambia. Available online: https:/ / www.res4africa.org/wp-content/uploads/2020/10/R4AF-Integration-of-Variable-Renewable-Energy-Sourcesin-the-National-Electric-System-of-Zambia.pdf (accessed on 30 June 2021).

131. International Renewable Energy Agency—IRENA. Renewable Power Generation Costs in 2019; IRENA: Abu Dhabi, United Arab Emirates, 2020. 